\title{
Cranial osteology of Moloch horridus (Reptilia: Squamata: Agamidae)
}

\author{
Christopher J. Bell ${ }^{1}$, Jim I. Mead ${ }^{2}$ and Sandra L. Swift ${ }^{2}$ \\ ${ }^{1}$ Department of Geological Sciences, Jackson School of Geosciences, \\ University of Texas, Austin, Texas 78712 USA. E-mail: cjbell@mail.utexas.edu \\ ${ }^{2}$ Department of Geosciences, Box 70357, East Tennessee State University, \\ Johnson City, Tennessee 37614 USA. E-mails: MEAD@mail.etsu.edu \& sandra.swiftone@Yahoo.com \\ Correspondence to: Christopher J. Bell; cjbell@mail.utexas.edu
}

\begin{abstract}
We provide a detailed description of the cranial and mandibular osteology of the Australian agamid lizard, Moloch horridus, based on a series of eight skeletal preparations and minimal preparation of a single specimen preserved in alcohol. Articulated and disarticulated material permits the description of individual elements and their articulations, and a preliminary assessment of patterns of cranial and mandibular variation within Moloch. Preliminary comparisons of osteological features of Moloch with those of other Australian agamids indicate that many elements of the skull and mandible of Moloch have specialized morphology. Basic knowledge of patterns of skeletal variation within and among Australian agamids is insufficiently established at present to permit reliable hypotheses of phylogenetic relationships based only on morphology. A paucity of adequate skeletal collections exacerbates the challenges of elucidating patterns of evolutionary morphology for the group as a whole. Nevertheless, our preliminary assessment suggests that at least the maxilla, parietal, pterygoid, supraoccipital, prootic, otooccipital, basioccipital, dentary, coronoid, and articular-prearticular of Moloch can be clearly distinguished from those of other Australian agamids, and probably can be used to develop a reliable and more comprehensive skeletal morphological diagnosis for Moloch.
\end{abstract}

Additional key words — Skull, morphology, variation, thorny devil

\section{INTRODUCTION}

\section{General form and natural history}

Moloch horridus Gray, 1841 (Reptilia: Squamata: Agamidae; thorny devil) is an unmistakable Australian lizard, unique in scalation and form (Warham 1956; Greer 1989; Witten 1993; Figure 1), and is a well-known and popular photographic subject in treatments on Australian natural history and herpetology. Many aspects of its basic biology and natural history are well-documented (e.g. Davey 1923; Pianka and Pianka 1970; Greer 1989; Pianka and Thompson 1998), but although the cranium and unusual teeth of Moloch were mentioned previously in the literature (e.g. Gervais 1861, 1873; Owen 1880; Siebenrock 1895; Cogger 1961; Edmund 1969; Moody 1980; Evans 2008), no detailed morphological description exists of these anatomical systems. As part of our efforts to understand the evolutionary morphology of Australian agamids, we provide a detailed description of the cranial osteology of this unusual lizard.
The head of Moloch is short and wide on a globular body with splayed limbs, all within an adult snout-vent length (SVL) of up to $110 \mathrm{~mm}$. Dorsal scalation is strongly heterogeneous: smaller granular scales are interspaced with longitudinal series of grossly enlarged spines, with the largest pair positioned over each eye and a pair on a large hump (or 'false head') on the nape (Gray 1841; Greer 1989; Cogger 1992). As with other agamids, dermal ossicles are absent (Estes et al. 1988), and there is no bony structural support for even the largest of the spines (Owen 1881). No clear-cut differences in sex are known, although adult females attain a larger size and stouter form than males $(\mathrm{SVL}=80-110 \mathrm{~mm}$ in females; less than approximately $96 \mathrm{~mm}$ in males; Pianka and Pianka 1970; Houston and Hutchinson 1998). Moloch is a sit-and-wait predator that is almost exclusively myrmecophagous, primarily consuming minute ants of the genera Iridomyrmex and Crematogaster (Brandson 1952; Withers and Dickman 1995). The thorny devil is a slow-moving diurnal lizard, known to live from 6-20 years and 


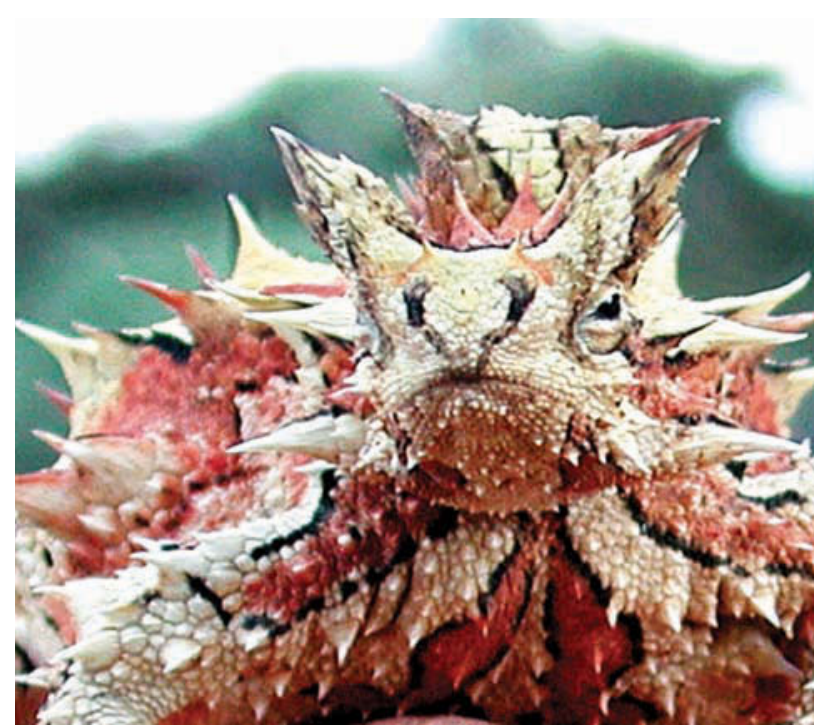

Figure 1 External morphology of Moloch horridus. WAM R146914, Mt. Gibson Station, west of Lake Moore, Western Australia, in life.

found in a variety of habitats from the sand and spinifex (Triodia spp.) deserts of central Australia to the arid scrublands of southern Western Australia (Pianka and Pianka 1970). The natural history of Moloch was reviewed by Pianka et al. (1998); relatively new information about reproductive biology was provided by Thompson (2003).

In terms of its ecology and external morphology Moloch is more similar to the North American iguanian Phrynosoma (Phrynosomatidae) than it is to other agamids (Pianka 1994; Meyers and Herrel 2005). Anatomically, the two taxa are quite distinct, perhaps most notably in that Moloch lacks the bony support for its cranial horns that is so characteristic and striking for Phrynosoma (Owen 1881; see also Pianka 2003).

\section{Phylogenetic relationships}

The phylogenetic position of Moloch has long been an intriguing problem. Its apparent morphological specializations undoubtedly contribute to popular notions that it represents an ancient, if not the most ancient, agamid lineage in Australia (e.g. Anonymous 1981), but formal phylogenetic assessments are relatively few. Moloch was allied with other Australian agamids by Moody (1980; his Group III), but his character scorings and polarity determinations were subsequently questioned by Estes et al. (1988). The unique morphology of Moloch led Witten (1982) to consider it a highly derived taxon, with no obvious close relationship to any extant agamid, but the absence of a lacrimal was accepted as confirmation of its affinity with other Australian endemic agamids in his analysis. In his phylogenetic hypothesis, he placed Moloch outside all other endemic Australian agamids. Preliminary albumin fixation data were presented by Baverstock and Donnellan (1990), and provided evidence that Moloch was part of the amphibolurine-group radiation of Australian endemics (represented in their analysis by Pogona, Ctenophorus and Lophognathus). An alternative position indicating closer affinity with Hypsilurus was weakly supported in an analysis by Macey et al. (2000), and the maximum likelihood tree presented by Melville et al. (2001) placed Moloch outside all other Australian agamids except Hypsilurus and Physignathus; in their strict consensus tree its position was unresolved. A position basal to all other endemic Australian agamids was recovered by Schulte et al. (2003). A recent analysis of mitochondrial and nuclear genes also yielded

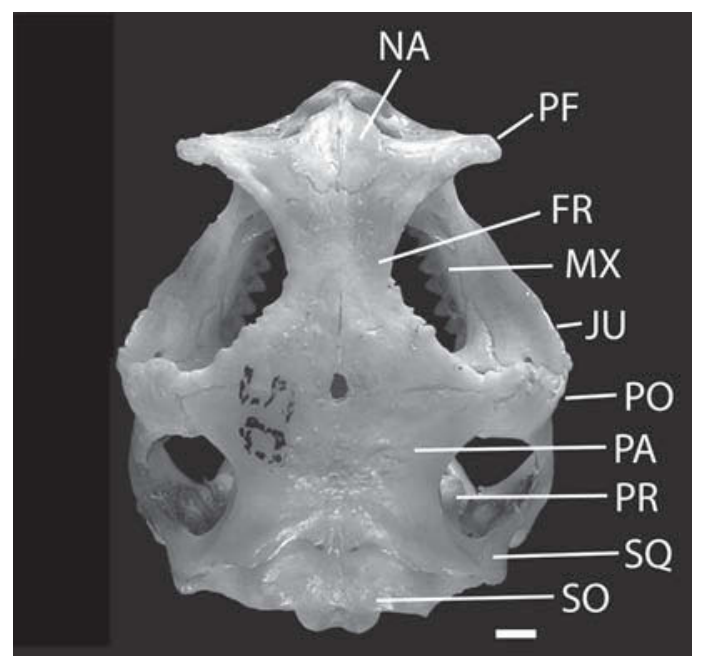

Figure 2 Dorsal view of articulated skull of Moloch horridus, ROM R50. Anterior to top. Scale bar $=1 \mathrm{~mm}$.

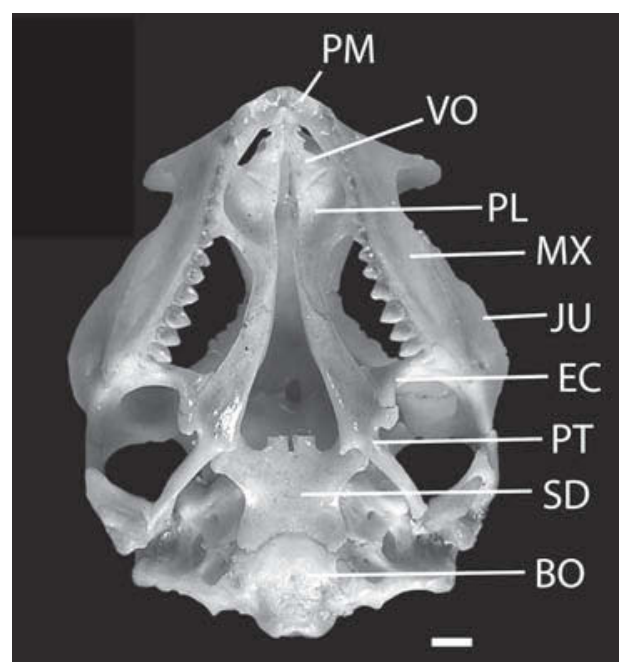

Figure 3 Ventral view of articulated skull of Moloch horridus, ROM R50. Anterior to top. Scale bar $=1 \mathrm{~mm}$. 
a hypothesis in which Moloch was consistently recovered in a basal position to other endemic Australian agamids, and in some analyses as sister to Chelosania brunnea, another monotypic agamid with uncertain relationships (Hugall et al. 2008). Moloch was not included in other recent modern phylogenetic analyses, including those of Joger (1991) and Honda et al. (2000), who used molecular data to elucidate some aspects of agamid phylogeny.

Its probable basal position among Australian agamids makes it a particularly important taxon for those seeking to understand morphological evolution within the Agamidae. A rigorous morphological re-evaluation of the Agamidae is warranted, and was recently initiated by Hocknull (2000). Although not yet published in full form, Hocknull's analysis of skeletal morphology resulted in relatively strong support for a sister-taxon relationship between Moloch and Tympanocryptis, a relationship also suggested by Greer (1989). Rankinia and Pogona were consecutive outgroups to that clade in Hocknull's analysis, and together all form a 'Tympanocryptis group'.

\section{Previous anatomical studies}

The skull and post-cranial skeleton of Moloch were superficially described by previous authors, but in each case details were lacking and descriptions were based almost entirely on articulated skulls (Gervais 1861, 1873; Owen 1880; Siebenrock 1895; Cogger 1961; Edmund 1969; Moody 1980). A lateral view of the skull and mandible was illustrated by Dowling and Duellman (1978), and a ventral view of the skull by Edmund (1969; that illustration was reproduced by Vorobjeva and Chugunova 1995). A 3-D digital model of the skeleton and skull were generated from a high-resolution $\mathrm{X}$-ray computed tomography (CT) scan, and are posted without description at $<\mathrm{http}$ ://digimorph.org/specimens/ Moloch_horridus/whole/> and <http://digimorph. org/specimens/Moloch_horridus/head/>. A stillimage of the lateral view of the skull based on the same CT data set was published by Pianka (2007). Lateral views of the left maxilla and dentary were provided by Covacevich et al. (1990), and the morphology of those elements was discussed in a comparative framework with other agamids by Hocknull (2002). The peculiar dentition received the most attention, and was discussed previously by Edmund (1969), Moody (1980), Vorobjeva and Chugunova (1995), Hocknull (2002), and Evans (2008). Other anatomical studies include discussion and illustration of the variant pedal phalangeal formulae of southwestern and central populations (Greer 1989), descriptions of the scale structure (Owen 1881; Scortecci 1941; Bentley and Blumer 1962; Gans et al. 1982; Sherbrooke et al. 2007), and the morphology of the parietal 'eye' and pineal gland (Kummer-Trost 1956) compared to those of other agamids. Our description of the skull of Moloch is the first to characterize the individual bones of the skull. There is no published fossil record for Moloch.

\section{MATERIALS AND METHODS}

\section{Specimens examined}

Our study was based primarily on examination of nine specimens including three articulated skulls, two partially disarticulated skulls, three completely disarticulated skulls, and a single specimen preserved in alcohol from which we removed a single scleral ring (Table 1). SVLs were not available for most of these specimens. We used length of the parietal table to provide a comparison of relative size of specimens. Our measurement was taken from just left of the frontoparietal fenestra posteriorly to a line perpendicular to the midline that corresponds to the greatest length of the parietal table (post-parietal processes were not included). Throughout the text, we adopted a terminological convention regarding the use of

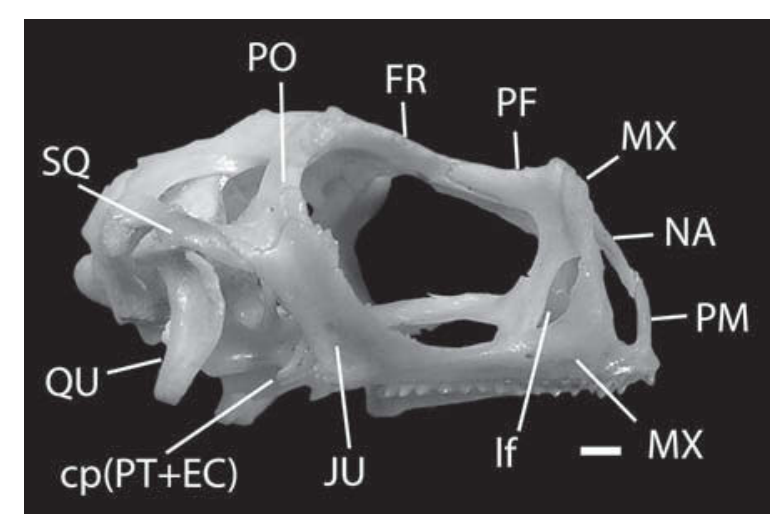

Figure 4 Right lateral view of articulated skull of Moloch horridus, ROM R50. Anterior to right. Scale bar $=1 \mathrm{~mm}$.

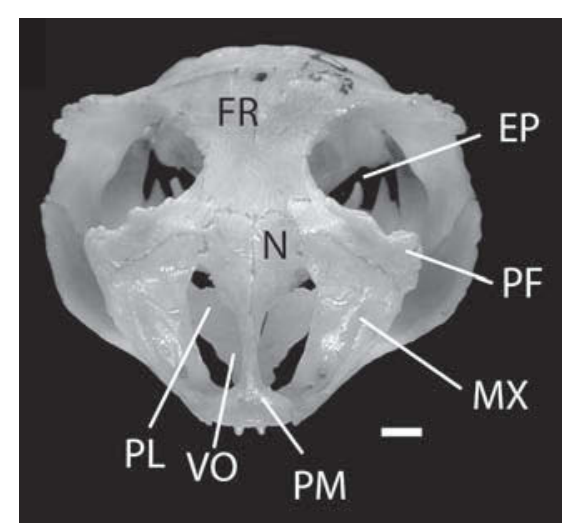

Figure 5 Anterior view of articulated skull of Moloch horridus, ROM R50. Scale bar $=1 \mathrm{~mm}$. 
'foramen' and 'fenestra.' In our usage, a foramen is an opening or penetration within a single element, and a fenestra is an opening whose margins are formed by more than one element. For example, we use 'fenestra ovalis' instead of 'foramen ovale' (of, for example, Oelrich 1956) because the opening is bounded by both the prootic and otooccipital bones. The sole exception to this convention is our retained use of the traditional, and now firmly entrenched, use of 'foramen magnum' for the posterior opening of the skull.

\section{Abbreviations}

Institutional abbreviations include NT R, Museum and Art Gallery of the Northern Territory, Darwin, Northern Territory, Australia; QM J, Queensland Museum, modern skeletal collection, Brisbane, Queensland, Australia; ROM, Royal Ontario Museum, Toronto, Ontario, Canada; SAMA, South Australian Museum, Adelaide, South Australia,

Table 1 Specimens of Moloch horridus utilized in this study. $\mathrm{A}=$ articulated; $\mathrm{D}=$ disarticulated; n.a. = not available; Par L = length of parietal table; $\mathrm{PA}=$ preserved in alcohol (not skeletonized); $\mathrm{PD}=$ partially disarticulated; $\mathrm{SVL}=$ Snout-to-vent length.

\begin{tabular}{llll}
\hline Specimen \# & SVL & Par L & Preparation \\
QM J11492 & n.a. & 5.41 & A \\
ROM R50 & n.a. & 4.20 & A \\
TMM-M721 & n.a. & n.a. & PD \\
WAM R2 & n.a. & n.a. & PA \\
WAM R97222 & $98 \mathrm{~mm}$ & 5.00 & D \\
WAM R27737A & $98 \mathrm{~mm}$ & 4.81 & D \\
WAM R27737B & n.a. & 4.80 & A \\
WAM R38691 & n.a. & 4.55 & PD \\
WAM R146914 & $85 \mathrm{~mm}$ & 3.51 & D \\
\hline
\end{tabular}

Australia; TMM-M, Vertebrate Paleontology Laboratory modern skeletal collection, University of Texas, Austin, Texas, USA; UMMZ, University of Michigan Museum of Zoology, Ann Arbor, Michigan, USA; WAM R, Western Australian Museum, Perth, Western Australia, Australia. A list of anatomical abbreviations used in the figures is provided in Appendix 1.

\section{DESCRIPTION OF THE SKULL}

\section{General features}

The skull is relatively small, with a blunt, nearly flattened face (Figures 2-5). The postorbital and supratemporal bars are complete. The skull roof is highest just posterior to the frontoparietal suture, and is widest just anterior to that same suture. The bones of the skull roof and the postorbital bar are robust, but those of the supratemporal bar and the palate are more delicate. The septomaxilla, lacrimal, postfrontal, and splenial bones are lacking as discrete elements. Except for its anterolateral edges, the supraoccipital is exposed in dorsal view. The lacrimal fenestra is large, but the sphenoccipital fenestra is extremely reduced and cannot be seen in an articulated skull.

The orbits are large and rounded. Each orbital margin is formed by the frontal, prefrontal, maxilla, jugal, and postorbital (Figures 2,4). The external nares are large oval-shaped openings formed between the maxillae, nasals, and premaxilla; they are oriented nearly vertically on the anterior end of the snout (Figure 5). Moloch shows a paleochoanate condition at the anterior palate, with the anterior opening for the vomeronasal organ confluent with the posterior internal naris (Evans 2008). The choanae are relatively narrow and bounded by the maxilla, palatine and vomer. The supratemporal fenestrae are open and more-or-less rounded, with margins formed by the parietal, postorbital,

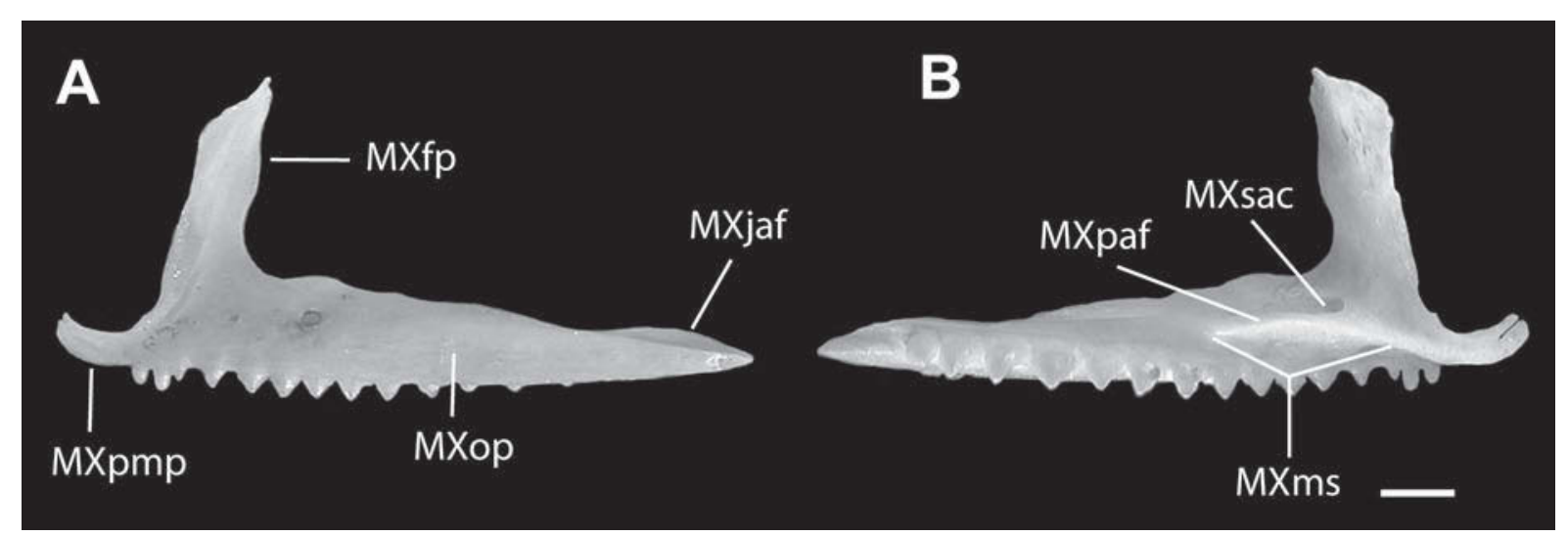

Figure 6 Left maxilla of Moloch horridus, WAM R146914. A. Lateral view, anterior to left. B. Slightly oblique medial view, to show position of the posterior opening of the superior alveloar canal, anterior to right. Scale bar $=1 \mathrm{~mm}$. 


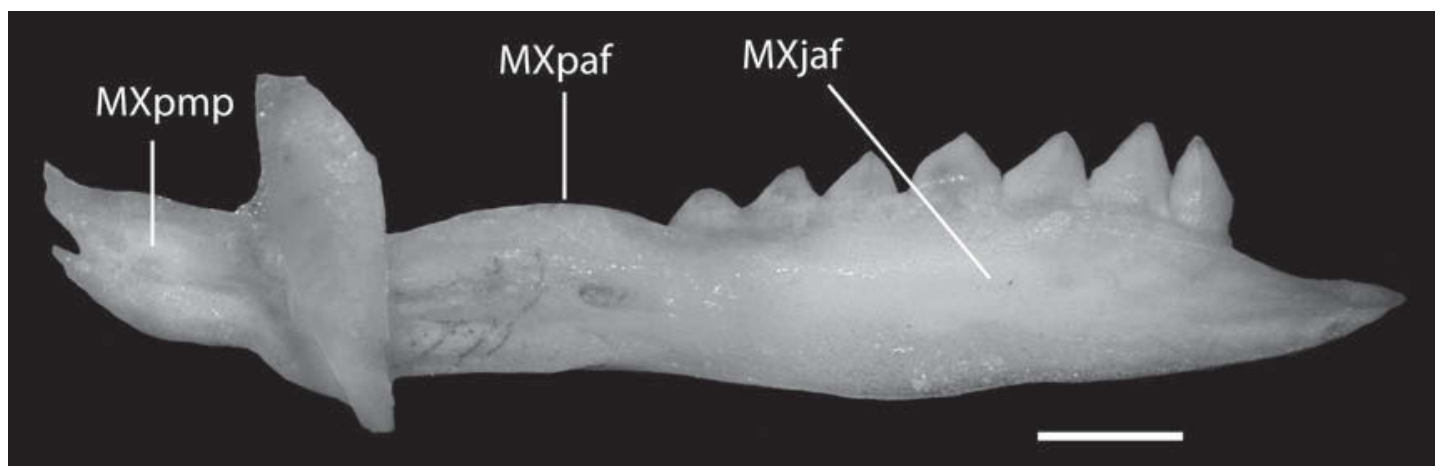

Figure 7 Dorsal view of mesial tip of left maxilla from WAM R146914, showing bifurcated premaxillary process. Anterior to left. Scale bar $=1 \mathrm{~mm}$.

and squamosal (Figures 2,4). The infratemporal fenestrae are open ventrally (as in all other squamates), and bordered by the jugal, squamosal and quadrate (Figure 4). The suborbital fenestra is large, and bordered by the maxilla, ectopterygoid, pterygoid and palatine (Figure 3). The margins of the large subtemporal fenestrae are formed by the ectopterygoid, pterygoid and quadrate (Figure 3). The post-temporal fenestrae are present as narrow openings between the parietal and the otooccipital and prootic portions of the braincase. The interpterygoid vacuity (pyriform recess of Oelrich 1956; Estes et al. 1988) is widest posteriorly; it tapers anteriorly, but fully separates the pterygoids and palatines, and separates the vomers for most of their length (Figure 3).

\section{Premaxilla}

The premaxilla is a small, somewhat gracile, unpaired element that forms the anteriormost portion of the snout (Figure 4). A distinct nasal process (internarial process of Moody 1980) forms the dorsal midline projection of the bone. A broader alveolar surface extends a short distance laterally from the midline. It serves as an attachment surface for a few pleurodont teeth, and bears weak lateral articulation facets for the maxillae. The premaxilla contacts the nasals dorsally, the maxillae laterally, and the vomers posteriorly (Figures 2, 3, 5). In other agamids, contact of the premaxilla and vomers is unusual because the maxillae meet at the midline beneath the alveolar portion of the premaxilla (Estes et al. 1988; Evans 2008).

The nasal process is broad at its base, but progressively tapers distally where it separates only the anterior portion of the nasals. Distinct nasal articulation facets are present, but they are small and situated near the tip of the ascending process. The nasal process forms the ventromedial margin of the external naris. On either side of the base of the nasal process, where it meets the alveolar portion of the bone, two small canals are present. In other iguanians (e.g. Ctenosaura [Oelrich 1956]), these canals transmit the medial ethmoid nerve (part of the ophthalmic division of the trigeminal nerve, V1). At the midline, and posterior to the tooth row, is a large, ventrally-directed incisive process. Just dorsal to the incisive process are narrow articulation surfaces for the vomers. Along the lateral edges of the alveolar portion are small articular facets for the premaxillary (anteromedial) process of the maxilla. The premaxilla and maxilla form an uninterrupted continuous arc along the anterior snout (Moody 1980). The dentition is discussed below.

\section{Maxilla}

The maxilla forms the anterolateral portion of the snout and is the major tooth-bearing element of the skull. The maxilla has three distinct processes, an anteromedial premaxillary process, an elongate orbital process posteriorly and a dorsal facial (ascending) process (Figure 6). The maxilla

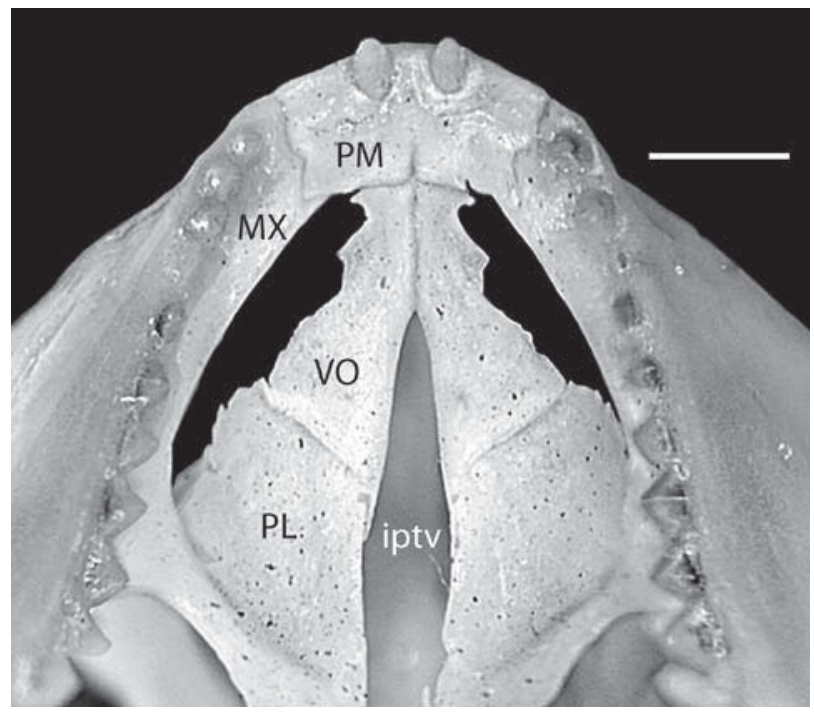

Figure 8 Anterior palate of Moloch horridus, ROM R50 in ventral view. Anterior to top. Scale bar $=1 \mathrm{~mm}$. 


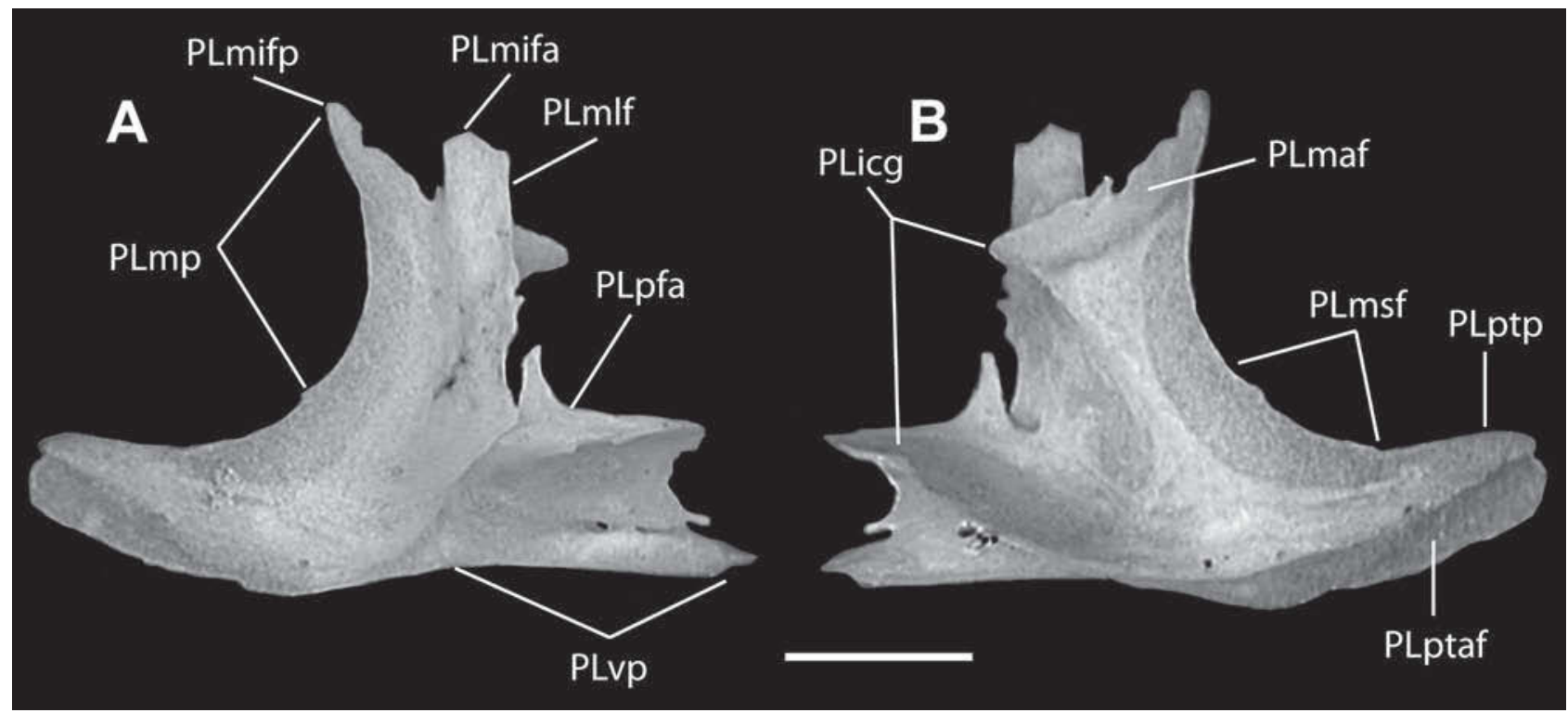

Figure 9 Left palatine of Moloch horridus, WAM R146914. A. Dorsal view, anterior to right. B. Ventral view, anterior to left. Scale bar $=1 \mathrm{~mm}$.

contacts the premaxilla and vomer anteromedially, the nasal and prefrontal dorsally, the palatine ventromedially, the jugal posteriorly and the ectopterygoid posteroventrally.

The premaxillary processes curve gradually towards the anterior midline, overlap the lateral edges of the premaxilla, but fail to contact one another along the anterior margin of the snout. At its mesial margin a short, finger-like process makes a sharp dorsal turn. This process sweeps up to articulate with the nasal process of the premaxilla, dorsal to the level of the medial ethmoid foramen on the premaxilla. The process is easily broken in disarticulated specimens; it is bifurcated (or notched) in WAM R146914 (Figure 7), but in other specimens, the notch is fully, or almost fully, closed to form a foramen. The premaxillary process of the maxilla is edentulous in WAM R146914 and WAM R27737A, but bears a single pleurodont tooth on each side in WAM R27737B, and a single pleurodont tooth on the left side of QM J11492. Unlike most other acrodontans (Cope 1864, 1892; Moody 1980; Estes et al. 1988; Evans 2008), the premaxillary processes do not meet behind the premaxilla, but they do form the ventral margins of the external nares.

The facial process of the maxilla is tall, and distinctly short and flattened anteroposteriorly. Its steep and nearly vertical orientation yields the somewhat flattened appearance to the facial portion of the skull (Figure 4). At its most dorsal extent it has an abbreviated, but definite, contact with the nasal (contra Moody 1980) in QM J11492, WAM R27737B and ROM R50 (Figure 5); posteriorly it shares a broad contact with the prefrontal. The facial process forms the lateral margin of the external naris. The posterior border of the facial process forms the lateral margin of the enlarged lacrimal fenestra (Figure 4). The base of the facial process is pierced by the superior alveolar canal; in other iguanians this canal transmits the superior alveolar nerve (maxillary branch of the trigeminal nerve; V2) and associated blood vessels (Oelrich 1956; Evans 2008). At its anterior end, the canal terminates at the anterior superior alveolar foramen, which is single in QM J11492, WAM R27737A and WAM R38691, but doubled in WAM R146914, ROM R50 and WAM R27737B. Within the canal, three or four foramina pierce the ventrolateral wall; they appear on the lateral surface of the maxilla as tiny foramina just lateral or ventrolateral to the anterior inferior alveolar foramen.

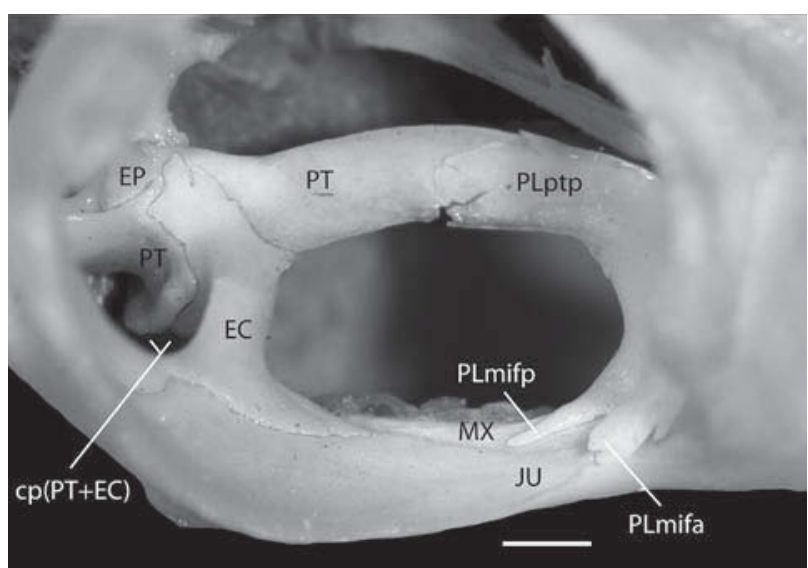

Figure 10 Oblique lateral view through right orbit, ROM R50. Anterior to right. Scale bar $=1 \mathrm{~mm}$. 
A short and narrow maxillary shelf is present along the medial side of the base of the facial process (Figure 6B). It extends posteriorly a short distance along the orbital process, reaching its widest point (most medial extent) and termination about half way along the length of the bone. This medial extension contacts the palatine along an area opposite where the teeth begin to show a medial inflection; as in other Australian agamids, the suture is approximately parallel to the tooth row, an orientation distinct from the transverse sutural contact seen in many Asian agamids (e.g. Calotes, Draco; Moody 1980). Just opposite the palatine facet another small foramen pierces the bone above the shelf. This foramen opens into a small canal that extends anteriorly a short distance and terminates in a small foramen on the lateral surface of the maxilla. The dorsal surface of the orbital process posterior to the palatine facet is smooth and relatively flat (Figure 7). All but the medial part of this region forms an elongated articulation facet for the jugal. At its posteriormost extent, the orbital process forms a complex articulation with the ectopterygoid ventrally and medially (Figure 3).

The posterior portion of the orbital process is inflected medially; thus, along the distal halves of the maxillary tooth rows, the apices of the teeth on either side approximately face one another (see

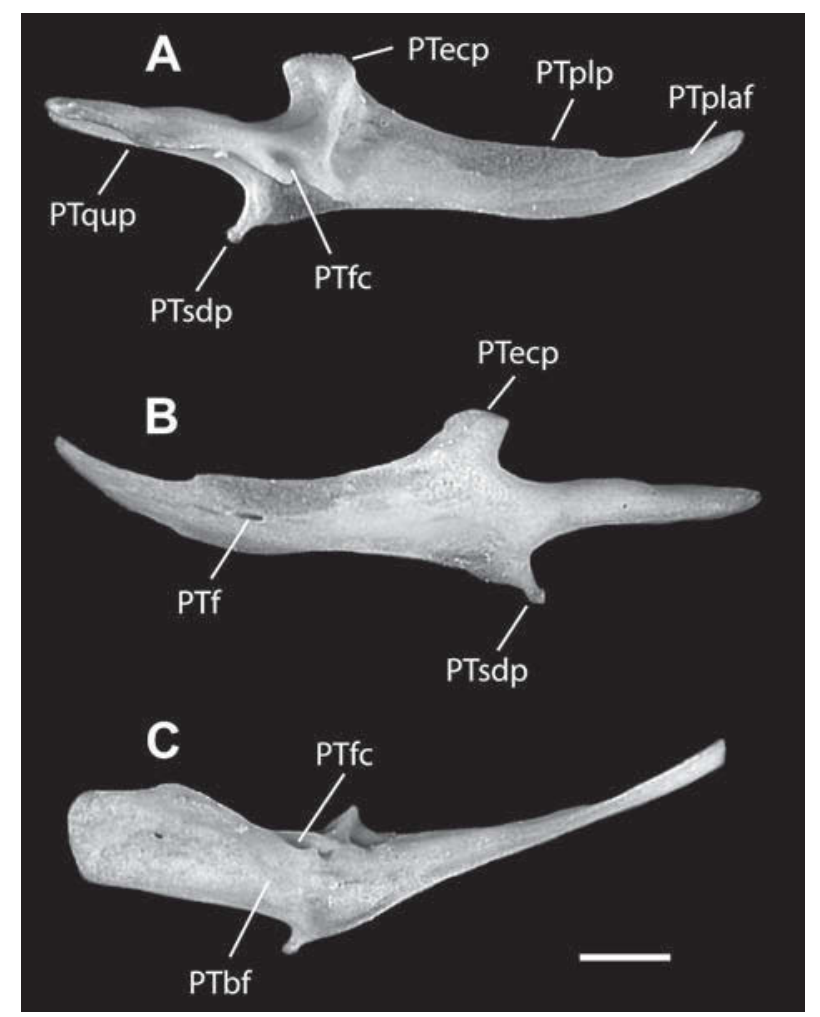

Figure 11 Left pterygoid, of Moloch horridus, WAM R146914. A. Dorsal view, anterior to right. B. Ventral view, anterior to left. C. Medial view, anterior to right. Scale bar $=1 \mathrm{~mm}$.
Dentition, below). The orbital process forms the lateral edge of the suborbital fenestra. The medial portion of the orbital process and the inflected posterior maxillary teeth are clearly visible beneath the suborbital fenestra in a dorsal view looking through the orbit (Figure 2).

\section{Septomaxilla}

There is no ossified septomaxilla in Moloch. Its loss or failure to ossify may be a result of the overall reduction of the region surrounding the nasal capsule (Moody 1980).

\section{Vomer}

The vomer is a delicate, fragile bone. It contacts the premaxilla anteriorly, the palatine posteriorly, and closely approaches or may be in weak contact with the premaxillary process of the maxilla anterolaterally (only visible through the external naris). The narrow anterior premaxillary processes are in contact for a short distance along the midline, but the vomers diverge as they widen posterolaterally, providing an anterior extension of the interpterygoid vacuity (Figure 8). The articulation with the premaxilla is restricted to a short shelf immediately posterior to the base of the nasal process of the premaxilla (Figure 8). The articulation with the palatine is more extensive

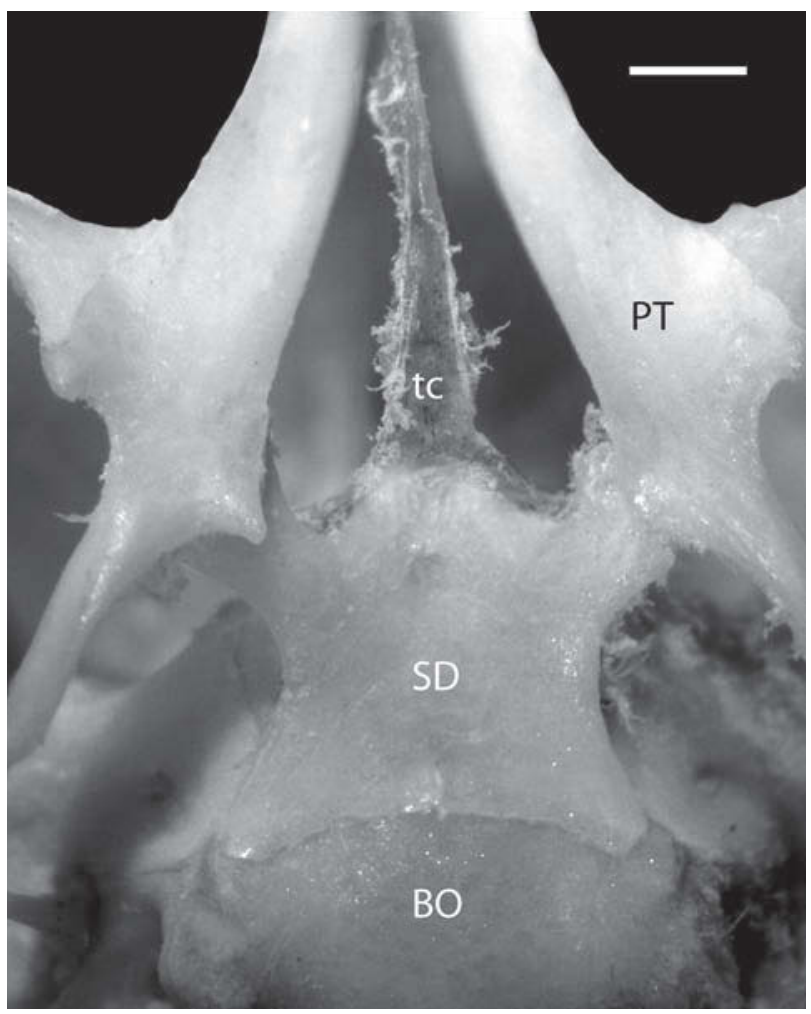

Figure 12 Ventral view of the palate of Moloch horridus, WAM R27737B, showing the cartilaginous trabecula communis. Anterior to top. Scale bar $=1 \mathrm{~mm}$. 


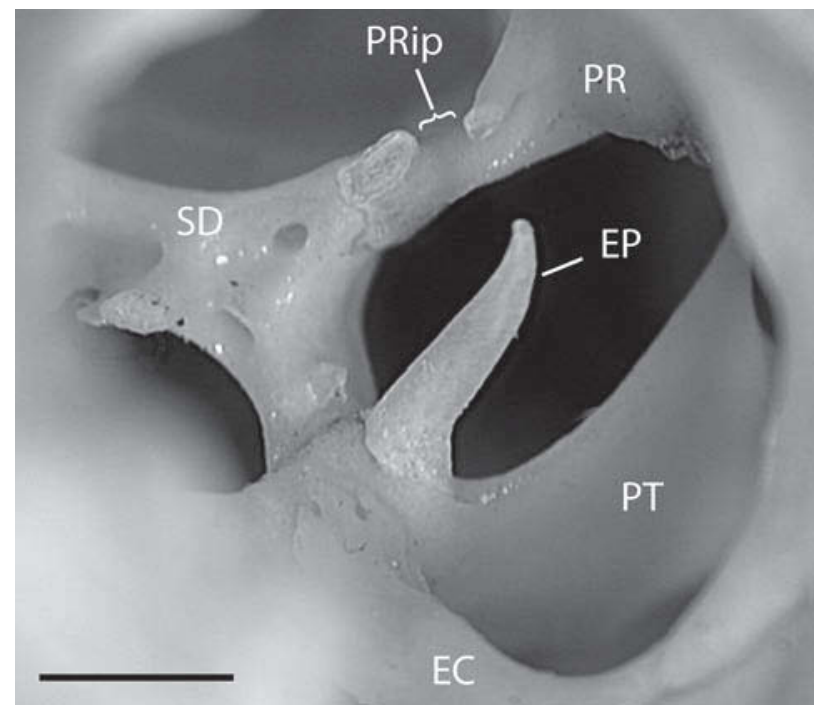

Figure 13 Oblique posterolateral view through left orbit, showing position and height of the epipterygoid in articulation; ROM R50. Scale bar $=1 \mathrm{~mm}$.

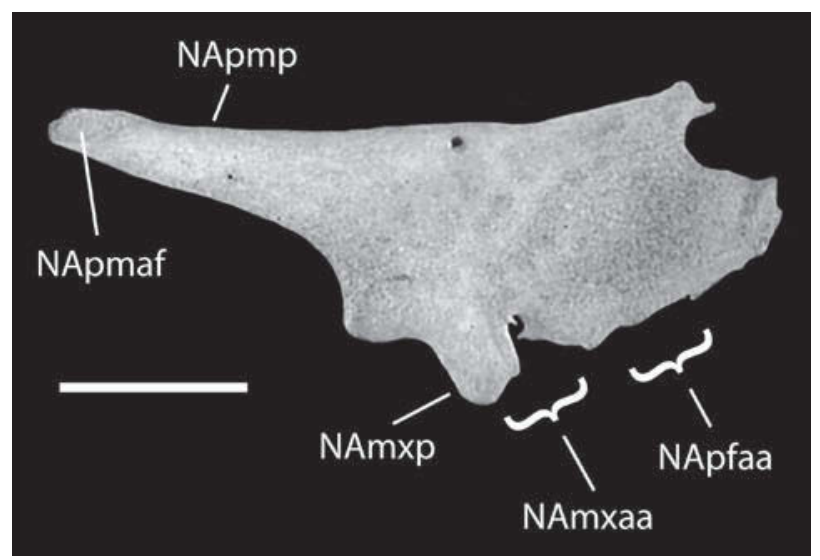

Figure 14 Left nasal in of Moloch horridus, WAM R146914, in dorsal view. Anterior to left. Scale bar $=1 \mathrm{~mm}$.

and is achieved via interfingering along the margin of the interpterygoid vacuity, accompanied by an overlapping articulation laterally (Figures 3, 8). The vomer is slightly convex dorsally, and the posterolateral portion is inflected slightly dorsally.

\section{Palatine}

The palatine is a delicate bone with a complicated morphology (Figure 9). It is the middle of three bones that make up the bony palate, and it forms the internal choanal groove. It marks the anterior and anteromedial margins of the suborbital fenestra, forms part of the floor of the orbit, and the floor of the posterior portion of the nasal capsule. The palatine contacts the vomer anteriorly, the maxilla ventrolaterally, the pterygoid posteriorly and the prefrontal dorsolaterally. Although they closely approach one another near the midline of the skull, the palatines do not contact one another, and are completely separated by the anterior extension of the interpterygoid vacuity (Figures 3, 8).

The palatine is a roughly triradiate bone (Figure 9), with two relatively robust processes anteriorly (the vomerine and maxillary processes) and a slender posterior pterygoid process. The anterolateral maxillary process contacts the maxilla along the maxillary shelf of the latter bone, near the level where the maxillary teeth begin a sharp medial inflection. Ventrally, their shared suture approximately parallels the tooth row (Figure 9B). Dorsally, the palatine overlaps a portion of the maxillary shelf, and there bifurcates to form the anterior and posterior bony margins of the infraorbital fenestra (Figures 9, 10). The lateral border of that fenestra is formed by the maxilla; the jugal closely approaches the margin but does not participate in it. Mediodorsal to the infraorbital fenestra, the palatine is sutured to the prefrontal; the palatine here forms the ventralmost portion of the medial margin of the expanded lacrimal fenestra (lacrimal foramen of other authors).

The anteromedial vomerine process of the palatine contacts the vomer in a slightly interdigitating suture along the margin of the interpterygoid vacuity; laterally the two bones share an overlapping articulation (Figures 3, 5). Dorsally, this process is somewhat cup-shaped (concave mediodorsally); at its lateral extent it forms a slightly interlocking articulation with the palatine process of the prefrontal. The anterior surface of the maxillary process and the lateral surface of the vomerine process together mark the space of the internal choana. Ventrally the internal choana appears as a broad groove (convex dorsally) entering into the palatal region from the anterolateral portion of the skull (Figure 9B).

The pterygoid process is distinct immediately posterior to the junction of the maxillary and vomerine processes (Figure 9). It extends in a gentle posterolateral curve, the medial surface of which contains a distinct groove for the articulation with the palatine process of the pterygoid. In both dorsal and ventral views, the palatine forms approximately one half of the medial longitudinal length of the suborbital fenestra (palatine fenestra of Moody 1980; our observations of this region differ from Moody's score for Moloch for his character 53).

\section{Pterygoid}

The pterygoid is a slender, weakly cruciform element that constitutes the posterior part of the bony palate (Figures 3, 11). It is edentulous in Moloch, as it is in other acrodont iguanians (Estes et al. 1988). The pterygoid contacts the palatine anteriorly, the ectopterygoid laterally, the epipterygoid dorsally, 
the basipterygoid processes of the sphenoid posteromedially and the quadrate posterolaterally. The medial margins of the two pterygoid bones are widely separated posteriorly on the palate, but gradually approach one another anteriorly, reaching their closest approximation at about the level of the pterygoid-palatine suture (at approximately the midpoint of the suborbital fenestra). They are never in contact. The cartilaginous trabecula communis is situated between the pterygoids (Figure 12).

Four distinct processes are evident; the anterior and posterior ones are elongate, the medial and lateral ones are short (Figure 11). The anterior palatine process is dorsoventrally flattened and narrow, exhibiting a gentle anterolateral curve that forms the posteromedial margin of the suborbital fenestra. At its anterior end is an indistinct articulation facet for the palatine. At approximately the middle of its length, the ventral surface is pierced by a tiny foramen that penetrates the interior of the bone posteriorly (Figure 11B); its function is unknown. The posterior quadrate process is more robust and has a dorsal inflection, with a progressive dorsal expansion posteriorly. That expanded sheet of bone is slightly concave medially, and anteriorly forms a distinct basipterygoid fossa that accommodates the basipterygoid process of the sphenoid. Posteriorly the lateral surface of the quadrate process is in direct contact with the quadrate.
A weak posteroventrally oriented cranial coronoid process, which in other agamids is formed by the ectopterygoid and pterygoid, is formed in Moloch predominantly by the ectopterygoid process of the pterygoid. The ventral extent of the cranial coronoid process is limited, reaching to just below the level of the most posterior point of the maxilla-jugal contact (Figure 4). The ectopterygoid process splits off from the main axis of the pterygoid just posterior to the midpoint of the bone's length. It is in broad contact with the ectopterygoid, in a complex articulation in which the ectopterygoid embraces the dorsal surface of the pterygoid and participates in the proximal part of the cranial coronoid process ventrally (Figures 4, 10).

The posteromedially-directed sphenoid process branches off the main axis of the pterygoid just posterior to the branching of the ectopterygoid process. The sphenoid process is roughly triangular in shape, with a rounded apex oriented posteromedially and forming a short shelf ventromedial to the anterior portion of the basipterygoid fossa.

The foot of the epipterygoid sits within the dorsal fossa columellae (Figure 11A). That fossa is positioned at the base of the dorsal sheet of bone that makes up the quadrate process. It forms a relatively shallow oval depression, elongated along an anteromedial-posterolateral axis.

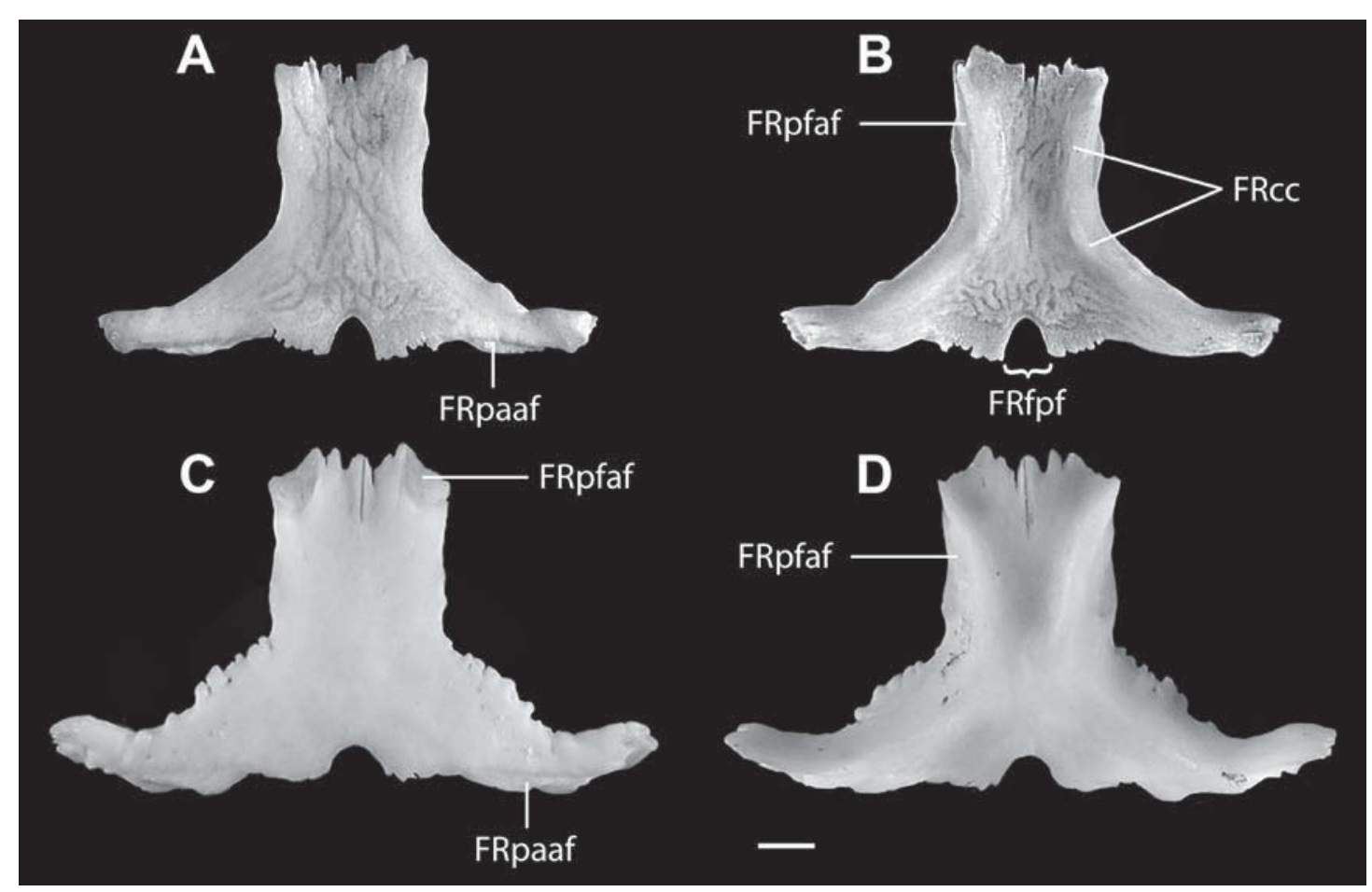

Figure 15 Frontals of Moloch horridus, showing ontogenetic transformations of morphology. Anterior to top for all. A. Dorsal view of our smallest (and presumably youngest) specimen, WAM R146914. B. Ventral view of smallest specimen, WAM R146914. C. Dorsal view of adult specimen WAM R38691. D. Ventral view of adult specimen WAM R38691. Scale bar $=1 \mathrm{~mm}$. 
The ventral surface of the pterygoid is flat (Figure 11B). Although the quadrate process narrows posteriorly, Moloch appears to be unique among Australian agamids because it does not form a sharp, blade-like ventral surface as seen in other taxa (e.g. Chelosania, Ctenophorus, Lophognathus, Pogona; Moody 1980).

\section{Epipterygoid}

The epipterygoid is incompletely formed in Moloch (Figure 13). It is broad at its base, where it sits in the fossa columellae of the pterygoid. It tapers just dorsal to this articulation and rises a variable distance as a columnar structure; in ROM R50 is rises to approximately the height of the incisura prootica of the prootic (Figure 13). In QM J11492 and WAM R27737B it extends a greater distance, to approximately the midpoint of the height of the ampullary recess of the anterior semicircular canal. Its dorsal end is slightly compressed mediolaterally and shows a slight medial inflection. The columnar portion of the bone rises from the anteromedial portion of the base. Posterolaterally the base appears as a short 'toe' extending a short distance beyond the level of the columnar portion. Combined with the medial inflection at the distal end of the bone, this lends a sinuous appearance to the bone in anterior view.

The reduction of the epipterygoid in Moloch is another interesting morphological convergence with some members of the North American horned lizards of the genus Phrynosoma. Phrynosoma solare was previously reported to lack an epipterygoid (Presch 1969) or to display various degrees of reduction (Axtell 1986).

\section{Nasal}

The nasal is a thin, delicate element that contacts the premaxilla anteriorly, the frontal posteriorly and the maxilla and prefrontal posterolaterally (Figure 5). In dried skulls, the nasals appear to be in contact along the midline for most of their length, but at least some of this contact area is filled with connective tissue, and no distinct articulation facets between the nasals are discernable. The premaxillary process of the nasal is splint-like and articulates with the lateral edge of the nasal process of the premaxilla via a weak articulation facet. The anterior ends of the nasals are thus separated by the nasal process of the premaxilla. The premaxillary process of the nasal forms the dorsomedial border of the external naris.

Posteriorly, the nasal expands laterally along a gentle curve that forms the dorsal margin of the external naris. Posterior to that margin, the nasal makes its initial contact with the facial process of the maxilla. In smaller individuals a short, fingerlike maxillary process (Figure 14) is distinct and marks the anterior part of the articulation with the maxilla. That articulation continues posteriorly a short distance, and a small fenestra between the two elements is present in smaller specimens; its position varies among specimens. In larger individuals, the maxillary process is less distinct, and forms the only area of contact between the two elements. No distinct articulation facets for the maxilla are present. Posterior to the maxillary contact area, the nasal is in broad contact with the prefrontal. In our smallest specimens (e.g. WAM R146914, Figure 14), no distinct articulation facet is visible, but in a larger disarticulated specimen (e.g.

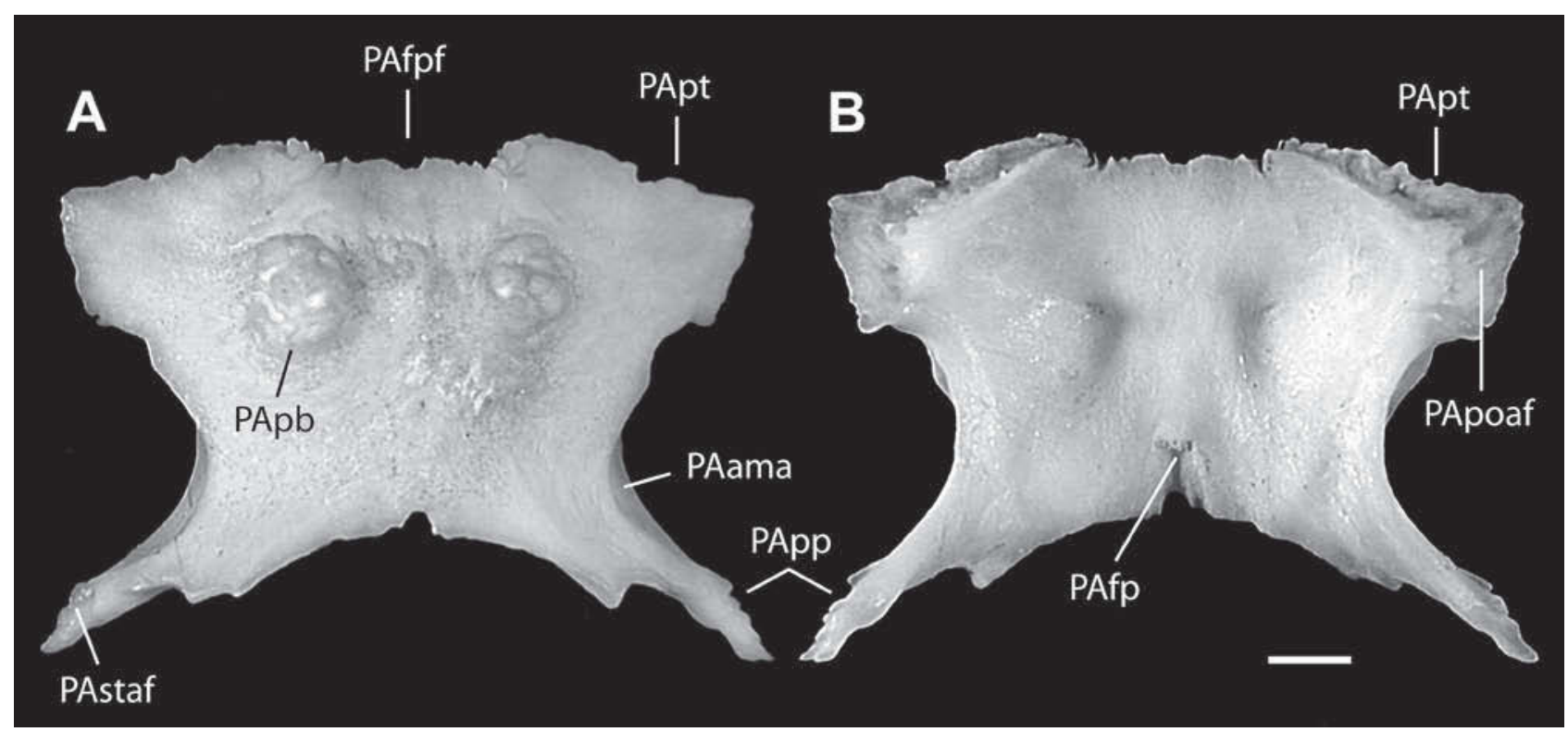

Figure 16 Parietal of Moloch horridus, WAM R27737A. A. Dorsal View. B. Ventral view. Anterior to top in both views. Scale bar $=1 \mathrm{~mm}$. 


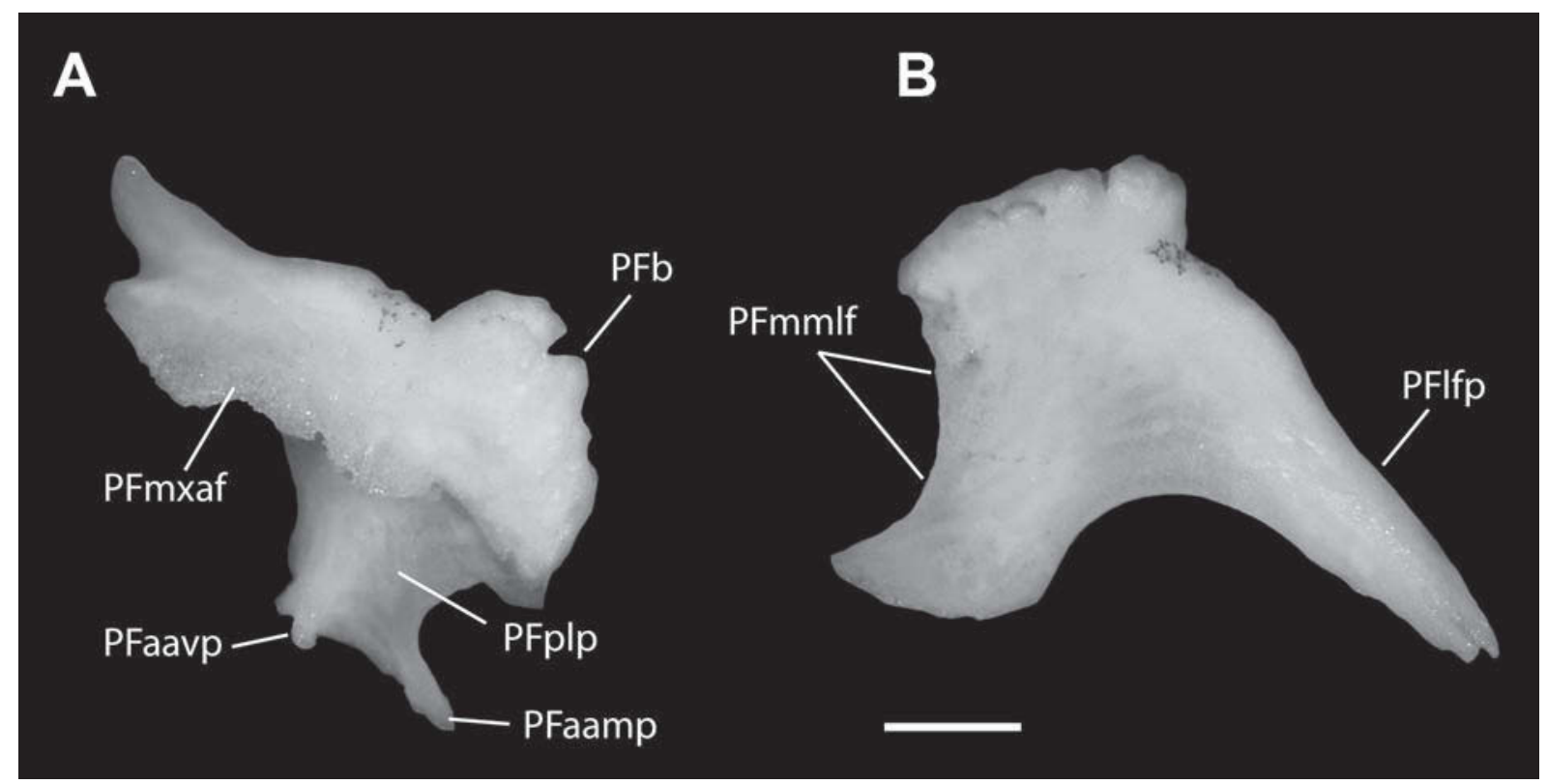

Figure 17 Left prefrontal of Moloch horridus, WAM R146914. A. Anterior view. B. Slightly oblique posterolateral view. Scale bar $=1 \mathrm{~mm}$.

WAM R27737A), an abutting articulation facet is present immediately posterior to the emargination marking the border of the tiny fenestra (in that case apparently marking the posterior edge of the maxillary articulation area).

At its posterior margin the nasal is in contact with the frontal; the nature of this contact is not clear, but distinct articular facets are not obvious on either element in disarticulated specimens (Figures $14,15)$. The posterior portion of the nasal is slightly concave dorsally, and forms a continuation of a shallow depression present on the central portion of the anterior half of the frontal. The premaxillary process forms a moderately steep ventral curve to meet the premaxilla. Moloch lacks the nasal foramen seen in the agamid Uromastyx (Moody 1980).

\section{Lacrimal}

There is no lacrimal.

\section{Frontal}

As in other iguanians, the embryonic frontals of Moloch appear to fuse into a single element early in prenatal ontogeny (Estes et al. 1988; Figure 15). The frontal is the dominant bone of the anterior skull roof, and contributes to the medial and posterior portions of the orbital margin (Figure 2). It is a dorsoventrally flattened, T-shaped bone (with the cross bar at the posterior end of the bone). The posterior margin is approximately three times the width of the anterior margin. It contacts the nasals anteriorly, the prefrontal anterolaterally, the parietal posteriorly and the postorbitals posterolaterally. Its dorsal surface lacks significant sculpture, but a few rugosities are present along the posterolateral processes in larger specimens (Figure 15C, D). The middle portion of the dorsal surface of the anterior half of the bone forms a shallow depression.

The anterior portion of the bone has an uneven margin, and appears slightly serrated in the disarticulated element. In young individuals, the lateral margins of the anterior portion of the frontal bear distinct, triangular, grooved facets for the prefrontal (Figure 15B). In the adult, a tighter, interlocking articulation is formed, and is reflected on the frontal by the clear presence of additional articulation facets on the dorsal surface (Figure 15C). The ventral surface is smooth along most of its extent, but distinct cristae cranii (descending processes of Estes et al. 1988) are weakly developed and converge slightly towards the midpoint of the length of the bone, then diverge sharply posterolaterally.

The posterior margin is interrupted at the midline by a notch, representing the anterior portion of the frontoparietal fenestra (= pineal or parietal foramen of other authors). On either side of that notch are two somewhat rounded posterior projections that articulate with the parietal in the adult; in smaller specimens, these form the anterior margin of an enlarged opening, the parietal fontanelle (e.g. Maisano 2001). Lateral to these are narrow, distinct shelves that serve as articular facets for the parietal. The posterolateral tips of the frontal are in contact with the postorbitals.

\section{Postfrontals}

There is no postfrontal. 


\section{Parietal}

The parietal is a single element (early ontogenetic fusion of the parietal is a squamate synapomorphy; Estes et al. 1988). It is somewhat vaulted dorsally, and roofs the anterior part of the otooccipital elements of the braincase. It contacts the frontal anteriorly, the postorbital anterolaterally, the squamosal and supratemporal posterolaterally and the supraoccipital posteriorly (via the processus ascendens on the latter element). It is closely associated with the paroccipital process of the otooccipital posteromedially.

In the adult, the posterior edge of the frontoparietal fenestra notches the anterior margin of the parietal along the middle of its length (the notch is distinctly deeper and wider in smaller individuals, where it represents the posterior margin of the progressively-shrinking parietal fontanelle of the juvenile; Figure 16; Maisano 2001). In the adult, the area on either side of the frontoparietal fenestra accommodates the posterior projections of the frontal in a weakly interdigitating suture. At the lateral edge of the dorsal surface a short parietal tab is present and overlaps the frontal. In ventral view, the posterior edge of the tab terminates at a narrow and short ventral process. Lateral to this is a roughly triangular (apex to dorsal) articular facet for the postorbital (Figure 16B).

Posterior to the postorbital articular facets, the parietal is constricted where it forms the medial border of the supratemporal fenestra. Along this margin, a smooth, ventrally-projecting surface marks the attachment of the adductor muscles; this surface is partially roofed by a slight overhanging projection from the dorsal surface of the parietal.

The post-parietal processes are strongly divergent, and project ventrolaterally. The angle of divergence changes through ontogeny, becoming wider with increased size of the parietal. The angle between the parietal table and the ventrolateral projection is slight. The post-parietal processes are widest at their base, taper distally, and are roughly triangular in cross-section (Figure 16). At the distal tip of each is a distinct articular facet for the supratemporal; the squamosal also articulates in this area, but no distinct facet is discernable.

At the posterior mid-point of our specimens, a distinct notch is visible in dorsal view (it appears more pronounced in the juvenile). Immediately ventral to this notch is a short excavated space that accommodates the processus ascendens of the supraoccipital, and terminates in the fossa parietalis (parietal fossa of Oelrich 1956; Figure 16B). In smaller individuals there is a small gap between the processus ascendens and the medial edge of the post-parietal processes. In larger individuals this gap may close, forming the appearance of a solid bony connection between the parietal and the dorsal portion of the braincase (Moody 1980). In incompletely cleaned specimens, the small gap may be filled with tissue, and may resemble the adult condition.

The dorsal surface of the parietal supports two

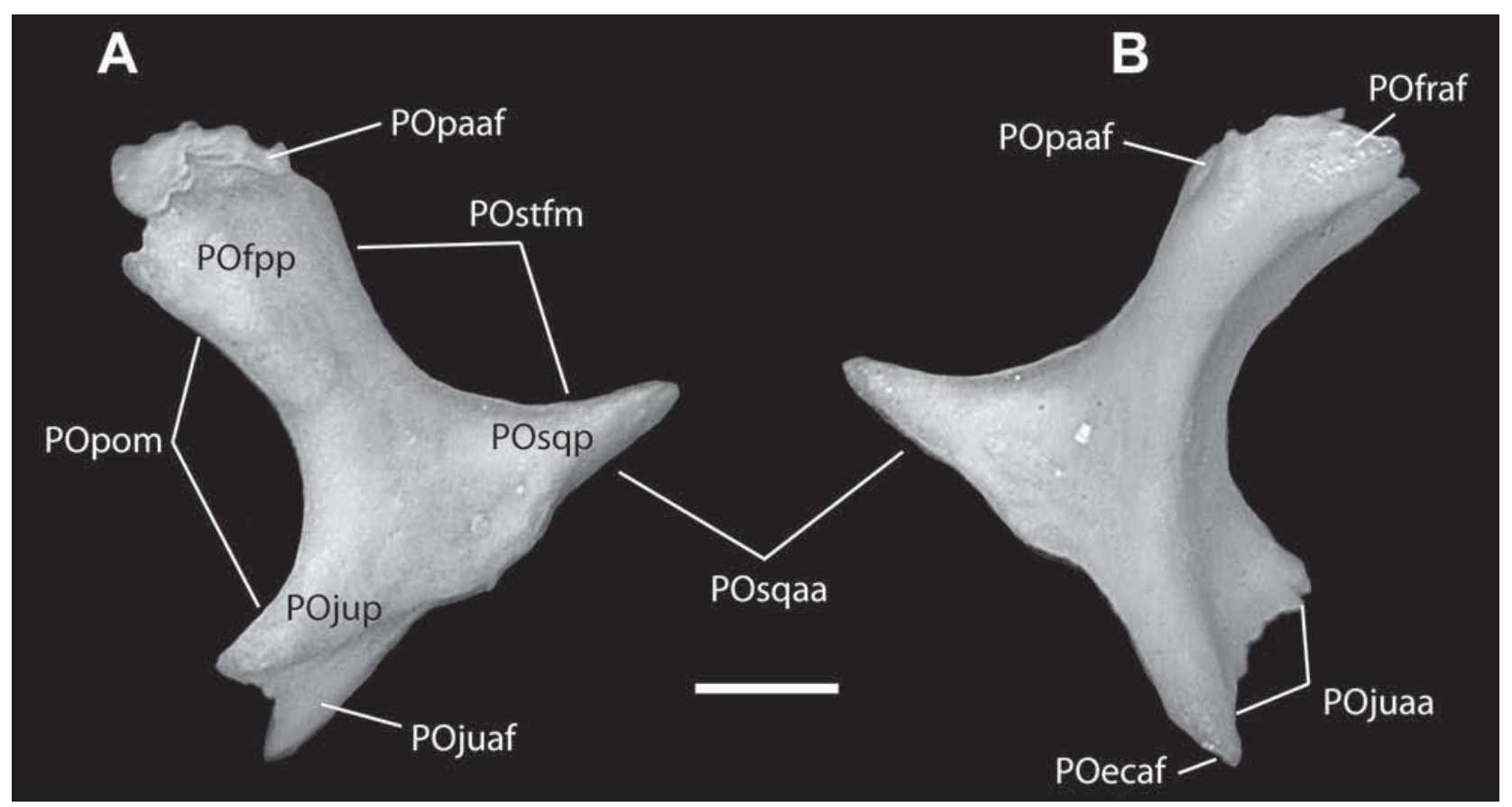

Figure 18 Left postorbital of Moloch horridus, WAM R146914. A. Lateral view, anterior to left. B. Medial view, anterior to right. Scale bar $=1 \mathrm{~mm}$. 


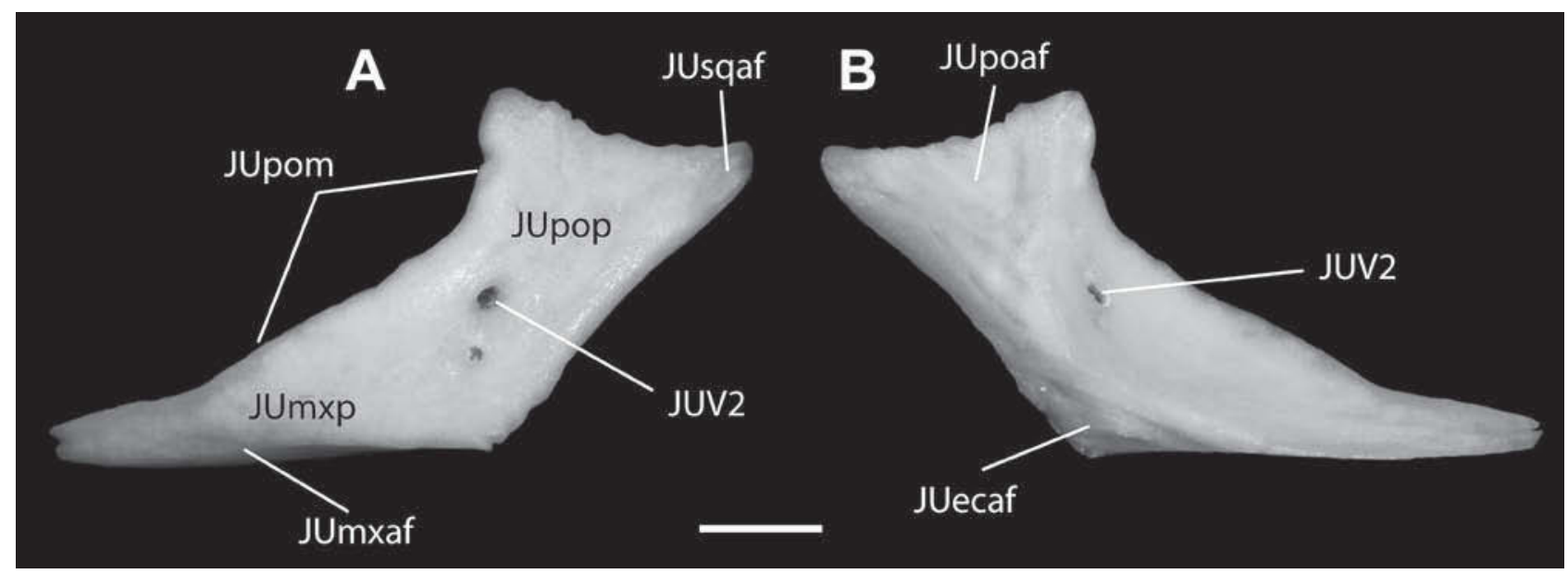

Figure 19 Left jugal of Moloch horridus, WAM R146914. A. Lateral view. B. Medial view. Scale bar =1 mm.

distinct parietal bosses (Evans 2008; Figure 16A). These are situated on either side of the midline, between approximately one-third (e.g. WAM R146914) or one-half (e.g. QM J11492) the distance along the length of the bone. The bosses are distinct, but small, in younger individuals, and increase in size and extent of development in larger individuals. The ventral surface of the parietal is concave beneath the bosses (Figure 16B).

\section{Prefrontal}

The prefrontal is a robust bone, forming the anterodorsal margin of the orbit, and most of the medial margin of the enlarged lacrimal fenestra (Figure 17). It contacts the facial process of the maxilla anteriorly, the nasal anteromedially, the frontal medially and the palatine ventrally. The dorsal and dorsolateral surfaces have a rough, knobby sculpturing, and form a weak boss (Figures $5,17)$.

Anterodorsally the prefrontal forms a ventrally directed, elongate shelf of bone, the ventral part of which forms a distinct articulation facet for the maxilla (Figure 17A). Behind that facet, a distinct dorsal slot is the bone is masked in anterior view by the maxilla (Figures 5, 17A). Ventral to that slot a distinct palatine process bifurcates slightly near its distal extent, with an anteromedial portion contacting the lateral surface of the vomerine process of the palatine, and a posterolateral portion articulating with the maxillary process of the palatine. Posteromedially, the lateral frontal process inserts into a distinct lateral groove on the anteroventral surface of the frontal. In adults, a dorsal frontal process is well developed, and articulated on the anterolateral dorsal surface of the frontal. The prefrontal does not contribute to the margin of the infraorbital fenestra (Figure 10).

\section{Postorbital}

The postorbital is a robust bone in Moloch. It forms the dorsal portion of the postorbital bar, and the anterodorsal portion of the temporal arch. It participates in the central posterior margin of the orbit, and the anterior margin of the supratemporal fenestra. It is a distinctly triradiate element, with a pronounced and robust frontoparietal process dorsally, a dorsoventrally flattened jugal process anteroventrally and a splint-like squamosal process posteroventrally (Figure 18). The postorbital contacts the frontal anterodorsally, the parietal posterodorsally, the jugal ventrolaterally, the ectopterygoid ventromedially and the squamosal posteroventrally.

The frontoparietal process has a distinct dorsal articulation facet; the medial and posterior portions of which firmly articulate with the parietal. Anterolaterally is a smaller articulation facet for the frontal. Distally, the jugal process expands medially to contact the ectopterygoid in a slightly interdigitated suture (the complexity of that articulation can be seen only in disarticulated material). Laterally that process joins the jugal in a relatively wide overlapping articulation. The squamosal process is short and dorsally over-rides the squamosal. The squamosal process forms the anterolateral margin of the supratemporal fenestra; the anterior margin of that fenestra is formed as a gentle curve along the posterior portion of the postorbital.

The broad, flattened, lateral surface of the bone is oriented obliquely towards the posterior end of the skull; in a direct lateral view this surface is less visible than it is in a direct posterior view (character 20 of Moody 1980). There is no distinct anterodorsal knob or boss on the postorbital. 


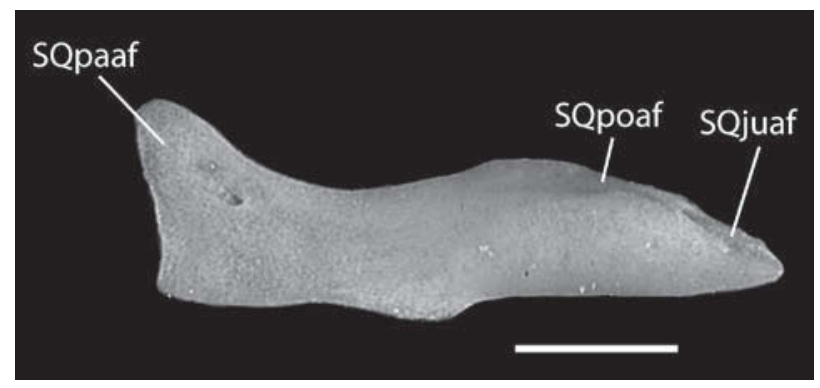

Figure 20 Left squamosal of Moloch horridus, WAM R146914, in ventromedial view. Anterior to right. Scale bar $=1 \mathrm{~mm}$.

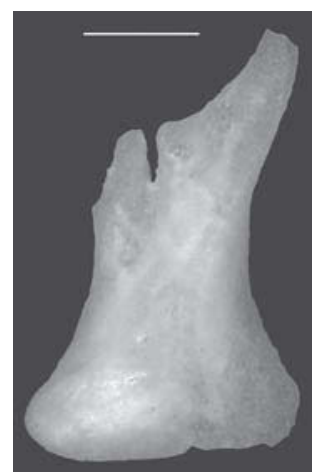

Figure 21 Left supratemporal of Moloch horridus, WAM R146914, in medial view. Anterior is to right, dorsal is to top. Scale bar $=0.5 \mathrm{~mm}$.

\section{Jugal}

The jugal forms the ventral and posteroventral portion of the orbital rim, and the anteroventral portion of the supratemporal arch. It represents the lateralmost extent of the skull in Moloch, and is a relatively robust bone, with distinct maxillary and postorbital processes (Figure 19). The jugal contacts the maxilla anteroventrally, the postorbital dorsally, the squamosal posterodorsally and the ectopterygoid medially. The jugal closely approaches, and in some specimens (e.g. ROM R50) may contact, the palatine anteriorly. The jugal is well developed in its dorsal extent but does not separate the postorbital from contact with the squamosal (Figure 4). It does not participate in the margin of the infraorbital fenestra, although it closely approaches it.

The jugal is prominently visible in a dorsal view through the orbit of the skull, and its ventromedial extent is best appreciated in that view (Figure 2). In lateral view, the anterior portion of the maxillary process is obscured from view by the orbital process of the maxilla. The maxillary process is in continuous contact with the orbital process of the maxilla until the distal end of the maxilla; the two elements there form a sharp corner, just posterior to the last maxillary tooth. Medial to that position, their articulation is braced by a strong contact with the ectopterygoid. The articulation facet for the ectopterygoid is distinct on the ventromedial surface of the disarticulated jugal (Figure 19B). Dorsally, the maxillary process begins a gentle crescent-shaped curve that extends along the anterior margin of the postorbital process of the jugal and marks the posteroventral portion of the orbit. The dorsomedial surface of the bone is dominated by a triangular articulation facet (apex to ventromedial side) for the postorbital (Figure 19B). A distinct, but less obvious, articulation facet for the squamosal is present on the lateral surface of the posterodorsal corner of the jugal. In lateral view of the articulated skull, the area of contact with the postorbital exceeds that of the area of contact with the squamosal. At least one distinct foramen (sometimes two) pierces the lateral surface of the jugal at about the midpoint of the postorbital process (Figure 19). It is oriented dorsomedially, and is present on the medial surface immediately ventral to the articulation with the postorbital. In other iguanians, a foramen in this position transmits a sub-branch of the maxillary branch of the trigeminal nerve (V2; Oelrich 1956).

\section{Squamosal}

The squamosal (paraquadratum of Siebenrock 1895) forms the posterior portion of the temporal arch, and the posterolateral margin of the supratemporal fenestra. It is weakly sinuous in shape (Figure 20), and is nearly uniform in thickness for the anterior two-thirds of its length;

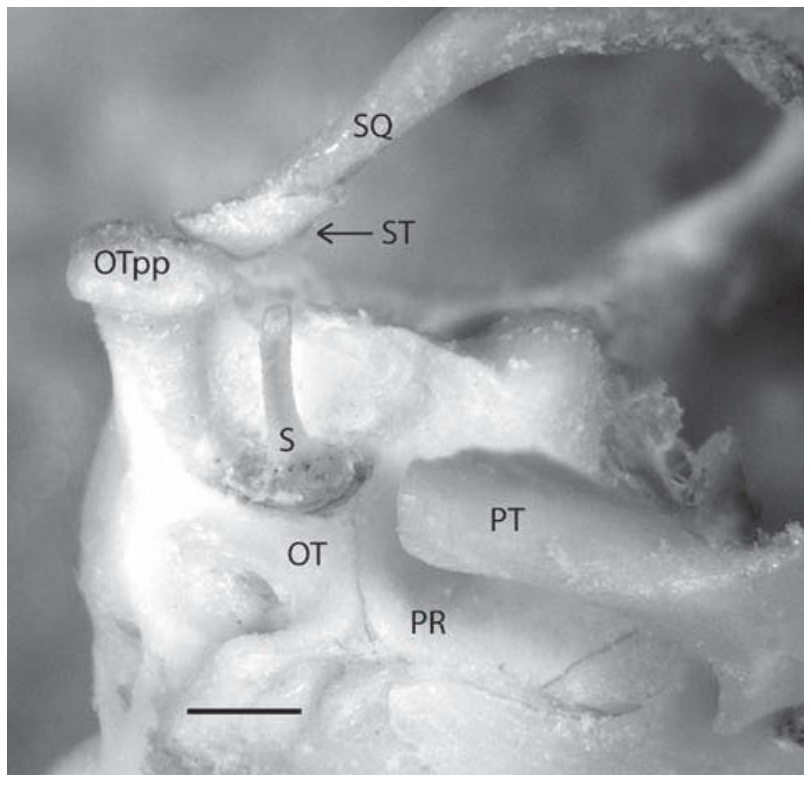

Figure 22 Oblique view of right ventrolateral portion of the skull of WAM R27737B, showing stapes in position in the fenestra ovalis, and the articulated supratemporal just beyond it. Anterior to right. Scale bar $=1 \mathrm{~mm}$. 
posteriorly it is dorsoventrally compressed. The squamosal contacts the postorbital anterodorsally, the jugal anteroventrally; posteroventrally it contacts the supratemporal laterally, and the postparietal process of the parietal medially. There is no clear articulation facet for the supraoccipital, and the two appear to articulate along a relatively smooth gliding surface. The squamosal is closely associated with, but not sutured to, the paroccipital process of the otooccipital. The articulation with the parietal obscures almost all of the contact with the supratemporal in dorsal view; in cleaned skulls, a corner of the supratemporal may be visible at the posterolateral edge of the squamosal. The squamosal lacks the posteroventral projection seen in some other Australian agamids (e.g. Caimanops, Hydrosaurus; Moody 1980).

\section{Supratemporal}

The supratemporal (squamosal of Siebenrock 1895) is significantly reduced in size but is present as a minute, roughly triangular bone that is obscured from view in all but the most immaculately cleaned articulated skulls (Figure 21). It is best exposed ventrally, where it articulates with the ventromedial surface of the squamosal (Figure 22). Its small size and obscured position explain previous reports of its absence in Moloch (Siebenrock 1895; Moody 1980; Witten 1993; Evans 2008). As an isolated element it is easily overlooked. We were able to identify the supratemporal in two articulated skulls (ROM R50 and WAM R27737B), two partially disarticulated skulls (TMM M721 and WAM R38691) and our fully disarticulated specimen (WAM R146914). The isolated element is most robust ventrally, thinning dorsally to a nearly transparent sheet of bone. Its dorsal end is notched near the posterior edge. It reaches its dorsalmost extent anteriorly where it narrows anteroposteriorly to a thin splint that appears to be broken in all isolated specimens available to us (Figure 21). A low and almost indistinct ridge traverses the medial face anterodorsal to posteroventral. Just anterior to its posteroventral extent, a minute foramen penetrates the bone in some specimens. The lateral surface is nearly flat, and closely abuts the squamosal (Figure 22).

The primary contact of the supratemporal is with the ventral surface of the posterior portion of the squamosal. It has a slightly interlocking articulation with the posterolateral tip of the postparietal process. Although there is no direct bony connection, the supratemporal is closely associated with the cephalic condyle of the quadrate and the paroccipital process of the otooccipital.

\section{Quadrate}

The quadrate forms the primary articulation between the skull and mandible via the cephalic and mandibular condyles. It forms the posterior margin of the infratemporal fenestra (open ventrally, as in all other squamates) and the subtemporal fenestra. It contacts the squamosal anterodorsally, the supratemporal dorsomedially, the pterygoid ventromedially and the articular (on the mandible) ventrally. There is no direct contact

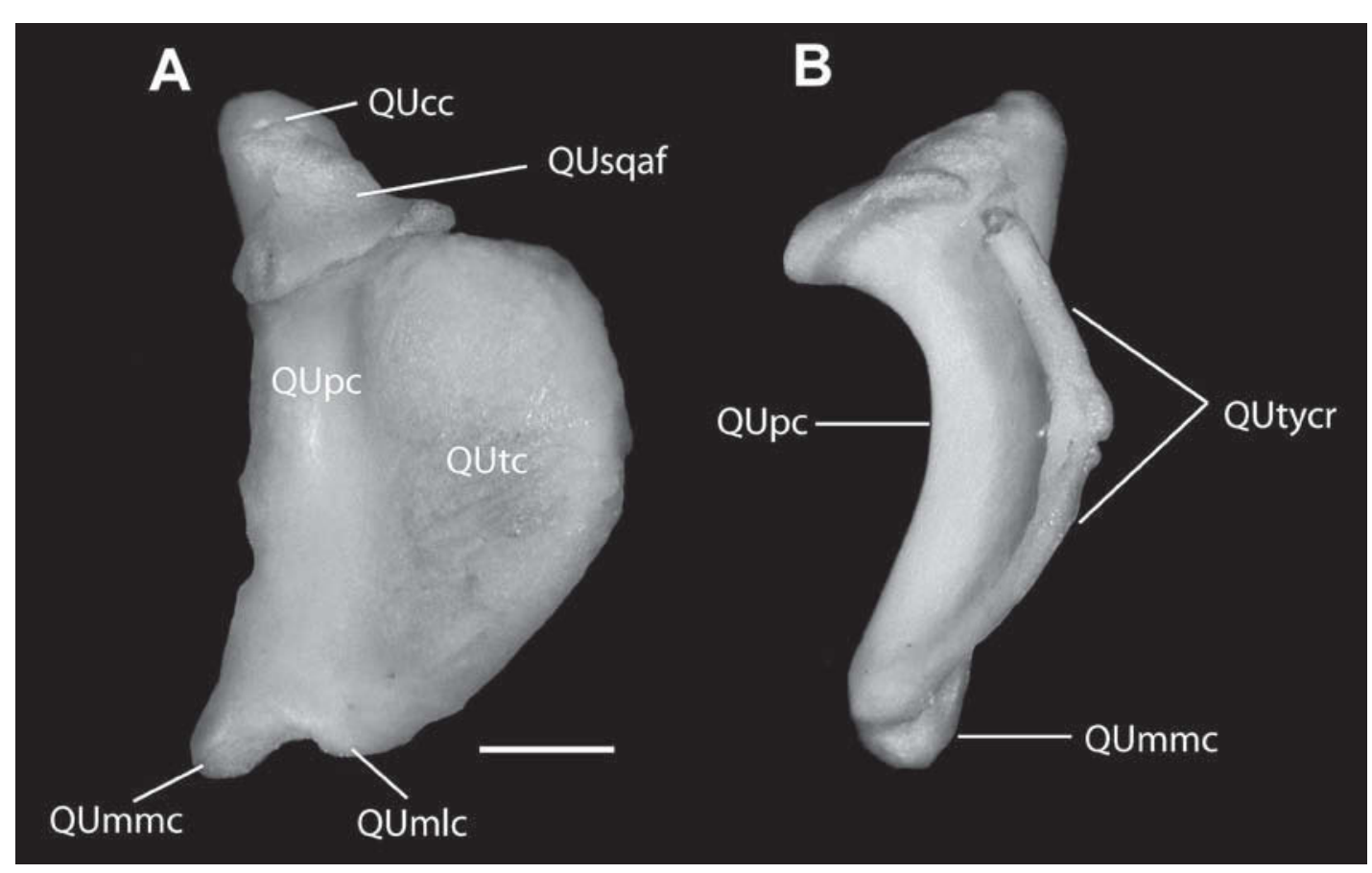

Figure 23 Right quadrate of Moloch horridus, WAM R27737A. A. Posterior view. B. lateral view. Scale bar $=1 \mathrm{~mm}$. 


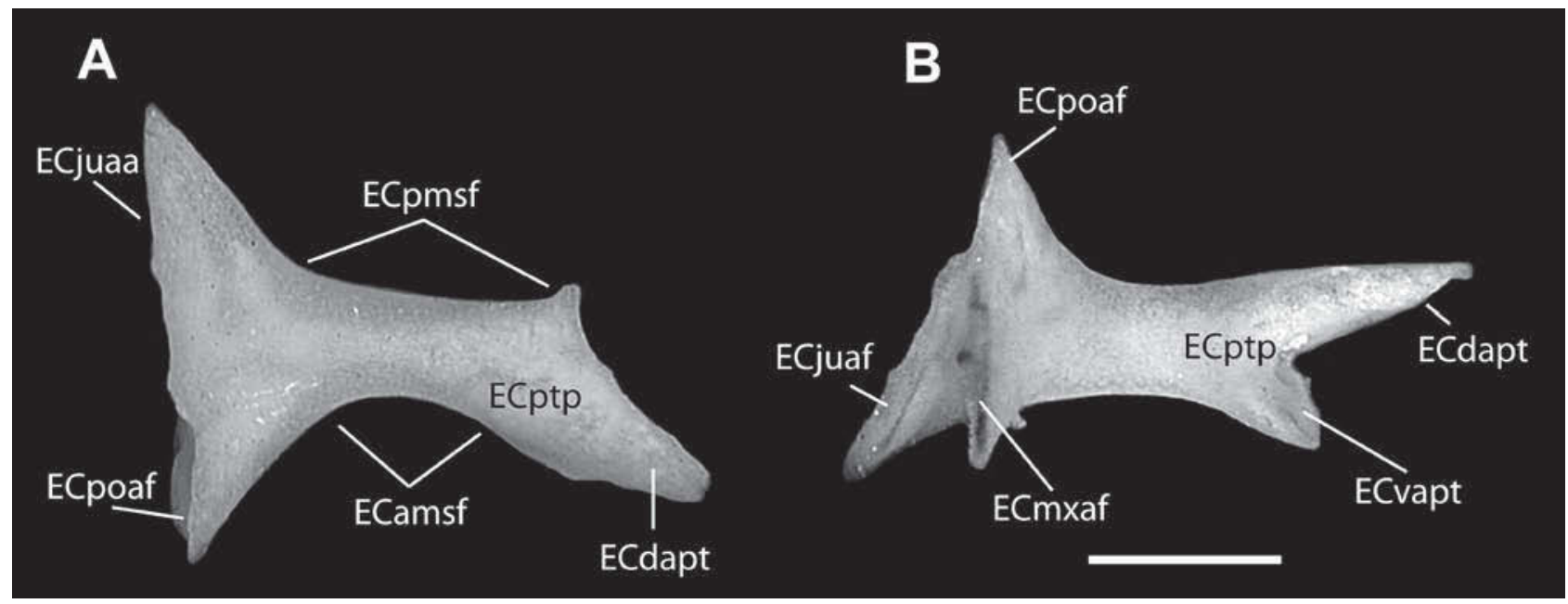

Figure 24 Left ectopterygoid of Moloch horridus, WAM R146914. A. Dorsal view. B. Posterior view. Medial to right in both views. Scale bar $=1 \mathrm{~mm}$.

with the paroccipital processes. A lateral tympanic conch is well-developed, but a medial lamina is at best only weakly developed (e.g. ROM R50) and a pterygoid flange is absent (Figure 23).

The cephalic condyle forms the dorsal extremity of the bone, and is larger than the mandibular condyle. In some individuals (e.g. ROM R50) a distinct dorsal notch is present just lateral to the cephalic condyle; it is absent in our smallest individual (WAM R146914) and in one of our largest specimens (TMM M-721).

The mandibular articulation has two distinct condylar surfaces. In smaller individuals (e.g. WAM R146914) the two are approximately equal in size (Moody 1980), but in larger individuals the medial condyle is distinctly larger (e.g. ROM R50, TMM M-721, WAM R27737B). The two have different orientations, with the long axis of the medial condyle oriented approximately anteroposteriorly, and the long axis of the lateral condyle oriented anterolaterally/posteromedially along an approximately 45 degree line relative to the midline of the skull. The medial condyle extends farther ventrally than does the lateral condyle (Figure 23A).

The anterior surface of the quadrate is curved and smooth. The posterior surface is concave and dominated by a dorsoventrally oriented posterior crest (Figure 23). There is no apparent groove marking the passage of the mandibular artery, nor a quadrate foramen as found on some iguanids (Oelrich 1956).

The tympanic crest (convex anteriorly) occurs as a broad arch along the lateral edge of the tympanic conch, and provides the attachment for the anterior portion of the tympanum (Figure 23B).

\section{Ectopterygoid}

The ectopterygoid (transversum of Siebenrock 1895) serves as a brace between the posterior palatal region and the lateral maxilla-jugal bar. It forms the posterior margin of the suborbital fenestra, and the anterior margin of the subtemporal fenestra. It contacts the pterygoid medially, the maxilla posterolaterally, the jugal laterally and the postorbital posterodorsally. These articulations are complex. The pterygoid process clasps the pterygoid, with a broad, elongated, posteromedially

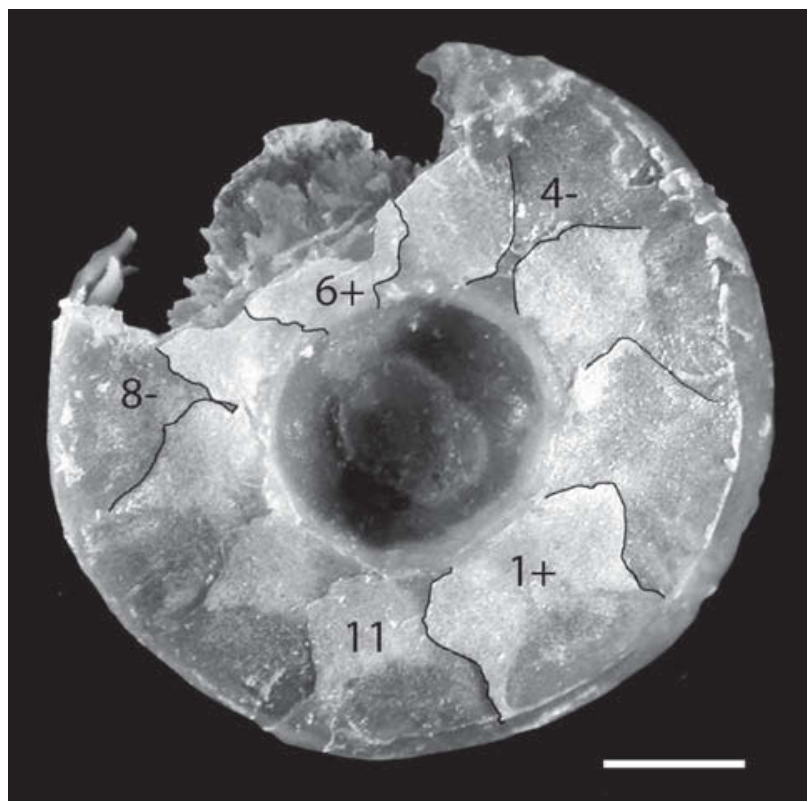

Figure 25 Articulated left scleral ring of Moloch horridus, WAM R2. First, last, positive, and negative ossicles are labeled; borders between some ossicles are highlighted for clarity. Scale bar $=$ $1 \mathrm{~mm}$. 
directed dorsal projection (Figure 10), and a shorter, posteroventrally oriented projection firmly sutured to the pterygoid and participating in the formation of the cranial coronoid process (Figure 4).

Laterally, the bone is triradiate (Figure 24). Anterolaterally, the ectopterygoid contacts the dorsal surface of the maxilla just above the posterior portion of the tooth row, and articulates with the ventromedial surface of the jugal in an abutting articulation. Posterodorsally, a short ramus contacts the ventralmost tip of the postorbital. Posteroventrally a broad ventral ramus embraces the posterior end of the maxilla just behind the last tooth, and abuts the jugal at the corner where the postorbital process begins is dorsal ascent.

\section{Scleral ring}

Acrodont iguanians (agamids and chameleons) have only 11 or 12 bony scleral ossicles in the eye (Estes et al. 1988). Although Moloch was included in an extensive summary of eye anatomy in lizards (Underwood 1970) specific details regarding scleral ring structure are not available in the literature. Moody (1980) scored Moloch as having 12 ossicles, but we cannot confirm that with material available to us.

The scleral ring morphology could be studied only in one of our specimens. We follow the terminology and nomenclature of Underwood (1970) for the scleral ring. The left eye of WAM R2 was removed from the head and dissected to reveal the ring. The dorsal portion of the ring was damaged prior to our examination (Figure 25), but a full ossicle count and formula could be determined, nonetheless. Eleven ossicles are present; ossicles 1 and 6 are positive (overlap both adjacent ossicles), and ossicles 4 and 8 are negative (are overlapped by both adjacent ossicles). This is the 'rare' condition for agamids according to Underwood (1970). The discrepancy between our data and those presented by Moody (1980) for Moloch suggest either that his matrix was incorrectly scored for this feature (his character 56), or that the ossicle count in the scleral ring of Moloch is polymorphic. Unfortunately, we were able to dissect only one eye from a single specimen.

\section{General features of the braincase}

The braincase can be viewed in two distinct components, the orbitotemporal region and the otooccipital region (Evans 2008). The former consists of the membranous braincase, the paired orbitosphenoid ossifications, and the associated cartilages. The otooccipital region is well ossified in Moloch, and consists of three unpaired midline elements (the supraoccipital dorsally, and the sphenoid and basioccipital ventrally) and the paired anterior prootics and posterior otooccipitals. In our largest specimens the sutures between those elements are still distinct, although the elements appear to be well fused (Figure 26).

In dorsal view of the articulated skull, the supraoccipital and paroccipital processes of the otooccipitals are visible, as are the anteromedial portions of the prootics (seen through the supratemporal fenestrae; Figure 2). The paroccipital processes are short, and terminate laterally with an anterior hook-like curvature. This forms the posterior and lateral margins of a rounded notch, the medial border of which is formed by a short

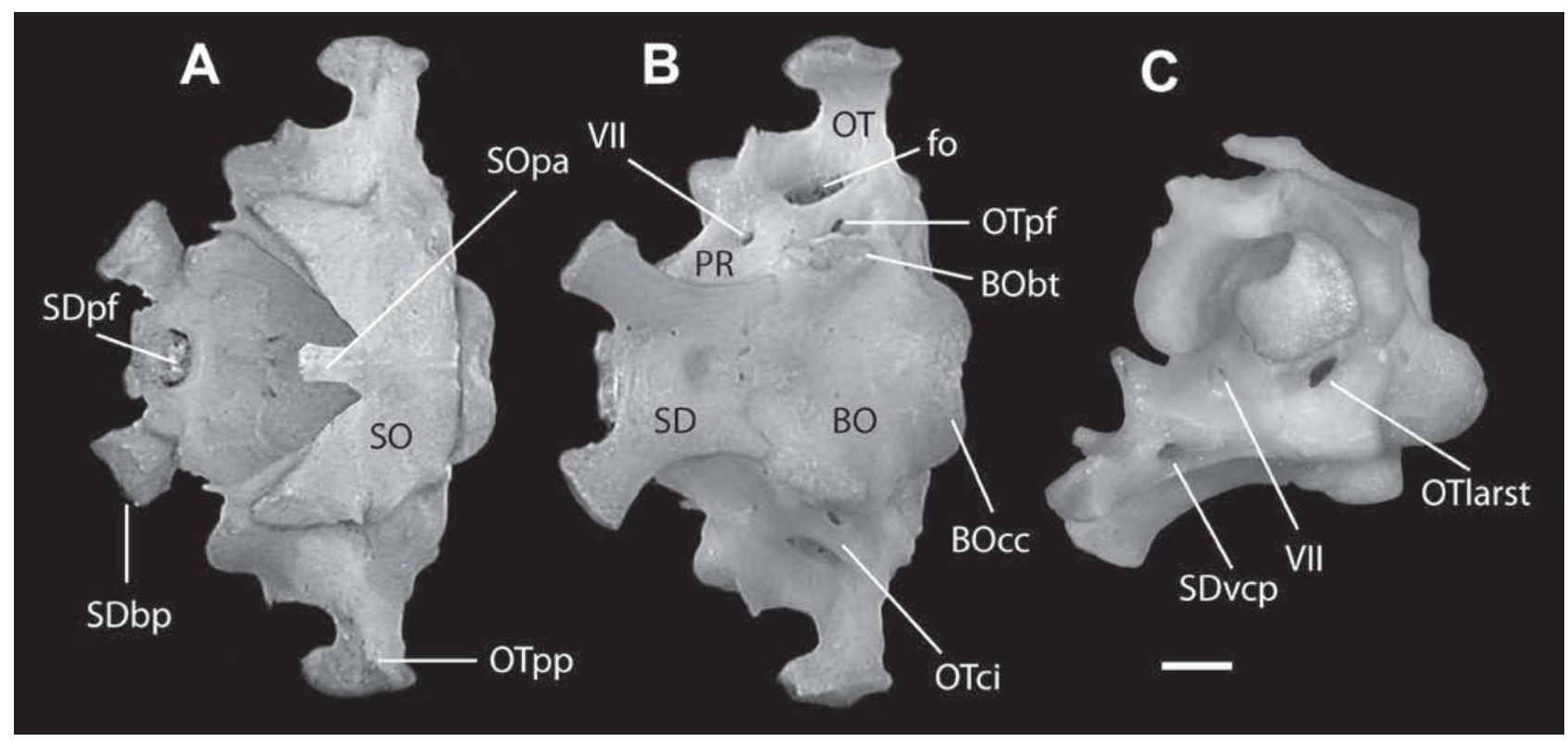

Figure 26 Articulated braincase of Moloch horridus, WAM R27737A. A. Dorsal view. B. Ventral view. C. Lateral view. Anterior to left in all views. Scale bar $=1 \mathrm{~mm}$. 


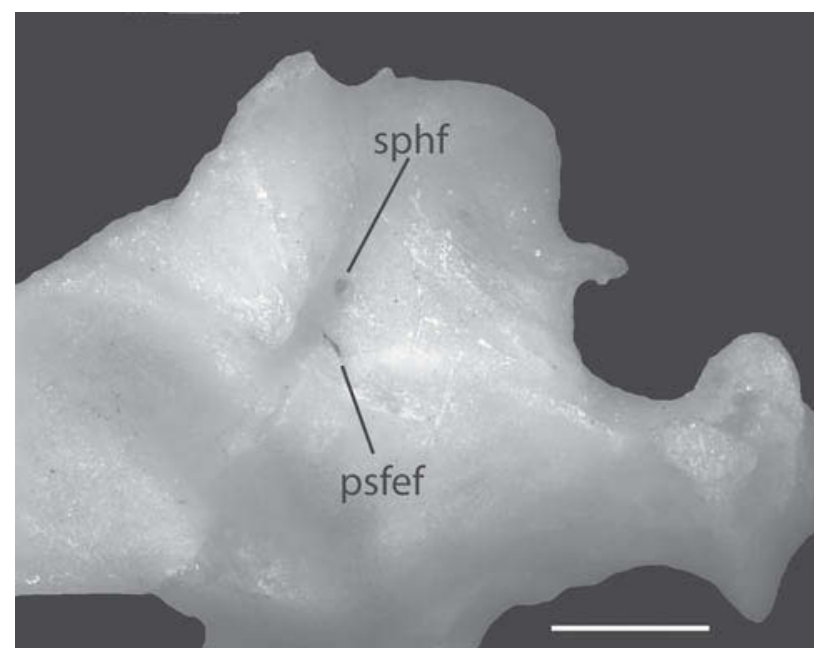

Figure 27 Detailed view of the dorsal surface of the right side of the otooccipital portion of the braincase of WAM R27737A. The right paroccipital process is visible on the right edge of the image, the reduced sphenoccipital fenestra (sphf), and the secondary foramen posterior to it (psfef) are shown (the latter communicates with the endolymphatic foramen). Scale bar $=1 \mathrm{~mm}$.

ridge on the prootic that overhangs the fenestra ovalis (Figure 26). In most specimens, the rounded notch is quite shallow, but in WAM R27737A a greater anterior extension of the paroccipital process results in a more pronounced notch (Figure 26). The parietal obscures other features of the braincase in dorsal view. Most notable of these is a distinct depression formed in the area surrounding the dorsal convergence of the supraoccipital, prootic, and otooccipital. In the two specimens where this feature can be readily examined, there is a small fenestra positioned near the anterior end of the depression, and between the semicircular canals (Figure 27). A tiny hair passed through this fenestra will enter the cranial cavity at or just anterior to the suture between the prootic and supraoccipital, the position at which the large sphenoccipital fenestra (epiotic foramen of Moody 1980) opens in other agamids. This fenestra thus apparently represents an extremely reduced sphenoccipital fenestra, an opening present in most agamids, but absent in Uromastyx and Leiolepis (Siebenrock 1895; Moody 1980; Evans 2008) and some species of Stellio (Moody 1980). In three previous discussions of agamid skulls (Siebenrock 1895; Moody 1980; Evans 2008) the fenestra was reported to be absent in Moloch. The reported absence may indicate variation in expression of this feature in Moloch, but more likely is a result of the small size of the fenestra and the fact that it is completely obscured by the parietal in articulated skulls.

In WAM R27737A a second minute foramen is situated immediately posterior to the sphenoccipital fenestra, at the point where the supraoccipital, prootic and otooccipital meet. This foramen communicates with the otic chamber, and a hair can be passed through it, exiting the otic chamber via the endolymphatic foramen on the anteroventral side of the supraoccipital.

In posterior view, the paroccipital processes project laterally and are not inclined dorsally (Moody 1980). The foramen magnum is roofed by a strong contribution from the supraoccipital. The basioccipital contributes to at best only a small portion of the ventral margin of the foramen magnum.

Our description of the disarticulated otooccipital elements is based on our smallest (and presumably youngest) specimen (WAM R146914). As a consequence, our description applies specifically to the younger ontogenetic stages of Moloch.

\section{Orbitosphenoid}

The orbitosphenoids are positioned medial to the posterior portion of the orbit in Moloch. They ossify from within the embryonic pila metoptica and are simple, weakly triradiate elements that support part of the membranous braincase (Säve-Söderbergh 1947; Oelrich 1956). They are slightly concave medially. There are no connections between the orbitosphenoids and other ossified elements of the skull, and they frequently are lost (or remain unrecognized) in skeletal preparations.

The ventral ramus of the orbitosphenoid is the longest of the three portions. It is slightly inflected posteriorly and is connected via a short cartilaginous strut to the hypochiasmatic cartilage. Dorsally, a short anterior process connects with the planum supraseptale, which extends from just beneath the posterior portion of the frontal, at the posterodorsal margin of the orbit. The orbitosphenoids are in place in QM J11492 (the only one of our specimens in which they remain intact in natural position). On the left side of this specimen, the bone is distinctly triradiate. On the right side there is no noticeable distinction between the anterodorsal and anteroventral rami. The orbitosphenoids also can be viewed in natural position in the digital model posted at $<$ http://digimorph.org/specimens/ Moloch_horridus/head/>. The morphology of the orbitosphenoid is known to change through ontogeny in some iguanian lizards, progressing from simple, weakly triradiate morphology through complex quadriradiate morphology as ossification proceeds along orbital cartilages associated with the membranous braincase (de Queiroz 1987). Our sample does not permit a clear understanding of the degree to which the morphology changes during ontogeny in Moloch. 


\section{Sphenoid}

The sphenoid is an unpaired median bone and forms the anterior part of the floor of the cranial cavity (Figures 26, 28). It contacts the basioccipital posteriorly, the prootic laterally and posterolaterally and the pterygoids anterolaterally via the basipterygoid processes. The sphenoid has a slightly greater anteroposterior length than the basioccipital in our smallest specimen (WAM R146914), but in the larger specimens they are approximately the same length along the midline. The ventral surface of the sphenoid is relatively smooth.

The anteriormost portion of the sphenoid consists of a pair of basipterygoid processes; these are directed anterolaterally with a ventral inflection. Their distal ends are somewhat bulbous and are oval in shape. Between the basipterygoid processes are the ossified bases of the trabeculae cranii. Immediately ventrolateral to each trabecula, the base of the basipterygoid process is pierced by the anterior opening of the vidian canal, a narrow canal floored by parasphenoid ossification (Stimie 1966) and transmitting the palatine branch of the facial nerve (cranial nerve VII) and the palatine artery (Oelrich 1956; Figure 28B). An ossified parasphenoid rostrum is not found in Moloch (Siebenrock 1895;
Evans 2008). In two of our specimens (WAM R97222 and WAM R27737B) a midline cartilaginous strut, the trabecula communis, is visible (Figure 12) and continuous anteriorly with a preserved portion of the interorbital septum.

In dorsal view, the bases of the trabeculae cranii continue posteriorly as two low, broad crests, the cristae trabeculares, that lie on either side of a shallow recess (the pituitary fossa) and terminate at a low vertical rise, the dorsum sellae (Figure 28A, B). At the base of the dorsum sellae, just medial to the cristae trabeculares, the carotid canals enter the base of the pituitary fossa, a shallow depression centered on the anterior end of the sphenoid (Figure 26). Each of these canals continues laterally to join the vidian canal within the body of the sphenoid. On the lateral side of the braincase the posterior opening of the vidian canal is housed completely within the sphenoid (Figure 28D).

The dorsum sellae is quite low in Moloch. Near its lateral edges it is pierced by the abducens canal, transmitting the abducens nerve (cranial nerve VI; Figure 28B, C). Dorsolateral to that foramen, the sphenoid reaches its greatest height at the alar process. The alar process articulates with the prootic dorsally, so the sphenoid does not participate in the margin of the incisura prootica

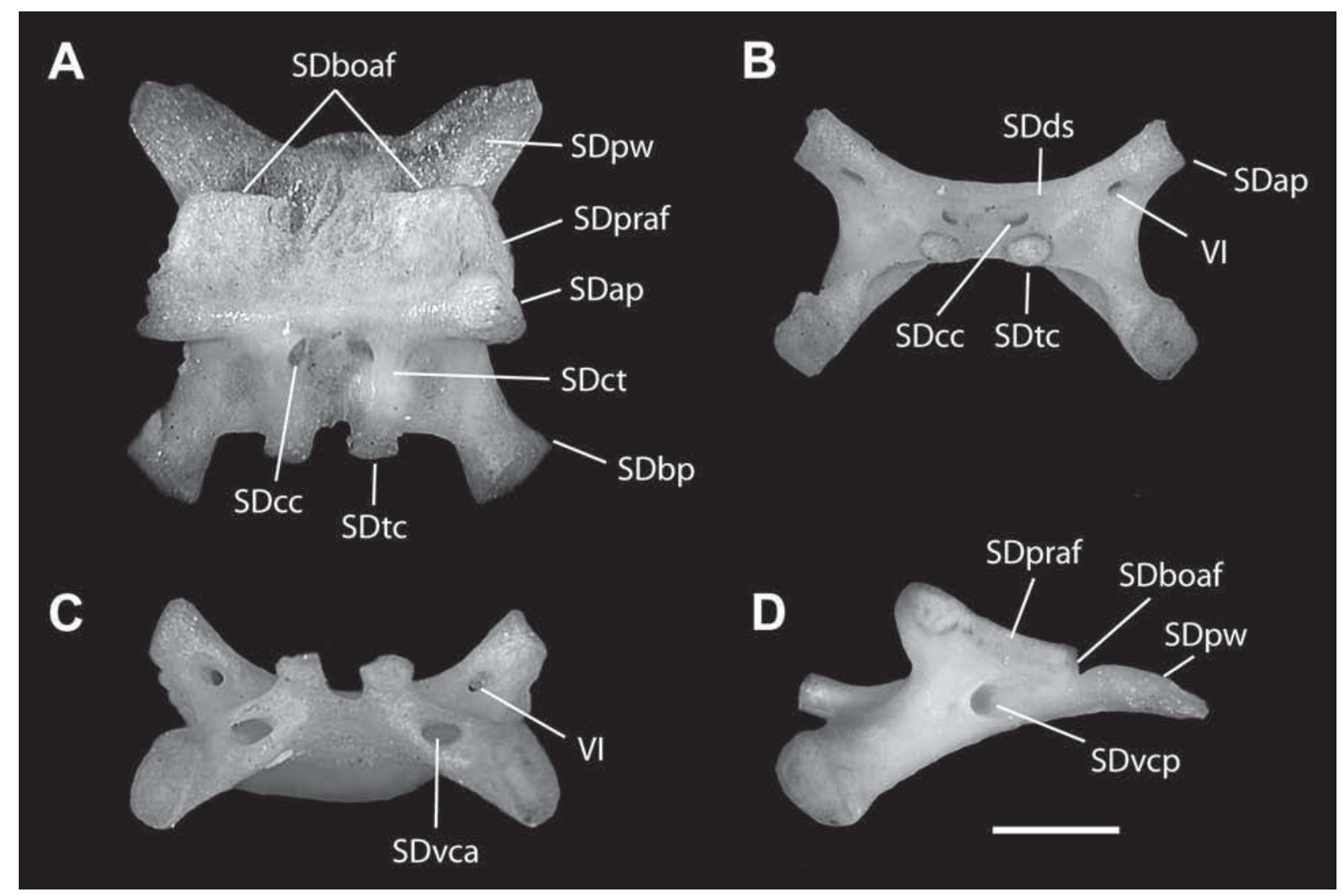

Figure 28 Sphenoid of Moloch horridus, WAM R146914. A. Dorsal view, anterior to bottom. B. Anterior view. C. Anteroventral view, showing anterior opening of vidian canal. D. Lateral view, anterior to left. Scale bar $=1 \mathrm{~mm}$. 
(Figure 13). Posterior to the alar process, the lateral edge of the sphenoid shows distinct articular facets for the anterior inferior process of the prootic (Figure 28A). Posteriorly, the prootic facets meet the mediolaterally-oriented articulation areas that sweep under the basioccipital (Figure 28A).

In posterior view (not shown) the sphenoid has two distinct articulation facets for the basioccipital (dorsal and lateral views of these are provided on Figure 28A, D). These sit on either side of the midline, but there is no articular region between them (a condition that may change with further ontogenetic development). The posteriormost portion of the sphenoid consists of an extensive sheet of parasphenoid ossification. This has a short extent along the midline, but is elongated posterolaterally into distinct parasphenoid wings (Figure 28A, D). The entire sheet forms a shelf that obscures the anterior portion of the basioccipital in ventral view in the articulated skull (Siebenrock 1895). The posterior parasphenoid region makes up approximately one-third of the total length of the sphenoid. Although Siebenrock (1895) indicated that the parasphenoid wings reached the anterior edge of the basal tubera in his specimens of Moloch, they fail to do so in all but one of the specimens we examined; the exception is QM J11492, in which the wings just reach the base of the tubera. Our observations are, thus, largely concordant with those of Moody (1980) for Moloch.

\section{Basioccipital}

The basioccipital is a relatively simple bone in Moloch (Figure 29). It forms the floor of the posterior portion of the cranial cavity and its posterior apex forms the ventromedial portion of the occipital condyle. It contacts the sphenoid anteriorly, the prootic anterolaterally, the otooccipital posterolaterally and facilitates the articulation with the atlas of the vertebral column via the occipital condyle.

In dorsal view, the basioccipital appears as a shallow basin, thinning somewhat at its anteromedial portion. Anteriorly, it bears paired articular facets for the sphenoid; the flattened area between them lacks a distinct articulation facet and simply rests on top of the central portion of the parasphenoid sheet of the sphenoid (Figure 29A; an association that may change with further ontogenetic development). The articulation facets for the prootic form the anterolateral edges of the basioccipital. On the posterolateral edges of the basioccipital are distinct, curving facets for the otooccipital. The basioccipital does not participate in flooring the recessus scalae tympani in Moloch.

The ventral surface is smooth and convex for much of its surface (Figure 29B). At the lateral edges the basal tubera are developed. These structures are small, ventral prominences in the juvenile, but become considerably more robust, and somewhat anteroposteriorly elongated in the adult. The relatively weak appearance in the juvenile is almost certainly a result of the loss, in our macerated specimen, of unfused apophysial ossifications present in juveniles of other lizards (Maisano 2002a; Bell et al. 2003). Even in the adult they are weakly developed relative to those of other agamids (Moody 1980). The apophysial ossifications are present and distinct in QM J11492 and TMM-M721, and contribute significantly to the ventral extent

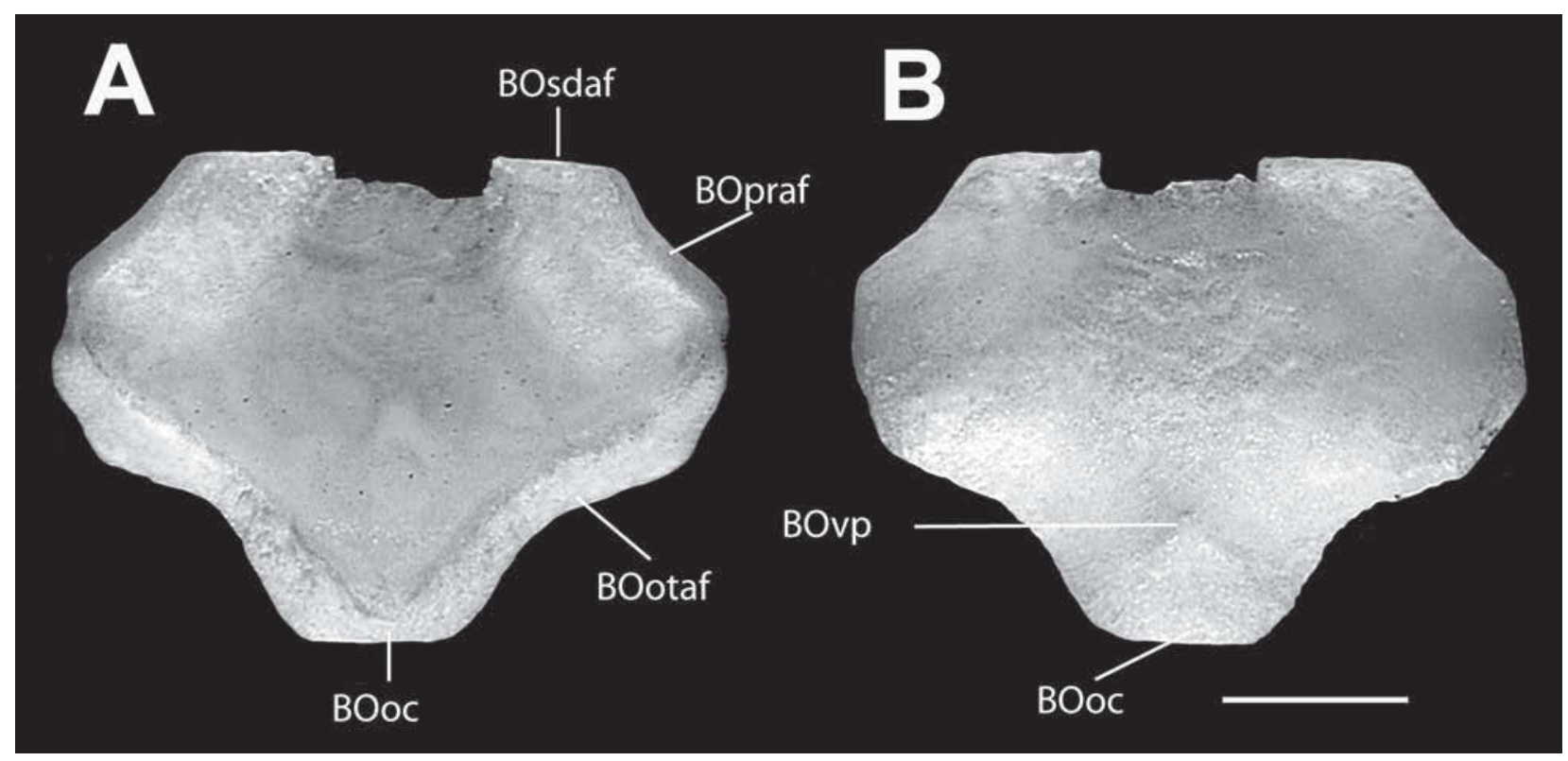

Figure 29 Basioccipital of Moloch horridus, WAM R146914. A. Dorsal view. B. Ventral view. Anterior to top in both views. Scale bar $=1 \mathrm{~mm}$. 
of the basal tubera (Figure 30). In our smallest specimen (WAM R146914) there is a small ventral projection, situated on the midline just anterior to the occipital condyle (Figure 29B). No similar structure is seen on the larger specimens.

\section{Prootic}

The prootic (otosphenoideum of Siebenrock 1895) forms the anterolateral portion of the otooccipital region of the braincase. Internally, it forms the anterior portion of the cavum capsularis and the cochlear recess (lagenar recess), and houses portions of the anterior and horizontal semicircular canals and their ampullae. Posteriorly it forms the anterior border of the fenestra ovalis. Its body is pierced by foramina for the facial (VII) and vestibulocochlear (VIII) nerves (Figure 31).

The prootic contacts the sphenoid anteroventrally, the basioccipital ventromedially, the otooccipital posteriorly and the supraoccipital dorsomedially. In lateral view, several distinct processes are visible. At the anterodorsal margin is a weak alar process, projecting beyond the anterior semi-circular canal. A distinct anterior inferior process forms the entire ventral margin of the incisura prootica ('trigeminal notch' of Oelrich 1956), a crescent-shaped notch in the anterior margin of the bone (Figures 13, 30, 31). The anterior inferior process bears an articular facet for the alar process of the sphenoid anteroventrally. In lateral view a narrow, spike-like supratrigeminal

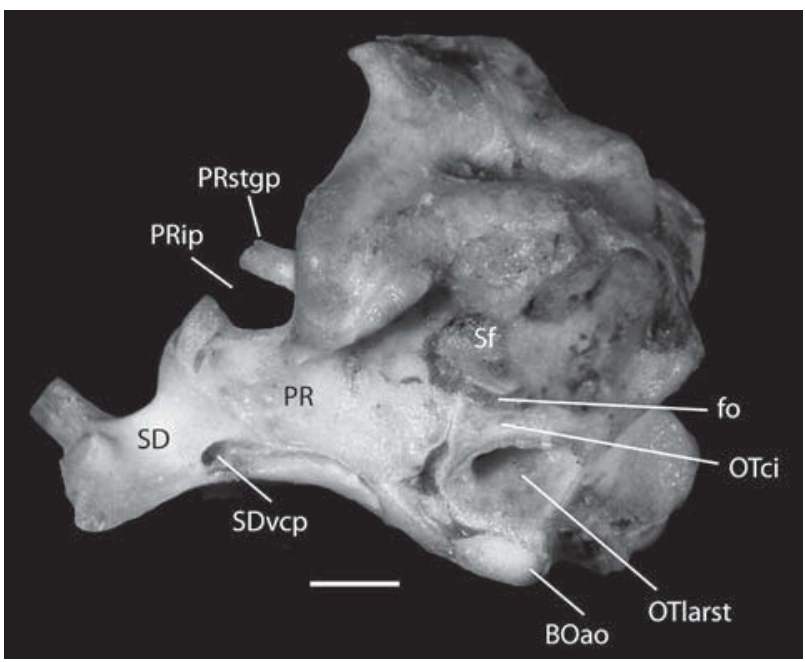

Figure 30 Left lateral view of braincase of TMM-M721, showing unfused apophysial ossification (BOao) augmenting the size of the basal tubera. The stapedial footplate and connective tissue fill the fenestra ovalis in this specimen. Scale bar $=1 \mathrm{~mm}$.

process projects anteriorly and bisects the incisura prootica (Figures 30,31). The supratrigeminal process is well developed in Moloch. It approaches (but does not reach) the anterodorsal tip of the anterior inferior process, thus accentuating the deep appearance of the incisura prootica.

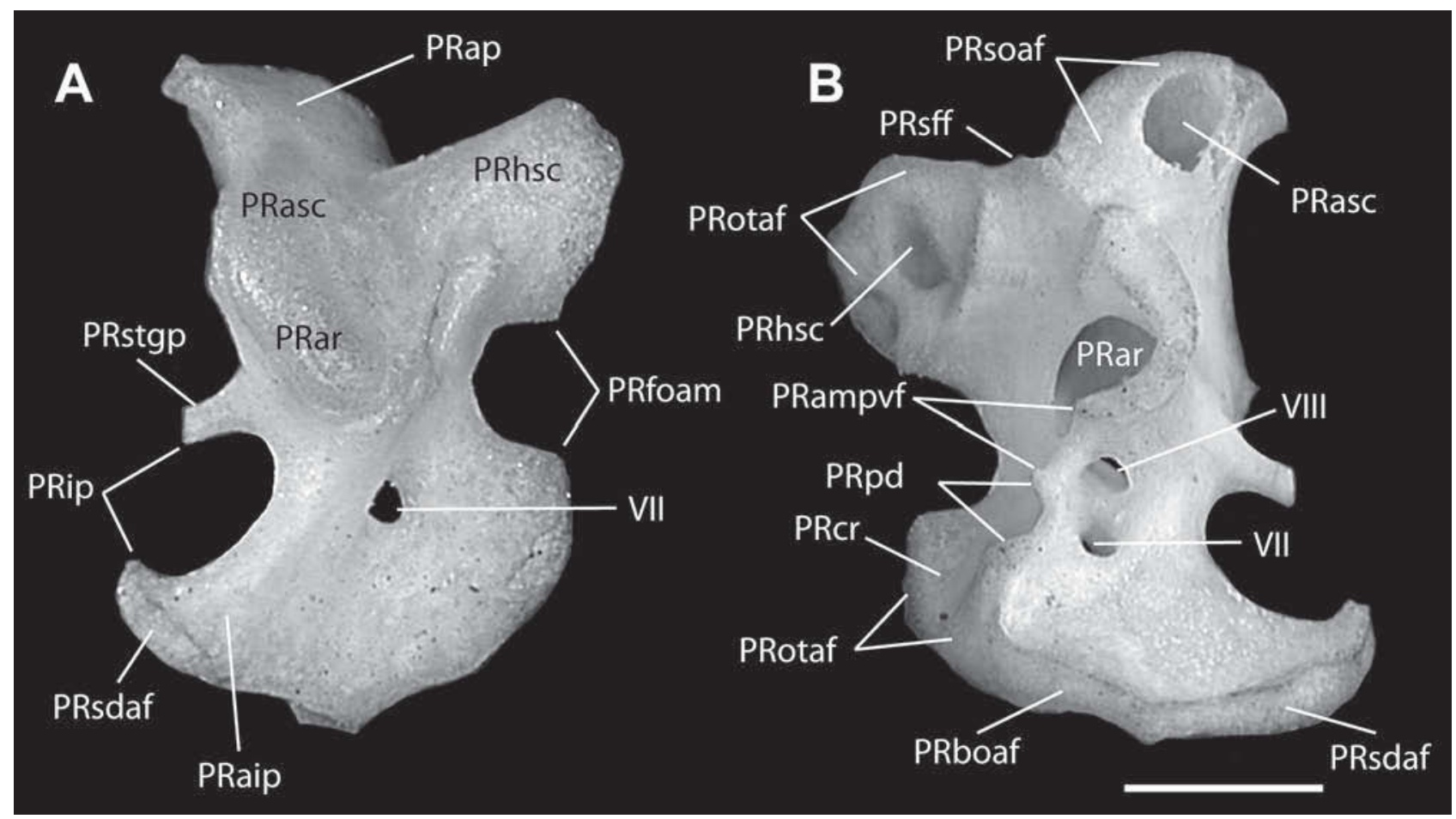

Figure 31 Prootic of Moloch horridus, WAM R146914. A. Lateral view, anterior to left. B. Posteromedial view, anterior approximately to right. The foramina for cranial nerves VII and VIII are housed within the acoustic recess, visible in B. Scale bar $=1 \mathrm{~mm}$. 


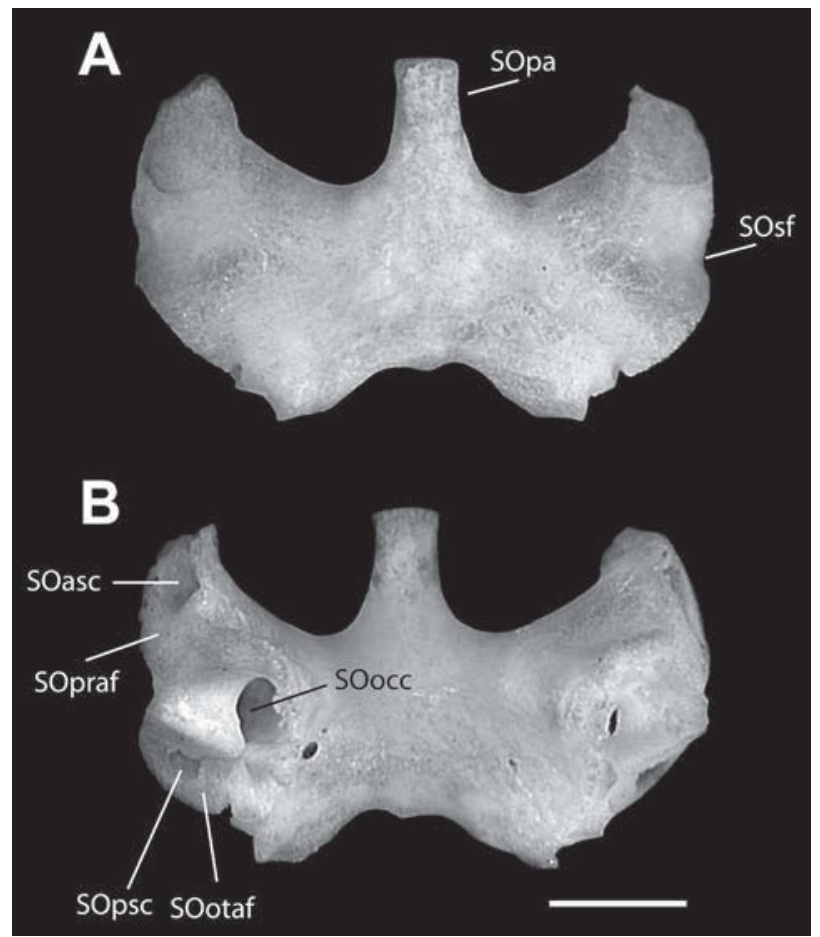

Figure 32 Supraoccipital of Moloch horridus, WAM R146914. A. Dorsal view. B. Ventral view. Anterior to top in both views. Scale bar $=1 \mathrm{~mm}$.

The large posterodorsal portion (posterior process of Oelrich 1956) of the prootic is in broad contact with the otooccipital and accommodates the passage of part of the horizontal semicircular canal. A bulbous lateral projection near the anterodorsal end of the bone represents the passage of the anterior semicircular canal and the swelling of the ampullary recess. Posterodorsal to this is a less conspicuous ridge marking the passage of the horizontal semicircular canal.

The facial foramen is clearly visible in lateral view. It sits ventral and slightly posterior to the swelling for the ampullary recess and is posterior to a weakly-developed crest running from anteroventral to posterodorsal. This crest begins near the base of the anterior inferior process, and extends posterodorsally to the base of the posterior process. This weak crest represents an extremely reduced crista prootica, usually well developed as a distinct ventrolaterally-projecting sheet of bone in other agamids. The crista prootica is indistinct in juvenile Moloch, but also poorly developed in adults, in stark contrast with most other Australian agamids.

Just posterior to the most dorsal extent of the crista prootica the lateral wall of the braincase in hollowed out in a shallow rounded depression. In the center of the depression is the large fenestra ovalis; the anterior one-half of the margin of the fenestra ovalis is formed by the prootic.

In posteromedial view, the prootic appears quite complex (Figure 31B). The anterodorsal portion of the bone is dominated by a large articular facet for the supraoccipital; near the anterior edge of this facet is an opening for the anterior semicircular canal. At the posterodorsal end of the bone is the larger dorsal articulation facet for the otooccipital. At its posterolateral margin, a short flange of bone projects posteriorly to embrace the anterior edge of the base of the paroccipital process. Between the two articulation facets the dorsal surface of the bone forms a shallow basin at the medial edge of which is a slight, almost imperceptible notch marking the prootic contribution to the margin of the tiny sphenoccipital fenestra.

Ventral to the dorsal articular facet for the otooccipital, a deep, curved notch (convex to anterior) marks the anterior border of the fenestra ovalis. A shallow groove runs along a ventromedial traverse medial to lower margin of the fenestra ovalis; this groove marks the passage of the perilymphatic duct. A short, more-or-less triangular excavation (apex to ventral) ventral to the groove is the anterior portion of the cochlear (or lagenar) recess; narrow articulation facets for the otooccipital surround the recess.

The central portion of the prootic in posteromedial view is dominated by a large circular opening into the tube-like ampullary recess. The anterior vestibulocochlear foramen (transmitting branches of cranial nerve VIII) perforates the floor of the bony tube just lateral to its posteromedial opening. Ventrally the anterior vestibulocochlear foramen opens into the dorsal portion of a shallow acoustic recess on the medial face of the prootic (Figure 31B). The lateral wall of the recess is pierced by the facial foramen (transmitting cranial nerve VII). Immediately posterior to the anterior vestibulocochlear foramen the posterodorsal wall of the acoustic recess is notched where it forms the anterior margin of the posterior vestibulocochlear fenestra. The posterior margin of that fenestra is formed by the otooccipital in older individuals, but does not appear to be fully formed in our youngest specimen (WAM R146914). Just ventral to the anterior vestibulocochlear foramen is a smooth, gradually sloping region that terminates in the articular facets for the sphenoid (anteriorly) and the basioccipital (posteriorly). In an anteromedial view, the supratrigeminal process is seen to be a continuation of a low crest that takes its origin dorsal and lateral to the acoustic recess.

\section{Supraoccipital}

The supraoccipital is an unpaired element that provides the roof of the posterior part of the braincase, and forms the dorsal margin of the foramen magnum. It contacts the prootic anterolaterally, the otooccipital posterolaterally, and 
the parietal anteriorly via the processus ascendens. The processes ascendens is an anterodorsal midline projection that is well ossified in Moloch, even in our smallest specimen (Figure 32). The processus ascendens inserts into the fossa parietalis on the ventral surface of the posterior portion of the parietal (Figure 16).

The dorsal surface of the supraoccipital shows a slightly raised area dorsal and medial to the prootic articular facet. Just posterior to that raised area is a shallow, ventrolaterally oriented depression that terminates in a small notch marking the supraoccipital contribution to the sphenoccipital fenestra. The dorsal surface otherwise is relatively smooth in the juvenile; in larger individuals a low, median crest extends posteriorly from the processus ascendens.

The anterolateral margin of the bone bears a distinct articular facet for the prootic. The facet is penetrated by the anterior semicircular canal. The posterolaterally positioned otooccipital facet is pierced by the posterior semicircular canal. In the juvenile the passage within the bone of these two canals is visible in dorsal view. They converge within the anterior portion of the bone and pass into the cavum capsularis along a ventrolaterally oriented canal, the osseous common crus. A ventrolateral view of the bone clearly shows the opening for both semicircular canals and the common crus; the latter surrounded by a dorsally excavated area that marks the dorsomedial roof of the cavum capsularis (Figure 32B). In the adult, the medial wall of this portion of the cavum capsularis is pierced by a canal for the endolymphatic duct that exits the bone within the cranial cavity. In the juvenile, the endolymphatic duct is not contained within the supraoccipital. Instead, a small notch is present just medial to the common crus; the endolymphatic duct in the juvenile appears to traverse a path from near the ventral junction of the supraoccipital, prootic and otooccipital.

\section{Otooccipital}

The otooccipital bone (pleuroccipitale of Siebenrock 1895; exoccipital of Oelrich 1956) represents a fusion of exoccipital (posteromedially) and opisthotic (anteriorly) components, but those elements are not distinguishable in any of our specimens (Figure 33). It forms the posterior portion of the otooccipital region of the braincase, the lateral border for the foramen magnum and contributes the lateral components of the occipital condyle. Internally it includes the posterior portion of the cavum capsularis and the cochlear recess, and houses parts of the horizontal and posterior semicircular canals. It forms the posterior border of the fenestra ovalis, and is penetrated by passages for the posterior cranial nerves.

The otooccipital contacts the basioccipital ventromedially, the prootic anteriorly and the supraoccipital dorsomedially. The paroccipital processes are closely associated with the postparietal processes of the parietal. In posterior view a single hypoglossal foramen (transmitting cranial

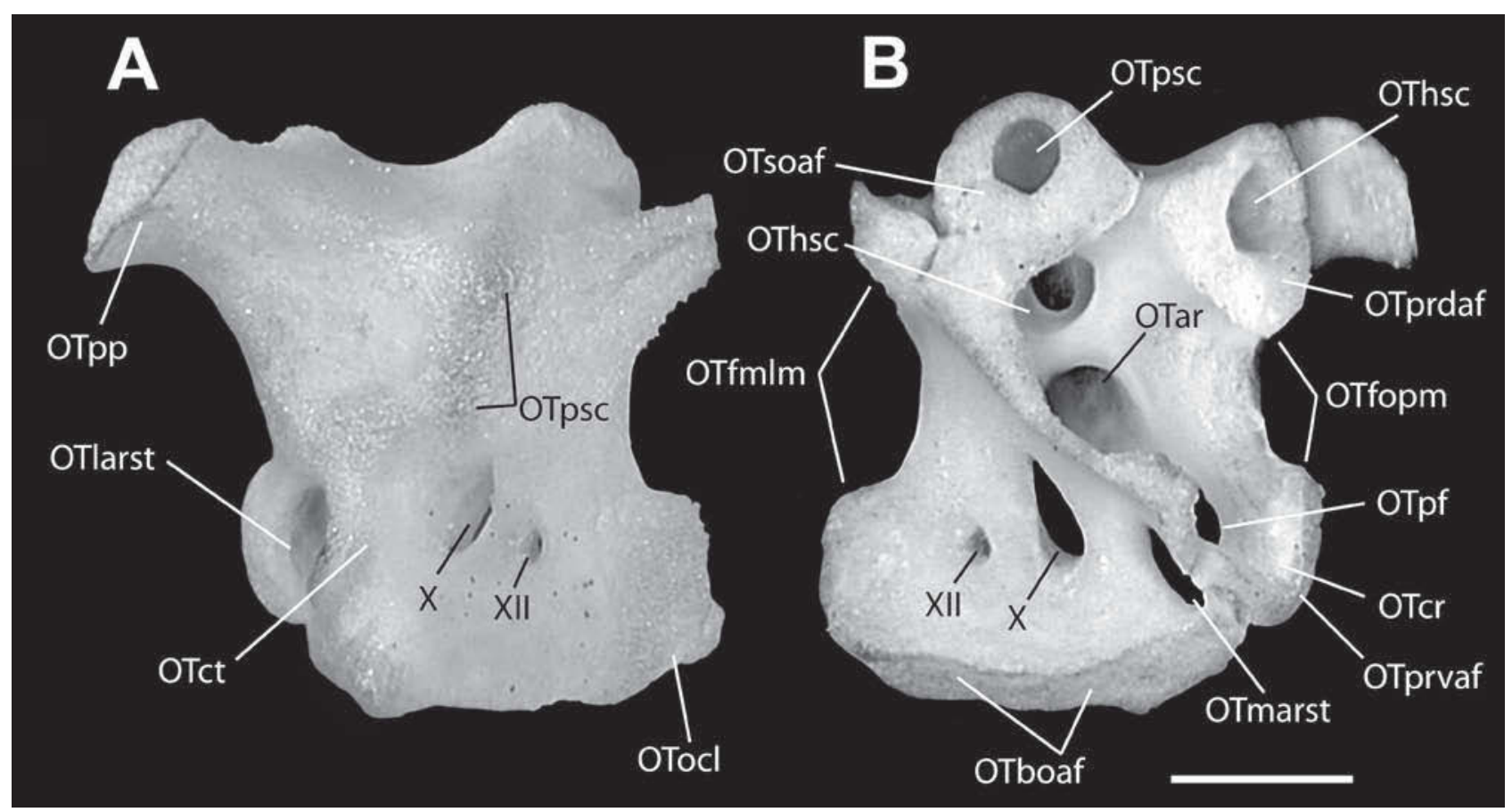

Figure 33 Left otooccipital of Moloch horridus, WAM R146914. A. Posterolateral view. B. Anteromedial view. Scale bar = $1 \mathrm{~mm}$. 
nerve XII) is visible lateral to the dorsal edge of the occipital condyle (Figure 33A). Just anterior and slightly dorsal to that foramen is the larger, narrow posterior opening of the vagus foramen (transmitting cranial nerve X). Siebenrock (1895) noted that only two nerve foramina were present in this region in Moloch, but his 'hypoglossal foramen' is our vagus, and his 'vagus' is our hypoglossal. He also noted that the glossopharyngeal nerve (cranial nerve IX) passes through the vagus foramen and leaves no separate bony trace. In two specimens (WAM R27737A and WAM R38691) a tiny foramen is present within the anterior wall of the vagus foramen on the left side of the skull; this could represent a separate passage for the glossopharyngeal nerve as seen in some other squamates (Kamal 1969; Bellairs and Kamal 1981), but we do not have material at hand to confirm that with dissection. No separate foramen is visible in medial view in WAM R38691, but in WAM R27737A the foramen pierces the strut of bone between the internal vagus foramen and the medial aperture of the recessus scalae tympani. If this does represent a separate foramen for cranial nerve IX, then it is positioned differently than other lizards that show an intracapsular course for this nerve (Kamal 1969; Bellairs and Kamal 1981). In our other specimens of Moloch the glossopharyngeal nerve presumably passes out the recessus scalae tympani as in most other iguanians (Gauthier and Bell, pers. obs.). It is interesting, but probably not significant, that the asymmetry favors the left side in both specimens showing a separate foramen. The path of the posterior semicircular canal can be seen running dorsomedially from just dorsal to the vagus

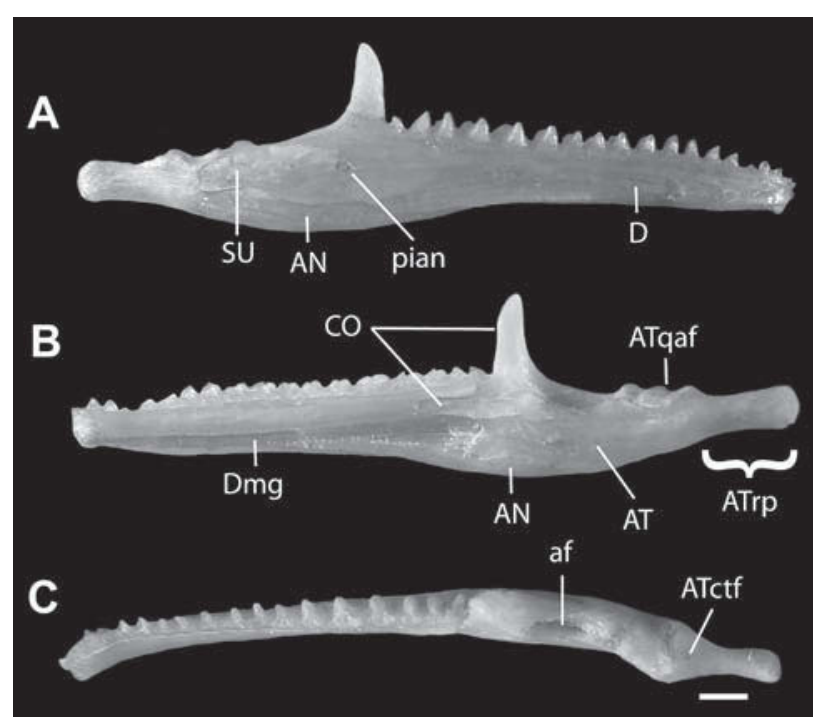

Figure 34 Articulated right mandible of Moloch horridus, WAM R27737B. A. Lateral view, anterior to right. B. Medial view, anterior to left. C. Dorsal view, anterior to left. Scale bar $=1 \mathrm{~mm}$. foramen to just behind the articular facet for the supraoccipital.

In lateral view, the posterior border of the fenestra ovalis is visible anterior to the paroccipital process. Posteroventral to it is the large lateral aperture of the recessus scalae tympani (LARST), a somewhat rounded opening of a tube-like cavity that extends from the internal cranial cavity (in cleaned skulls, the medial aperture of the recessus scalae tympani [MARST] is visible through the LARST). The recessus scalae tympani in Moloch is completely contained within the otooccipital; the basioccipital does not participate in its margin (Figure 33B). Just dorsal and slightly medial to the LARST is the perilymphatic foramen, an oval opening into the roof of the recessus scalae tympani. A welldeveloped crista interfenestralis (Säve-Söderbergh 1947) separates the LARST from the fenestra ovalis (Figures 26C, 30). A second crest, the crista tuberalis (Säve-Söderbergh 1947), runs dorsoventrally just posterior to the LARST and separates the LARST from the vagus foramen (Figure 33A).

In medial view the posteroventral surface is a smooth slope of bone descending from the posteromedial cranial surface of the cavum capsularis. Just dorsal to the articular facet for the basioccipital, and posterior to the ventral articular facet for the prootic, the smooth slope is pierced anteriorly by the MARST (Figure 33B). Posterior to the MARST is the slit-like vagus foramen, followed by a single, round hypoglossal foramen. In at least one specimen (WAM R27737A) an additional tiny foramen pierces the bony strut between the MARST and the internal vagus foramen on the left side of the braincase (see above).

In anterior and anteromedial views, the posterior portion of the cavum capsularis and the cochlear recess are visible (Figure 33B). Two articulation facets are positioned posterodorsally. On the medial side the passage for the posterior semicircular canal is visible in the large, medially-oriented articular facet for the supraoccipital. On the lateral side, just medial to the paroccipital process, the horizontal semicircular canal pierces the dorsal articular facet for the prootic. The area ventral to these articular facets is the posterior portion of the cavum capsularis, where two large openings are clearly visible. The dorsal opening is continuous with a groove on the medial wall and represents the passage of the horizontal semicircular canal towards the utricular recess. The larger, ventral, opening is the ampullary recess for the posterior semicircular canal. Lateral to that recess is a shallowly grooved surface that lies just medial to the fenestra ovalis. The groove is oriented dorsoventrally and its ventral extent is the posterior portion of the cochlear recess. On either side of the cochlear recess are the ventral articulation facets 


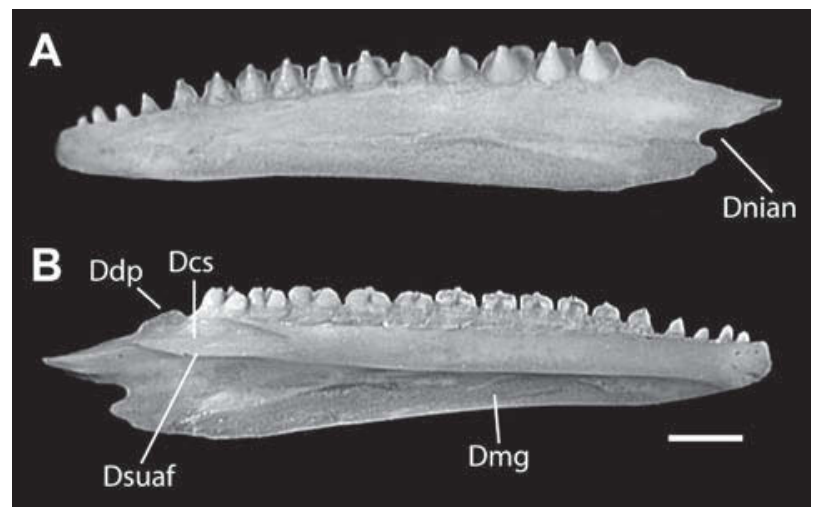

Figure 35 Left dentary of Moloch horridus, WAM R146914. A. Lateral view, anterior to left. B. Medial view, anterior to right. Scale bar $=1 \mathrm{~mm}$.

for the prootic. Medial to the cochlear recess, the oval-shaped perilymphatic foramen exits into the recessus scalae tympani (Figure 33B; our label points to the rim of the perilymphatic foramen; the dark space beyond represents a view through the LARST).

\section{Stapes}

The stapes is imperforate. The footplate sits within the fenestra ovalis. A well-developed stapedial shaft extends ventrolaterally from the anteromedial portion of the footplate, and reaches the level of the lateral edge of the paroccipital process of the otooccipital (Figure 22).

\section{Dentary}

The dentary is the only tooth-bearing bone on the mandible (Figures 34, 35). It is a tubular bone bearing acrodont and pleurodont teeth along its dorsal ridge. The dentary contacts the angular ventrally and posterolaterally, the surangular posteriorly and the coronoid posterodorsally. In lateral view it extends well posterior to the coronoid process, and reaches a level almost equal to the posterior extent of the posterolateral process of the coronoid bone. A few small mental foramina occur along the anterolateral surface of the dentary. The Meckelian fossa is open medially along its most of its length, but rotates to a ventral opening at the symphysis (Figure 35B). The posterior part of the dentary is marked with a complex series of articulation facets, and its distal extent is weakly bifurcated. The bifurcation is formed by an anterior notch that marks the passage of part of the inferior alveolar nerve (Oelrich 1956; Figure 35). That nerve forms a complete foramen in the surangular (the anterior surangular foramen; Figure 36); the dentary notch forms a 'pseudoforamen', effectively contributing to a lateral continuation of the true foramen in the surangular. The pseudoforamen is clearly visible on the lateral surface of the articulated mandible, ventral and slightly posterior to the coronoid eminence (Figure 34A).

On the medial side of the dentary, three distinct articulation facets are visible posteriorly (Figure 35B). The dorsal facet (the dorsal prominence) is a short dorsal extension of thin bone rising from the lateral surface of the dentary, and represents a weak coronoid process that does not rise above the height of the tooth row. Just medial and anterior to that process is a short coronoid shelf immediately ventral to the posteriormost teeth, marking the articulation with the anteroventral dentary process of the coronoid. The ventral surface of that articulation facet forms the dorsal surface of a strong flange of medially-inflected bone that marks the articulation with the surangular. The dentary has a strong overlapping articulation with the surangular, so that approximately one-third the length of the surangular is obscured from view laterally in the articulated mandible. There is no distinct facet for the ventral articulation with the angular.

The dentary is roughly straight along much of its length, but there is a slight mesial curvature near the symphysis where the mesial tip forms a smooth articulation surface for the corresponding dentary. The dentition is described below.

\section{Surangular}

The surangular (supra-angular of Oelrich 1956) is a relatively flat bone that forms a significant portion

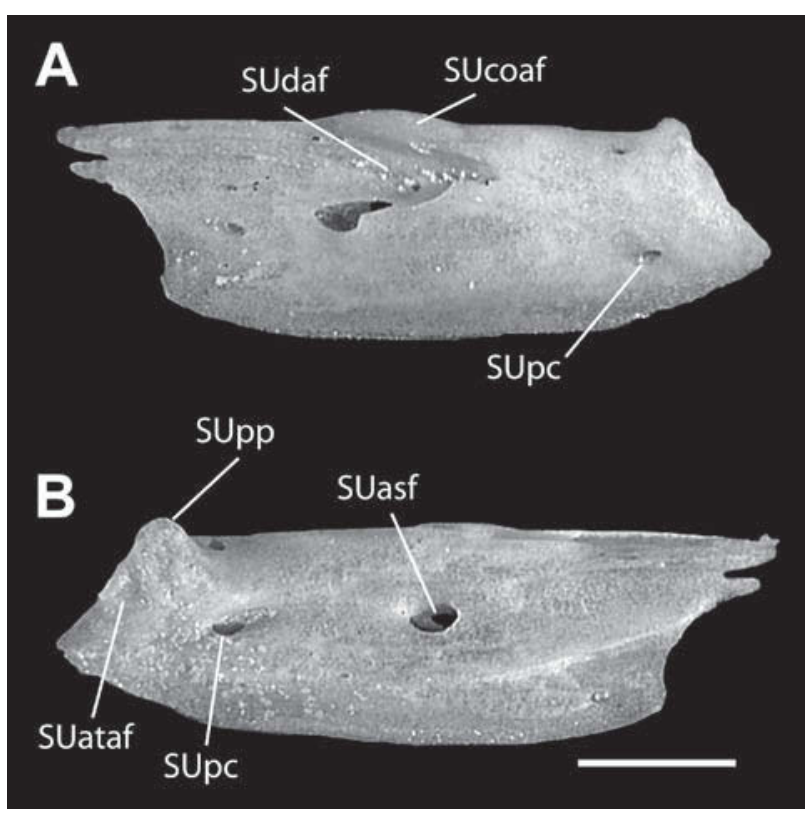

Figure 36 Left surangular of Moloch horridus, WAM R146914. A. Lateral view, anterior to left. B. Medial view, anterior to right. Scale bar $=1 \mathrm{~mm}$. 
of the posterolateral wall of the mandible and most of the lateral rim of the adductor fossa (Figure 36). It articulates with the coronoid dorsally, the dentary anteriorly, the angular ventrally and the articular posteriorly. The anterior one-third of its length is concealed by the dentary in the articulated mandible, but it extends anteriorly to the same level as the articular-prearticular. In older individuals, the two bones may fuse (e.g. WAM R27737A). In medial view of the articulated mandible a small portion of its medial surface is visible as the lateral wall of the adductor fossa. Laterally it shows a sinuous articulation with the angular ventrally. At its anterior articulation with the dentary, the anterior surangular foramen is visible. That foramen is fully formed in the surangular; the contribution of the dentary creates an external pseudoforamen. The anterior surangular foramen passes through the bone and opens from the adductor fossa at the posterior end of the Meckelian canal.

Posteriorly the surangular expands into a dorsoventrally crescentic articulation that clasps the articular just anterior and lateral to the articular condyle. At the dorsal end of that articulation it forms a small prearticular process. The anterior and central portions of the lateral surface are marked by a strong articulation surface with dentary; this terminates in a dorsal notch that accommodates the posterodorsal portion of the dentary in a tightly-interlocking articulation. The anterior end of the notch sits just above the anterior surangular foramen. Medial and slightly dorsal to the notch, a shallow but distinct articulation facet for the coronoid is present. A second, smaller, posterior canal (with lateral and medial openings) penetrates the bone ventrally near the articulation with the angular. These foramina transmit branches of the inferior alveolar nerve (Oelrich 1956).

\section{Coronoid}

The coronoid is a roughly triangular bone with a pronounced coronoid process (Figure 37). It has ventral contacts anteriorly with the dentary, posterolaterally with the surangular and posteromedially with the prearticular. The coronoid process is triangular in cross-section, and oriented nearly vertically with predominantly parallel sides. At its base the lateral surface abuts against the dorsal prominence of the dentary. There is no anterolateral process, but an anteriorly-directed, elongated medial process has a strong articulation with the coronoid shelf of the dentary.

Posteriorly the coronoid bifurcates into short lateral and medial processes. The lateral process follows the posterodorsal limit of the dentary and has a short articulation with the lateral surface of the surangular. The medial process extends as a short splint of bone, forming a weak ridge that makes up the anteromedial portion of the dorsal border of the adductor fossa (mandibular foramen of Oelrich 1956). Ventrally it contacts clear articulation facets on the dorsal surface of the anteromedial portion of the prearticular.

Moloch is the only known Australian agamid in which the posterior medial process of the coronoid fails to extend vertically to the ventral margin of the mandible (Moody 1980; Figure 38). We evaluated this in a large collection of specimens including all Australian agamid genera except Cryptagama (Appendix 2); the condition in Cryptagama is unknown.

\section{Angular}

The angular bone is a long slender bone that forms the ventral surface of the central portion of the mandible. The main body of the angular forms a trough-like structure that articulates with the

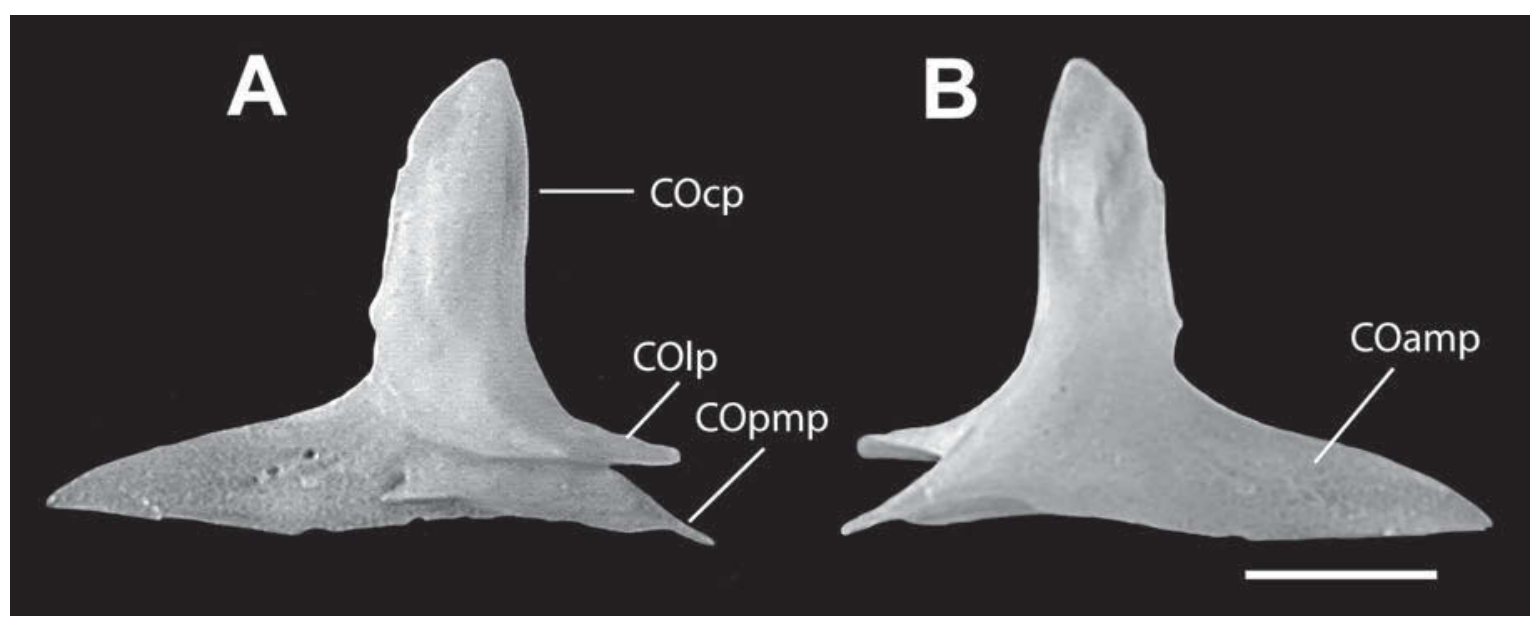

Figure 37 Left coronoid of Moloch horridus, WAM R146914. A. Lateral view, anterior to left. B. Medial view, anterior to right. Scale bar $=1 \mathrm{~mm}$. 


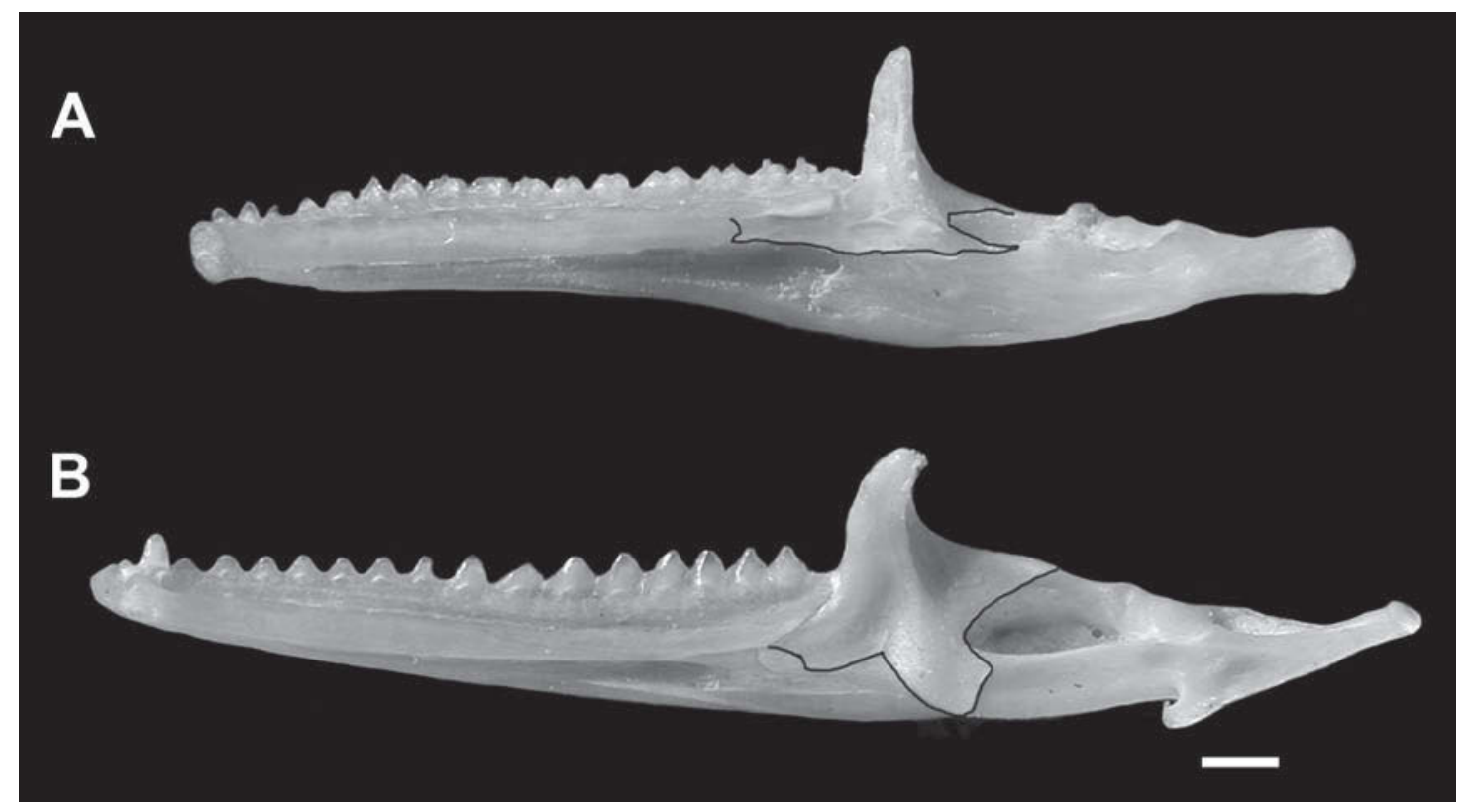

Figure 38 Medial views of the right mandible of Moloch horridus, WAM R27737B (A), and Ctenophorus caudicinctus, WAM R167665 (B). Anterior to left. Ventral border of the coronoid bone in each specimen is highlighted. Scale bar $=1 \mathrm{~mm}$.

ventral edge of the surangular on the lateral wall, and with the prearticular on the medial wall. The trough structure becomes shallower anteriorly, where the medial side of the angular shallows in dorsoventral extent (Figure 39).

The ventral border of the posterior half of the Meckelian groove is formed by the angular bone. Approximately half way along the length of the bone, the medial surface shows a slight step, which forms the ventral portion of a small fenestra, the dorsal margin of which is formed by the prearticular. Posteriorly the medial and lateral walls are pierced by a minute posterior angular foramen.

\section{Splenial}

There is no separate splenial in Moloch. It is not clear whether it is lost, or fused to another element of the mandible. An earlier suggestion that it is fused with the angular (Moody 1980) cannot be confirmed with any of our material. Given the gracile configuration of the angular, it seems more likely that the splenial (if present) is fused with the prearticular.

\section{Articular-prearticular}

The endochondral articular is inseparably fused with the dermal prearticular in Moloch (Figure 40). It contacts the angular ventrally, the surangular laterally, the dentary anteriorly and the coronoid anterodorsally. The prearticular portion is expressed predominantly as an extensive medial wall with a narrow ventral margin. Except for its posteriormost extent the bone is, thus, largely obscured in lateral view of the articulated mandible (by the angular, surangular and dentary); medially it is visible along most of its length, but is partially obscured ventrally by the angular, and dorsally by the coronoid (Figure 34). The central portion of the prearticular forms the medial wall of the mandibular fossa. A nearly straight retroarticular process is present immediately posterior to the articular surface itself. The total length of the retroarticular process is approximately one-quarter the length of the tooth row (Moody 1980). That process is pierced anteriorly just to the medial side of the midline on the dorsal surface by a foramen that transmits the chorda tympani branch of the facial nerve (CN VII) and probably the posterior condylar artery (Oelrich 1956). Two articulation facets for the quadrate are present, the lateral one is smaller than the medial one. There is no distinct medial (angular) process of the articular; at most there is a small bump beneath the medial articulation facet. The articulation facet for the angular is distinct ventrally.

\section{Dentition}

\section{General configuration}

Dietary specialization in Moloch is mirrored by morphological specialization of its dentition. It is obligately myrmecophagous and is known to consume ants at a rate of $\sim 45 \mathrm{~min}^{-1}$, or up to about 1,350 individuals per day (Davey 1923); 2,500 Iridomyrmex were recovered from a stomach by Pianka and Pianka (1970). The dentition of Moloch 
is unique, and previously was discussed by Gervais (1861, 1873), Edmund (1969), Moody (1980), Vorobjeva and Chugunova (1995), Hocknull (2002) and Evans (2008). Teeth are located on the premaxilla, maxilla, and dentary. Tooth implantation is predominantly acrodont, but also includes pleurodont teeth on the premaxilla and mesially on each of the maxillae and dentaries. The pleurodont teeth are few in number and are composed of simple conical pillars, all approximately the same size (Moody 1980), and situated on the premaxilla and mesial portions of the maxilla and dentary. The total number of pleurodont teeth from the three bones was reported to range between 11 and 13 by Moody (1980). He did not specify functional teeth versus tooth positions, but we assume he was referring to tooth positions. The presence of caniniform teeth was one potential agamid synapomorphy suggested by Estes et al. (1988: 194), but Moloch lacks caniniform teeth on the maxilla (Evans 2008).

\section{Premaxillary Teeth}

The alveolar border has positions for at least four, and as many as six, pleurodont teeth. Three functional teeth (two on the left and one on the right side of the midline) are present on the premaxilla of WAM R27737B; the opposite arrangement applies to WAM R97222, but the two teeth on the right are absolutely adjacent, suggesting that additional tooth spaces could be occupied. Only one functional tooth is present on each side of the midline in other specimens we examined (Figure 8). Three and five premaxillary teeth were recorded by Edmund (1969) for two specimens he examined, but the specimen he illustrated (reprinted by Vorobjeva and Chugunova 1995: 82) shows only two functional teeth (one on each side of midline).

\section{Maxillary Teeth}

The maxillary tooth row in Moloch (Figure 41) is among its most novel anatomical features. The premaxillary process is sometimes edentulous, and in those specimens the tooth row begins immediately ventral to the anterior edge of the facial process (Figure 41B). In the specimens we observed, a series of one to four short, conical teeth are positioned at the mesial end of the maxillary tooth row. The type of tooth implantation is difficult to determine for many of these teeth (Vorobjeva and Chugunova 1995), but at least some are pleurodont; two to three maxillary pleurodont teeth were reported by Hocknull (2002).

The tooth row distal to the simple conical teeth consists of 11 to 14 acrodont teeth. A slightly higher count of 15 to 16 teeth was indicated by Edmund (1969), but he appears to have included pleurodont and acrodont teeth in his count; 15 acrodont teeth were reported by Hocknull (2002). All the acrodont teeth have the shape of mediolaterally compressed pyramids, having a broad base where they ankylose to the maxilla (Figure 41D). Tooth size increases distally along the tooth row (as noted by Siebenrock 1895). The last tooth usually closely abuts the penultimate tooth, and is positioned just anterior to the articulation facet for the ectopterygoid.

The first and second most mesial acrodont teeth are small triangular blades (mediolaterally compressed), positioned with the apical crests oriented ventrally (Figure 41A). Medial and lateral faces are slightly convex. Torsion continues so that by the third mesial acrodont tooth, the orbital process of the maxilla and its corresponding tooth row begin an inward (lingual) torsion (Siebenrock 1895). By the posterior end of the tooth row the apical ends of the teeth have rotated and are oriented approximately $60-80^{\circ}$ toward the midline of the skull (Figure 41C). With the inward torsion of the tooth row, each tooth develops a slight curvature to reorient the apices toward a somewhat more ventral orientation, instead of horizontal. This is best observed in young individuals because with abrasion of the teeth the ventral orientation tends to lessen.

\section{Dentary Teeth}

One to three simple, conical, pleurodont teeth are present at the mesial end of the dentary (Figure 35; two to three pleurodont teeth were reported by Hocknull 2002). The pleurodont teeth are approximately the same size and shape as those on the premaxilla and maxilla (Moody 1980). We found 12 to 14 acrodont teeth posterior to the pleurodont teeth. Edmund (1969: 160), reported 16 to 18 teeth on the dentary, but he apparently included pleurodont and acrodont teeth in his count; other acrodont tooth counts include 15 (Siebenrock 1895) and 15 or

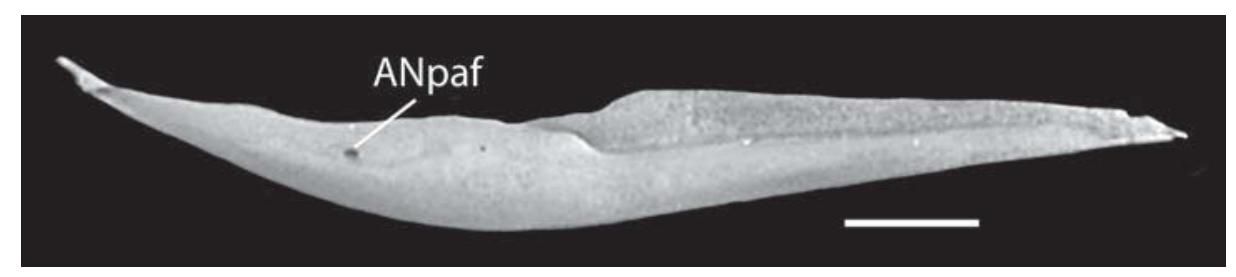

Figure 39 Left angular of Moloch horridus, WAM 146914, in medial view; anterior to right. Scale bar $=1 \mathrm{~mm}$. 


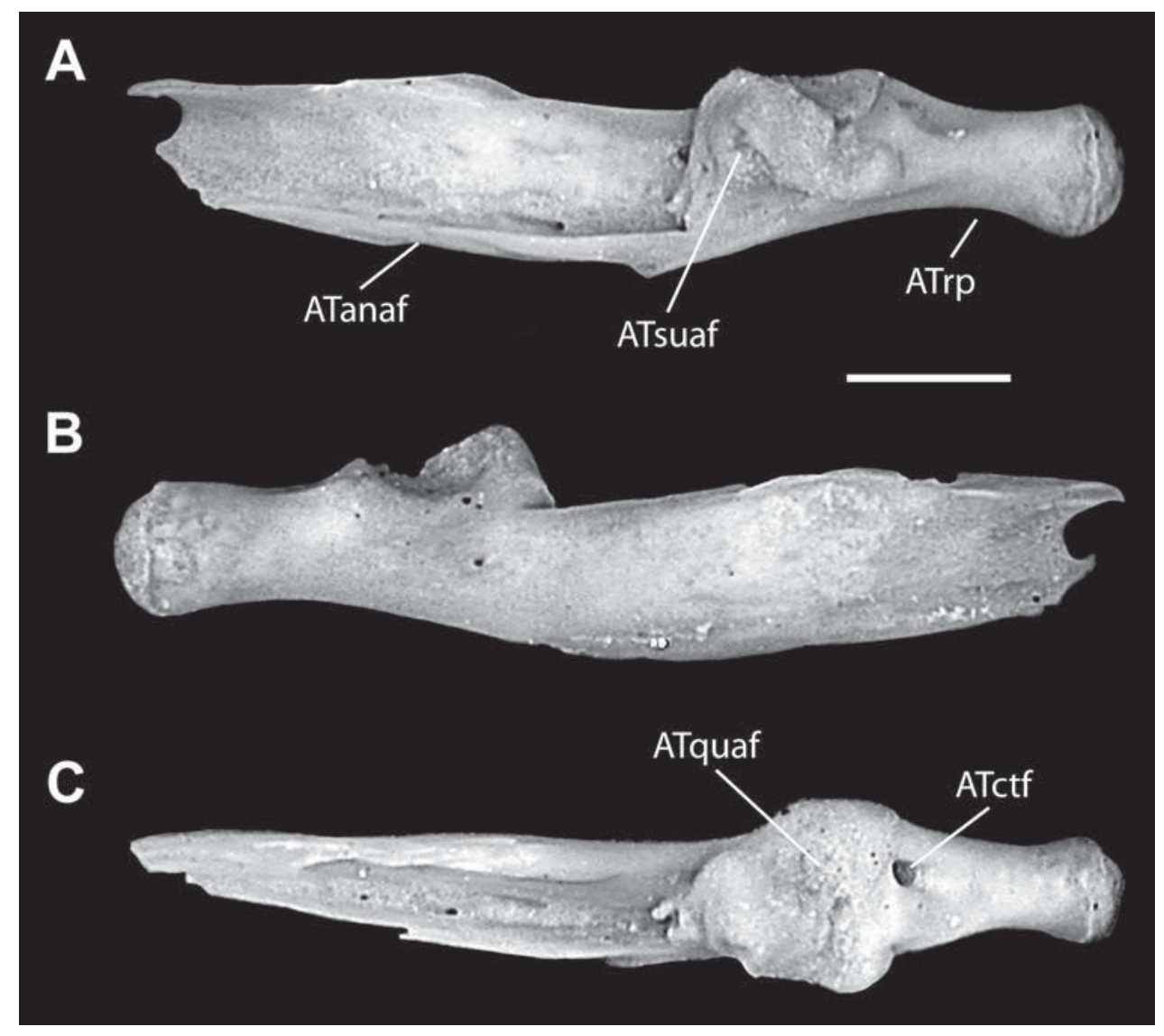

Figure 40 Left articular-prearticular of Moloch horridus, WAM 146914. A. Lateral view, anterior to left. B. Medial view, anterior to right. C. Dorsal view, anterior to left. Scale bar $=1 \mathrm{~mm}$.

\section{6 (Hocknull 2002).}

Teeth become overall larger and wider distally along the jaw (Figure 35). The apical pattern on the first acrodont tooth is a simple, single apex with shear abrasion in a V-shape. The apices are not centrally positioned but on the lateral edge of the tooth (Figure 42). The teeth widen mediolaterally beginning with the second acrodont tooth. With the widening of the tooth, the V-shaped apical shear abrasion pattern progresses to a $\Upsilon$ configuration with the apex at the midpoint (Figure 42A). The widening also permits the development of secondary conules (that appear to be wings $\gamma$, when viewed medially (Figure 42B) so that by the third acrodont tooth, the apical pattern has evolved into an affectively 'triconodont' tooth (Figures 35, 42). All the 'cones' are connected by a shearing ridge. With wear, the shearing ridges are reduced, and the flared medial conules can be worn to bump-like structures situated mesial and distal to the position of the central cone of the tooth.

\section{ONTOGENETIC CHANGES}

Studies of ontogenetic variation in skeletal morphology of squamates are relatively few, and agamids are among the least-studied group of lizards in this regard. It is clear from previous work on other squamate groups that ontogenetic transformations in the morphology of cranial elements are significant and extend beyond allometric changes associated with growth (e.g. Barahona and Barbadillo 1998; Rodríguez et al. 2000; Maisano 2001, 2002a, b; Bell et al. 2003; Bever et al. 2005; Nance 2007). Our own preliminary observations of Australian agamids suggest that this is an important area for additional study, but adequate collections of skeletal specimens do not exist for most taxa. Although we lack specimens of Moloch that show early stages of postnatal ontogeny, our relatively small sample of specimens does yield minimal data on ontogenetic transformations of the skull bones. More thorough exposition must await a broader sampling of ontogenetic stages in skeletal collections.

In the skull roofing bones, ontogenetic changes in the processes and articulation facets indicate that Moloch, like other squamates, shows greater overlap and increasingly solid articulations between elements with age. In the juvenile, the nasal shows a distinct maxillary process that contacts the maxilla in a loose articulation; in the adult that process is no longer distinguishable, and the contacts of the maxillary facial process with the nasal and prefrontal are tighter. The development on the frontal of dorsally placed articulation facets for the 
prefrontal also exemplifies a stronger construction of the preorbital region of the skull in later stages of ontogeny. The frontal and parietal bones show changes in their laterally directed processes. In the frontal, the posterolateral arms are thicker and more robust in the adult, and show increased development of rugosities along the posterodorsal orbital margin. The angle of divergence between the post-parietal processes of the parietal increases with age, as do the size and extent of the dorsal parietal bosses. The frontoparietal fontanelle progressively closes with increased age, so that in later stages on ontogeny, a relatively small frontoparietal fenestra is all that remains.
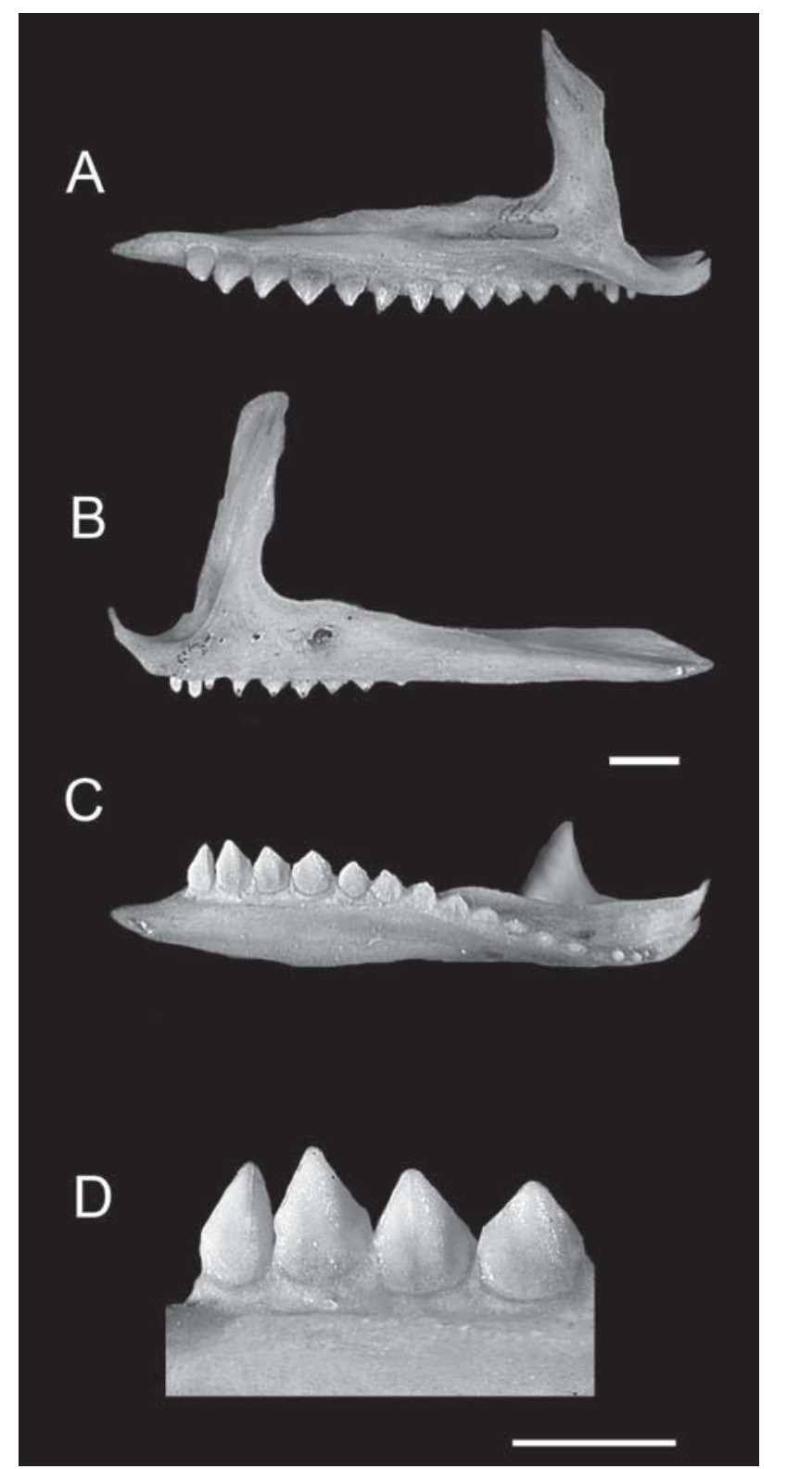

Figure 41 Left maxilla of Moloch horridus, WAM 146914. A. Medial view, anterior to right. B. Lateral view, anterior to left. C. ventral view, anterior to right. D. Four most distal maxillary teeth in ventral view. Scale bars $=1 \mathrm{~mm}$.
Although the sphenoid is longer than the basioccipital in the juvenile, their relative lengths become more equal with age. In our smallest specimen a small midline, ventral projection is present on the basioccipital immediately anterior to the occipital condyle; no other specimens show a similar structure; it is not clear if this is an individual variant, or an ontogenetic one. Increased development of the basal tubera through ontogeny is at least partly related to the ossification of apophysial elements during ontogeny. During ontogeny the supraoccipital develops a low midline crest that extends posteriorly from the processus ascendens. In smaller specimens, there is a gap between the processus ascendens and the postparietal processes, but this gap narrows, yielding the appearance of a solid connection between the parietal and the dorsal surface of the braincase. The endolymphatic duct in the adult clearly exits the cavum capsularis through the supraoccipital; in the juvenile, it appears to exit at or near the junction of the supraoccipital, prootic and otooccipital.

The mandibular condyles of the quadrate are approximately equal in size in the juveniles, but the medial one is distinctly larger in the adult. In some older individuals, the surangular may fuse with the articular-prearticular.

\section{COMPARISONS}

Unfortunately, the anatomical systems of most Australian agamids are not well known, and detailed studies of their osteology are lacking. Two unpublished studies remain the most comprehensive assessments to date; one formed a major portion of Scott Moody's PhD dissertation (Moody 1980), and the other was produced as an undergraduate Honour's thesis by Scott Hocknull (2000). Data from those works, and additional statements gathered from elsewhere in the literature, are combined with our own preliminary observations to highlight some specialized features of Moloch and to discuss the distribution of these among other endemic Australian agamids.

Unsurprisingly, Moloch has many features that are unique among Australian endemic agamids. The extremely specialized cusp morphology of the dentary teeth is unique among lizards, and the lack of caniniform teeth on the mesial portion of the tooth row is not seen in other Australian agamids. The degree of torsion of the orbital process of the maxilla, and the resultant medial inclination of the distal teeth towards the midline of the skull is unique to Moloch. However, we saw similar torsion in an unregistered specimen of Hypsilurus modesta (sometimes rendered as Arua modesta) housed at the Queensland Museum, but in that species the torsion is not as extreme, and the inclination of the teeth is therefore less than that seen in Moloch. The 
weak basal tubera on the basioccipital, extreme reduction of the sphenoccipital fenestra, and the possible separate exit in some specimens for the glossopharyngeal nerve are all features of the braincase not found in other endemic Australian agamids. The noticeably flattened quadrate process of the pterygoid also is unique.

The lack of contact in Moloch between the premaxillary processes of the maxillae was previously noted as a specialized condition among Australian agamids (Moody 1980; Evans 2008). In at least some Ctenophorus (e.g. Ctenophorus reticulatus, WAM R167514) the contact, if present, is obscured in palatal view by posterior extension of the premaxilla. That condition is distinct from that seen in Moloch, in which the maxillae do not even closely approach one another, but it is important to distinguish between actual contact of the elements and the appearance of contact in a palatal view (which may be obscured). Expression of variation in this feature within Ctenophorus needs to be more fully explored. Unique features of the mandible relative to other Australian endemics include the absence of the medial process of the prearticular, the loss (or possible fusion) of the splenial, and the restriction of the medial process of the coronoid to the dorsal portion of the mandible.

Moloch shows a greater reduction in the development of the epipterygoid than any other Australian agamids we have seen, although there is significant variation. In the morphological analysis conducted by Moody (1980), Moloch, Diporiphora, Chelosania and Tympanocryptis were scored identically for this feature (his character 26). His character definition suggests that the scoring is probably accurate as given, but we note a significant degree of variation within taxa in our sample, suggesting that expanding the description to encompass more states might be appropriate. No specimens we have seen of those other taxa show as pronounced a reduction as does Moloch.

In several other features, our observations are not completely concordant with those summarized by Moody (1980). The differences usually result from our observations of the expression of variation among specimens; those worth discussing are summarized here. His suggestion that the condylar morphology of the quadrate in Moloch was unique (Moody 1980, character 25) appears to have resulted from ontogenetic variation; large specimens of Moloch share the general configuration of other Australian agamids, in which the medial condylar facet is larger than the lateral. Contact between the nasal bone and the facial process of the maxilla does occur in Moloch (contra Moody 1980, character 41 ), but the intent of his scoring is clear and relevant. In all other Australian agamids, the two elements are in fairly broad contact along the dorsal surface of the skull. In Moloch, the contact is weak and is restricted to the posteromedial tip of the facial process. Moody noted that the contribution of the ectopterygoid to the cranial coronoid process was small, and that the ectopterygoid failed to reach the distal end of the process. In his analysis Moloch was the only Australian agamid noted to have this condition, but we found a similar condition in some Rankinia diemensis (e.g. SAMA R12959). Our single specimen of Chelosania (WAM R41565) shows a strong dorsal inflection of the retroarticular process of the mandible (contra Moody's scoring for his character 63); the same is true for at least some Diporiphora as well (e.g. Diporiphora bennettii, WAM R162905, WAM R162906). We agree that it is also the condition in Tympanocryptis, and also for Caimanops

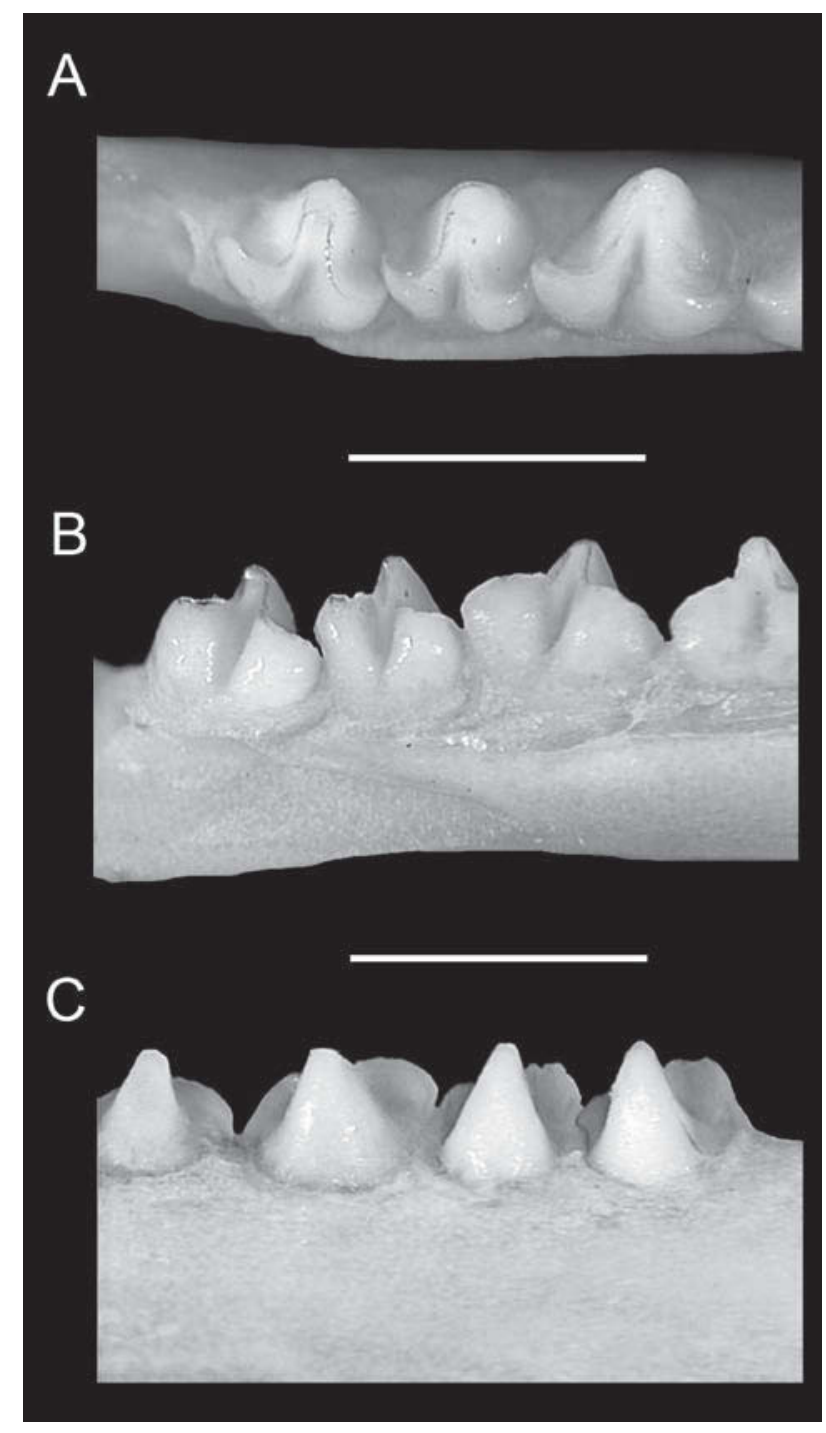

Figure 42 Dentition of the left dentary of Moloch horridus, WAM R146914. A. Apical (dorsal) view of three distalmost teeth, anterior to right. B. Slightly oblique dorsomedial view of four distalmost teeth, anterior to right. C. Lateral view of four distalmost teeth, anterior to left. Scale bars $=1 \mathrm{~mm}$. 
(a taxon not included in Moody's analysis). We see no significant difference between Moloch and other endemic Australian agamids in the medial extent of the dorsal projection of the pterygoid process of the ectopterygoid (contra Moody, character 52).

Moloch was previously identified as sharing several specialized features with Tympanocryptis, including loss of digits (in at least some populations of Moloch; see Greer 1989), enlarged scales, a short tail and completely terrestrial habitus (Greer 1989; Witten 1993). In the skull, we note that at all stages of ontogeny Moloch lacks a significant crista prootica. That crest is also reduced in Tympanocryptis cephalus (e.g. QM J21659; NT R16768; but these specimens may represent $T$. intima instead; see Shoo et al. 2008) and Tympanocryptis tetraporophora (QM unregistered, temporary number JJ00005). In T. lineata (NT R18746) the crest is better developed, but is sufficiently reduced that the facial foramen is just visible in lateral view of the prootic. In each case, these are relatively small-bodied taxa, suggesting that the crest may be more poorly developed in some small-bodied agamids. It is clear that in larger species the development of the crest varies with ontogeny; this is exemplified by a series of skulls of Ctenophorus caudicinctus in which progressive development of the crest corresponds clearly with increasing SVL. The crest is absent dorsally and poorly developed along its middle and ventral portions in WAM R167679 (32 mm SVL), fully formed but without extensive ventrolateral projection along its entire length in WAM R167667 (64 $\mathrm{mm}$ SVL), ventrolaterally expanded in WAM R167632 (96 mm SVL) and fully formed in WAM R167652 (79 mm SVL), where its dorsal portion closely approaches the dorsomedial edge of the quadrate.

Moloch shares with at least some Ctenophorus species an supratemporal fenestra that is wider than it is long, and a hook-like anterior projection at the lateral edge of the paroccipital processes (e.g. Ctenophorus caudicinctus, WAM R167632; Ctenophorus isolepis, WAM R111736, WAM R111894). Loss of the ventral process of the squamosal occurs in Moloch, and Diporiphora; at least some Ctenophorus and Lophognathus have a short, laterally directed process that appears to be positionally homologous with the ventral projection in other taxa. Horizontal orientation of the paroccipital processes (when viewed posteriorly) occurs in Moloch, Diporiphora and Caimanops; the processes also are horizontally oriented in Lophognathus longirostris (e.g. WAM R162768), but are angled dorsally in Lophognathus gilberti (e.g. WAM R162929).

\section{CONCLUSIONS}

Our investigation provides some additional tentative comparative assessments of patterns of osteological features among endemic Australian agamids, and specifically of the similarities and differences of Moloch to other endemic Australian taxa. As with many other reptile groups, our understanding of patterns of morphological variation among Australian agamids currently is insufficiently developed to permit reliable hypotheses of relationship based solely on morphological data (see discussion by Joyce and Bell 2004). The features discussed here help to characterize Moloch horridus, and will undoubtedly be of use in subsequent morphologically-based phylogenetic analyses. Such analyses will contribute to a reliable morphological diagnosis of Moloch, and will also assist paleontologists in establishing reliable identifications of fossil agamids from Australia. Our preliminary evaluation suggests that many elements of the skull and mandible are probably diagnostic of Moloch, even if found in isolation in the fossil record; they can certainly be distinguished clearly from other Australian agamids. These include (minimally) the maxilla, parietal, pterygoid, supraoccipital, prootic, otooccipital, basioccipital, dentary, coronoid and articular-prearticular.

\section{ACKNOWLEDGEMENTS}

We thank H. Cogger, S. Evans, C. Gans, A. Greer, S. Hocknull, E. Pianka and P. Withers for their discussions and input about the morphology, biology and evolution of Moloch. S. Evans and S. Hocknull kindly shared data from their unpublished and in press works. S. Evans, M. Lee, P. Doughty and G. Swartz provided helpful comments on ealrier version of this manuscript. For access to laboratory space and accommodation of our needs while visiting their collections, we gratefully acknowledge A. Baynes, N. Cooper, P. Doughty, B. Maryan and C. Stevenson from the WAM, and A. Cook and S. Hocknull from the QM. M. Hollenshead has proven herself to be an excellent colleague and collaborator in the study of evolutionary morphology of Australian lizards, and inspired us to finally finish this work. M. Triffitt at WAM provided invaluable assistance in navigating the voluminous literature on Australian herpetology, and G. Gustafson (Northern Arizona University) and D. Trombatore (University of Texas) assisted with helping us obtain some obscure titles. P. Doughty and B. Maryan (WAM), S. Hocknull (QM), M. Hutchinson (SAMA) and K. Seymour (ROM) provided access and long-term loans to specimens in their care. S. Gunter assisted in the translation from Russian of the work by Vorobjeva and Chugunova. Financial support for this research was provided by Northern Arizona University and the Geology Foundation in the Jackson School of Geosciences at the University of Texas at Austin. 


\section{LITERATURE CITED}

Anonymous. (1981). Australian Snakes and Lizards. Bay Books: Sydney, NSW.

Axtell, R.W. (1986). The epipterygoids in Phrynosoma solare, still present, but disappearing. Journal of Herpetology 20: 79-81.

Barahona, F. and Barbadillo, L.J. (1998). Inter- and intraspecific variation in the post-natal skull of some lacertid lizards. Journal of Zoology (London) 245: 393-405.

Baverstock, P.R. and Donnellan, S.C. (1990). Molecular evolution in Australian dragons and skinks: a progress report. Memoirs of the Queensland Museum 29: 323-331.

Bell, C.J., Evans, S.E. and Maisano, J.A. (2003). The skull of the gymnophthalmid lizard Neusticurus ecpleopus (Reptilia: Squamata). Zoological Journal of the Linnean Society 139: 283-304.

Bellairs, A. d'A. and Kamal, A.M. (1981). The chondrocranium and the development of the skull in recent reptiles (pp. 1-263). In: Gans, C. and Parsons, T. S. (eds.) Biology of the Reptilia Volume 11, Morphology F. Academic Press: New York, NY, USA.

Bentley, P.J. and Blumer, W.C.F. (1962). Uptake of water by the lizard, Moloch horridus. Nature 194: 699-700.

Bever, G.S., Bell, C.J. and Maisano, J.A. (2005). The ossified braincase and cephalic osteoderms of Shinisaurus crocodilurus (Squamata, Shinisauridae). Palaeontologia Electronica 8(1); 4A: 1-36.

Brandson, J. (1952). I adopted three dragons. Walkabout 18(8): 19-20.

Cogger, H.G. (1961). An Investigation of the Australian Members of the Family Agamidae (Lacertilia) and their Phylogenetic Relationships. Unpublished M.Sc. thesis, University of Sydney, NSW.

Cogger, H.G. (1992). Reptiles and Amphibians of Australia, Fifth Edition. Reed Books, Cornell University Press: Ithaca, NY, USA.

Cope, E.D. (1864). On the characters of the higher groups of Reptilia Squamata - and especially of the Diploglossa. Proceedings of the Academy of Natural Sciences of Philadelphia 1864: 224-231.

Cope, E.D. (1892). The osteology of the Lacertilia. Proceedings of the American Philosophical Society 30: 185-221, Plates 2-6.

Covacevich, J., Couper, P., Molnar, R.E., Witten, G. and Young, W. (1990). Miocene dragons from Riversleigh: new data on the history of the family Agamidae (Reptilia: Squamata) in Australia. Memoirs of the Queensland Museum 29: 339-360.

Davey, H.W. (1923). The moloch lizard, Moloch horridus, Gray. The Victorian Naturalist 40: 58-60.

de Queiroz, K. (1987). Phylogenetic systematics of iguanine lizards: a comparative osteological study. University of California Publications in Zoology 118: 1-203.

Dowling, H.G. and Duellman, W.E. (1978 [1974]). Systematic Herpetology: A synopsis of Families and Higher Categories. Publications in Herpetology Number 7 (with minor revisions, 1975-1978). HISS Publications: New York, NY, USA [Family Agamidae, pp. 76.176.2].

Edmund, A.G. (1969). Dentition (pp. 117-200). In: Gans,
C., Bellairs, A. d'A. and Parsons, T.S. (eds.) Biology of the Reptilia. Volume 1. Morphology A. Academic Press: New York, NY, USA.

Estes, R., de Queiroz, K. and Gauthier, J. (1988). Phylogenetic relationships within Squamata (pp. 119-281). In: Estes, R. and Pregill, G. (eds.) Phylogenetic Relationships of the Lizard Families: Essays Commemorating Charles L. Camp. Stanford University Press: Stanford, CA, USA.

Evans, S.E. (2008). The skull of lizards and tuatara (pp. 1-347). In: Gans, C., Gaunt, A. S. and Adler, K. (eds.) Biology of the Reptilia Volume 20. Morphology H (The Skull of Lepidosauria). Society for the Study of Amphibians and Reptiles: Ithaca, NY, USA.

Gans, C., Merlin, R. and Blumer, W.F.C. (1982). The watercollecting mechanism of Moloch horridus re-examined. Amphibia-Reptilia 3: 57-64.

Gervais, P. (1861). L'ostéologie du Moloch, genre de sauriens propres a la Nouvelle-Hollande. Annales des Sciences Naturelles (Zoologie) 15: 86-90.

Gervais, P. (1873). Du Moloch et de l'Héloderme, reptiles de l'Ordre des Sauriens. Journal de Zoologie 2: 451-463, Plates 12, 18.

Gray, J.E. (1841). Description of some new species and four new genera of reptiles from Western Australia, discovered by John Gould, Esq. The Annals and Magazine of Natural History 7: 86-91.

Greer, A.E. (1989). The Biology \& Evolution of Australian Lizards. Surrey Beatty \& Sons, Pty Limited: Chipping Norton, NSW.

Hocknull, S.A. (2000). The Phylogeny and Fossil Record of Australopapuan Dragon Lizards (Squamata: Agamidae). Unpublished B.Sc. Honours Thesis, Department of Zoology and Entomology: University of Queensland, Brisbane, QLD.

Hocknull, S.A. (2002). Comparative maxillary and dentary morphology of the Australian dragons (Agamidae: Squamata): a framework for identification. Memoirs of the Queensland Museum 48: 125-145.

Honda, M., Ota, H., Kobayashi, M., Nabhitabhata, J., Yong, H.-S., Sengoku, S. and Hikida, T. (2000). Phylogenetic relationships of the family Agamidae (Reptilia: Iguania) inferred from mitochondrial DNA sequences. Zoological Science 17: 527-537.

Houston, T. and Hutchinson, M. (1998). Dragon Lizards and Goannas of South Australia. Second Edition. South Australian Museum: Adelaide, SA.

Hugall, A.F., Foster, R., Hutchinson, M. and Lee, M.S.Y. (2008). Phylogeny of Australasian agamid lizards based on nuclear and mitochondrial genes: implications for morphological evolution and biogeography. Biological Journal of the Linnean Society 93: 343-358.

Joger, U. (1991). A molecular phylogeny of agamid lizards. Copeia 1991: 616-622.

Joyce, W.G. and Bell, C.J. (2004). A review of the comparative morphology of extant testudinoid turtles (Reptilia: Testudines). Asiatic Herpetological Research 10: 53-109.

Kamal, A.M. (1969). The relation between the glossopharyngeal nerve and the chondrocranium in Squamata. Proceedings of the Zoological Society U.A.R. 3: 23-29. 
Kummer-Trost, E. (1956). Die Bildungen des Zwischenhirndaches der Agamidae, nebst Bemerkungen über die Lagebeziehungen des Vorderhirns. Morphologisches Jahrbuch 97: 143-192.

Macey, J.R., Schulte, J.A. II, Larson, A., Ananjeva, N.B., Wang, Y., Pethiyagoda, R., Rastegar-Pouyani, N. and Papenfuss, T.J. (2000). Evaluating trans-Tethys migration: An example using acrodont lizard phylogenetics. Systematic Biology 49: 233-256.

Maisano, J.A. (2001). A survey of state of ossification in neonatal squamates. Herpetological Monographs 15: 135-157.

Maisano, J.A. (2002a). The potential utility of postnatal skeletal developmental patterns in squamate phylogenetics. Zoological Journal of the Linnean Society 136: 277-313.

Maisano, J.A. (2002b). Postnatal skeletal ontogeny in Callisaurus draconoides and Uta stansburiana (Iguania: Phrynosomatidae). Journal of Morphology 251: 114-139.

Melville, J., Schulte, J.A. II and Larson, A. (2001). A molecular phylogenetic study of ecological diversification in the Australian lizard genus Ctenophorus. Journal of Experimental Zoology (Part B: Molecular and Developmental Evolution) 291: 339-353.

Meyers, J.J. and Herrel, A. (2005). Prey capture kinematics of ant-eating lizards. Journal of Experimental Biology 208: 113-127.

Moody, S.M. (1980). Phylogenetic and Historical Biogeographical Relationships of the Genera in the Family Agamidae (Reptilia: Lacertilia). Unpublished Ph.D. Dissertation, University of Michigan, Ann Arbor, MI, USA.

Nance, H.A. (2007). Cranial osteology of the African gerrhosaurid Angolosaurus skoogi (Squamata; Gerrhosauridae). African Journal of Herpetology 56: 39-75.

Oelrich, T.M. (1956). The anatomy of the head of Ctenosaura pectinata (Iguanidae). University of Michigan Museum of Zoology Miscellaneous Publications 94: 1-122, Figures 1-59.

Owen, R. (1880). Description of some remains of a gigantic land-lizard (Megalania prisca, Owen) from Australia. - Part II. Philosophical Transactions of the Royal Society of London for the Year 1880 (vol. 171): 1037-1050, Plates 34-38.

Owen, R. (1881). Description of some remains of a gigantic land-lizard (Megalania prisca, Owen) from Australia. - Part III. Philosophical Transactions of the Royal Society of London for the Year 1881 (vol. 172): 547-556, plates 64-66.

Pianka, E.R. (1994). Biodiversity of Australian desert lizards (pp. 259-281). In: Peng, C.-I. and Chou, C. H. (eds.) Biodiversity and Terrestrial Ecosystems. Institute of Botany, Academia Sinica Monograph Series (Taipei, Taiwan) 14.

Pianka, E. (2003). Moloch horridus (on-line), Digital Morphology. Accessed February 19, 2008 at <http:// digimorph.org/specimens / Moloch-horridus / whole/>.

Pianka, E.R. (2007). Molokki - piikikäs paholainen. Herpetomania 16: 5-11. [In Finnish].

Pianka, E.R. and Pianka, H.D. (1970). The ecology of
Moloch horridus (Lacertilia: Agamidae) in Western Australia. Copeia 1970: 90-103.

Pianka, G.A., Pianka, E.R. and Thompson, G.G. (1998). Natural history of thorny devils Moloch horridus (Lacertilia: Agamidae) in the Great Victoria Desert. Journal of the Royal Society of Western Australia 81: 183-190.

Presch, W. (1969). Evolutionary osteology and relationships of the horned lizard genus Phrynosoma (family Iguanidae). Copeia 1969: 250-275.

Rodríguez, M.A., Castillo, C., Sánchez, S. and Coello, J.J. (2000). El Lagarto Gigante de El Hierro. Publicaciones Turquesa: Gobierno de Canarias, Santa Cruz de Tenerife.

Säve-Söderbergh, G. (1947). Notes on the brain-case in Sphenodon and certain Lacertilia. Zoologiska Bidrag från Uppsala 25: 489-516.

Schulte, J.A. II, Melville, J. and Larson, A. (2003). Molecular phylogenetic evidence for ancient divergence of lizard taxa on either side of Wallace's Line. Proceedings of the Royal Society of London, Series B, Biological Sciences 270: 597-603.

Scortecci, G. (1941). I recettori degli Agamidi. Memorie della Società Italiana di Scienze Naturali e del Museo Civico di Storia Naturale di Milano 10: 207-326.

Sherbrooke, W.C., Scardino A.J., de Nys, R. and Schwarzkopf, L. (2007). Functional morphology of scale hinges used to transport water: convergent drinking adaptations in desert lizards (Moloch horridus and Phrynosoma cornutum). Zoomorphology 126: 89-102.

Shoo, L.P., Rose, R., Doughty, P., Austin, J.J. and Melville, J. (2008). Diversification patterns of pebble-mimic dragons are consistent with historical disruption of important habitat corridors in arid Australia. Molecular Phylogenetics and Evolution 48: 528-452.

Siebenrock, F. (1895). Das Skelet der Agamidae. Sitzungsberichte der Mathematisch-Naturwissenschaftlichen Classe der Kaiserlichen Akademie der Wissenschaften 104: 1089-1196, plates 1-6.

Stimie, M. (1966). The cranial anatomy of the iguanid Anolis carolinensis (Cuvier). Annals of University of Stellenbosch, Series A 41: 239-268.

Thompson, S.A. (2003). Reproductive observations of a thorny devil, Moloch horridus, in a natural semi-arid environment. The Western Australian Naturalist 24: 73-78.

Underwood, G. (1970). The eye (pp. 1-97). In: Gans, C. and Parsons, T.S. (eds.) Biology of the Reptilia. Vol. 2, Morphology B. Academic Press: New York, NY, USA.

Vorobjeva, E.I. and Chugunova, T. Yu. (1995). Zubnaya Sistyema Yashchyerits. Takconomicheskoye $i$ Ekologicheskoye Raznoobraziye. [The Dental System of Lizards. Taxonomic and Ecological Diversity]. Nauka Publishing House: Moscow, Russia [in Russian].

Warham, J. (1956). Mountain devil (Moloch horridus). Walkabout 22(9): 35-36

Withers, P.C. and Dickman, C.R. (1995). The role of diet in determining water, energy and salt intake in the thorny devil Moloch horridus (Lacertilia: Agamidae). Journal of the Royal Society of Western Australia 78: 3-11.

Witten, G.J. (1982). Phyletic groups within the family Agamidae (Reptilia: Lacertilia) in Australia (pp. 
225-228). In: Baker, W.R. and Greenslade, P.J.M. (eds.) Evolution of the Flora and Fauna of Arid Australia. Peacock Publications: Frewville, SA.

Witten, G.J. (1993). Family Agamidae (pp. 240-252). In: Glasby, C.J., Ross, G.J.B. and Beesley, P.L. (eds.) Fauna of Australia Volume 2A Amphibia and Reptilia. Australian Government Publishing Service: Canberra, ACT.

Manuscript received 31 July 2008; accepted 31 December 2008.

\section{APPENDIX 1}

\section{Anatomical Abbreviations}

af Mandible: adductor fossa

AN Angular

ANpaf Angular: posterior angular foramen

AT Articular-Prearticular

ATanaf Articular-Prearticular: angular articulation facet

ATctf Articular-Prearticular: chorda tympani foramen

ATquaf Articular-Prearticular: quadrate articulation facet

ATrp Articular-Prearticular: retroarticular process

ATsuaf Articular-Prearticular: surangular articulation facet

BO Basioccipital

BOao Basioccipital: apophysial ossifications on basal tubera

BObt Basioccipital: basal tubera

BOoc Basioccipital: occipital condyle

BOotaf Basioccipital: otooccipital articulation facet

BOpraf Basioccipital: prootic articulation facet

BOsdaf Basioccipital: sphenoid articulation facet

BOvp Basioccipital: ventral projection

CO Coronoid

COamp Coronoid: anteriorly directed medial process

COcp Coronoid: coronoid process

COlp Coronoid: lateral process

COpmp Coronoid: posteriorly directed medial process

cp Cranial coronoid process

D Dentary

Dcs Dentary: coronoid shelf

Ddp Dentary: dorsal prominence

Dmg Dentary: Meckelian groove

Dnian Dentary: notch for inferior alveolar nerve

Dsuaf Dentary: surangular articulation facet

EC Ectopterygoid

ECamsf Ectopterygoid: anterior margin of subtemporal fenestra

ECdapt Ectopterygoid: dorsal articulation with pterygoid

ECjuaa Ectopterygoid: jugal articulation area

ECjuaf Ectopterygoid: jugal articulation facet
ECmxaf Ectopterygoid: maxilla articulation facet

ECpmsf Ectopterygoid: posterior margin of suborbital fenestra

ECpoaf Ectopterygoid: postorbital articulation facet

ECptp Ectopterygoid: pterygoid process

ECvapt Ectopterygoid: ventral articulation with pterygoid

EP Epipterygoid

fo $\quad$ Fenestra ovalis

FR Frontal

FRcc Frontal: crista cranii

FRfpf Frontal: frontoparietal fenestra

FRpaaf Frontal: parietal articulation facets

FRpfaf Frontal: prefrontal articulation facet

iptv Interpterygoid vacuity

JU Jugal

JUecaf Jugal: ectopterygoid articulation facet

JUmxaf Jugal: maxillary articulation facet

JUmxp Jugal: maxillary process

JUpoaf Jugal: postorbital articulation facet

JUpom Jugal: posterior orbital margin

JUpop Jugal: postorbital process

JUsqaf Jugal: squamosal articulation facet

JUV2 Jugal: maxillary nerve foramen

If Lacrimal fenestra

MX Maxilla

MXfp Maxilla: facial process

MXjaf Maxilla: jugal articulation facet

MXms Maxilla: maxillary shelf

MAop Maxilla: orbital process

MXpaf Maxilla: palatine articulation facet

MXpmp Maxilla: premaxillary process

MXsac Maxilla: superior alveolar canal

NA Nasal

NAmxaa Nasal: maxilla articulation area

NAmxp Nasal: maxillary process

NApfaa Nasal: prefrontal articulation facet

NApmaf Nasal: premaxilla articulation facet

NApmp Nasal: premaxillary process

OT Otooccipital

OTar Otooccipital: ampullary recess for posterior semicircular canal

OTboaf Otooccipital: basioccipital articulation facet

OTci Otooccipital: crista interfenestralis

OTcr Otooccipital: cochlear recess (lagenar recess)

OTct Otooccipital: crista tuberalis

OTfmlm Otooccipital: foramen magnum (lateral margin)

OTfopm Otooccipital: fenestra ovalis, posterior margin

OThsc Otooccipital: horizontal semicircular canal

OTlarst Otooccipital: recessus scalae tympani, lateral aperture

OTmarst Otooccipital: recessus scalae tympani, medial aperture 
OTocl Otooccipital: occipital condyle, lateral portion

OTpf Otooccipital: perilymphatic foramen

OTpp Otooccipital: paroccipital process

OTprdaf Otooccipital: prootic dorsal articulation facet

OTprvaf Otooccipital: prootic ventral articulation facet

OTpsc Otooccipital: posterior semicircular canal

OTsoaf Otooccipital: supraoccipital articulation facet

PA Parietal

PAama Parietal: adductor muscles attachment surface

PAfp Parietal: fossa parietalis

PAfpf Parietal: frontoparietal fenestra

PApb Parietal: parietal boss

PApoaf Parietal: postorbital articulation facet

PApp Parietal: post-parietal process

PApt Parietal: parietal tab

PAstaf Parietal: supratemporal articulation facet

PF Prefrontal

PFaamp Prefrontal: articulation area for maxillary process of palatine

PFaavp Prefrontal: articulation area for vomerine process of palatine

$\mathrm{PFb} \quad$ Prefrontal: boss

PFlfp Prefrontal: lateral frontal process

PFmmlf Prefrontal: medial margin of lacrimal fenestra

PFmxaf Prefrontal: maxillary articulation facet

PFplp Prefrontal: palatine process

pian Pseudoforamen for the inferior alveolar nerve (mandible)

PL Palatine

PLicg Palatine: internal choanal groove

PLmaf Palatine: maxilla articulation facet

PLmifa Palatine: anterior bony margin of infraorbital fenestra

PLmifp Palatine: posterior margin of infraorbital fenestra

PLmlf Palatine: margin of lacrimal fenestra

PLmp Palatine: maxillary process

PLmsf Palatine: margin of suborbital fenestra

PLpfa Palatine: prefrontal articulation area

PLptaf Palatine: pterygoid articulation facet

PLptp Palatine: pterygoid process

PLvp Palatine: vomerine process

PM Premaxilla

PO Postorbital

POecaf Postorbital: ectopterygoid articulation facet

POfraf Postorbital: frontal articulation facet

POfpp Postorbital: frontoparietal process

POjuaa Postorbital: jugal articulation area

POjuaf Postorbital: jugal articulation facet

POjup Postorbital: jugal process

POpaaf Postorbital: parietal articulation facet

POpom Postorbital: posterior orbital margin
POsqaa Postorbital: squamosal articulation area

POsqp Postorbital: squamosal process

POstfm Postorbital: supratemporal fenestra margin

PR Prootic

PRaip Prootic: anterior inferior process

PRampvf Prootic: anterior margin of the posterior vestibulocochlear fenestra

PRap Prootic: alar process

PRar Prootic: ampullary recess

PRasc Prootic: anterior semicircular canal

PRboaf Prootic: basioccipital articulation facet

PRcr Prootic: cochlear recess (= lagenar recess)

PRfoam Prootic: fenestra ovalis, anterior margin

PRhsc Prootic: horizontal semicircular canal

PRip Prootic: incisura prootica

PRotaf Prootic: otooccipital articulation facet

PRpd Prootic: groove for passage of the perilymphatic duct

PRsdaf Prootic: sphenoid articulation facet

PRsf Prootic: sphenoccipital fenestra

PRsoaf Prootic: supraoccipital articulation facet

PRstgp Prootic: supratrigeminal process

psfef Posterior secondary foramen (communicates with endolymphatic foramen)

PT Pterygoid

PTbf Pterygoid: basipterygoid fossa

PTecp Pterygoid: ectopterygoid process

PTf Pterygoid: foramen on palatine process

PTfC Pterygoid: fossa columellae

PTplaf Pterygoid: palatine articulation facet

PTplp Pterygoid: palatine process

PTqup Pterygoid: quadrate process

PTsdp Pterygoid: sphenoid process

QU Quadrate

QUcc Quadrate: cephalic condyle

QUmlc Quadrate: mandibular lateral condyle

QUmmc Quadrate: mandibular medial condyle

QUpc Quadrate: posterior crest

QUsqaf Quadrate: squamosal articulation facet

QUtc Quadrate: tympanic conch

QUtycr Quadrate: tympanic crest

S Stapes

Sf Stapes: footplate

SD Sphenoid

SDap Sphenoid: alar process (articulation with prootic)

SDboaf Sphenoid: basioccipital articulation facet(s)

SDbp Sphenoid: basipterygoid process

SDcc Sphenoid: carotid canal

SDct Sphenoid: crista trabecularis

SDds Sphenoid: dorsum sellae

SDpf Sphenoid: pituitary fossa

SDpraf Sphenoid: prootic articulation facet

SDpw Sphenoid: parasphenoid wings

SDtc Sphenoid: bases of trabeculae cranii

SDvca Sphenoid: vidian canal; anterior opening 
SDvcp Sphenoid: vidian canal; posterior opening SO Supraoccipital

SOasc Supraoccipital: anterior semicircular canal

SOotaf Supraoccipital: otooccipital articulation facet

SOocc Supraoccipital: osseous common crus

SOpa Supraoccipital: processus ascendens

SOpraf Supraoccipital: prootic articulation facet

SOpsc Supraoccipital: posterior semicircular canal

SOsf Supraoccipital: sphenoccipital fenestra

sphf Sphenoccipital fenestra (otooccipital, prootic, supraoccipital)

SQ Squamosal

SQjuaf Squamosal: jugal articular facet

SQpaaf Squamosal: parietal articular facet

SQpoaf Squamosal: postorbital articular facet

ST Supratemporal

SU Surangular

SUasf Surangular: anterior surangular foramen

SUataf Surangular: articular articulation facet

SUcoaf Surangular: coronoid articulation facet

SUdaf Surangular: dentary articulation facet

SUpc Surangular: posterior canal

SUpp Surangular: prearticular process

tc Trabecula communis

VI Sphenoid: abducens canal (cranial nerve VI)

VII Prootic: facial nerve foramen (cranial nerve VII)

VIII Prootic: vestibulochochlear nerve foramina (cranial nerve VIII)

VO Vomer

$\mathrm{X}$ Otooccipital: vagus nerve foramen (cranial nerve X; also probably XI)

XII Otooccipital: hypoglossal nerve foramen (cranial nerve XII)

\section{APPENDIX 2}

\section{Specimens examined}

Amphibolurus norrisi: WAM R98121

Caimanops amphiboluroides: WAM R14464

Chelosania brunnea: NT R9924

Chlamydosaurus kingii: QM J3718; QM J21929; QM J45307; QM J47642

Ctenophorus butleri: WAM R165705

Ctenophorus caudicinctus: QM J21654; WAM R47832; WAM R93130; WAM R111747; WAM R162819; WAM R162820; WAM R162888; WAM R167625; WAM R167626; WAM R167632; WAM R167652; WAM R167665; WAM R167667; WAM R167670; WAM R167673; WAM R167676; WAM R167679

Ctenophorus chapmani: SAMA R4819

Ctenophorus clayi: SAMA R13756A; WAM R156957

Ctenophorus cristatus: NT R1096; SAMA R3029B

Ctenophorus decresii: NT R9596

Ctenophorus femoralis: WAM R162889; WAM R162891
Ctenophorus fionni: NT R8263

Ctenophorus isolepis: WAM R111736

Ctenophorus isolepis gularis: WAM R111894

Ctenophorus isolepips isolepis: WAM R111903; WAM R111904

Ctenophorus maculatus maculatus: WAM R164148

Ctenophorus maculosus: SAMA R63137

Ctenophorus nuchalis: NT R18819; QM J705; WAM R28140; WAM R47837; WAM R111752; WAM R111880; WAM R111893; WAM R111905; WAM R121964; WAM R162805; WAM R162817; WAM R162899

Ctenophorus ornatus: WAM R30073

Ctenophorus pictus: QM J48074

Ctenophorus reticulatus: WAM R47834; WAM R93129; WAM R156678; WAM R162742; WAM R162760; WAM R162856; WAM R162878; WAM R167503; WAM R167514; WAM R167575; WAM R 167591

Ctenophorus rubens: WAM R162900

Ctenophorus scutulatus: WAM R26646; WAM R47838; WAM R82657

Diporiphora australis: QM J29907

Diporiphora bennettii: NT R9490; WAM R162905; WAM R162906

Diporiphora bilineata: QM J46361

Diporiphora lalliae: NT R1514

Diporiphora magna: NT R1516

Gonocephalus grandis: WAM R49516

Hypsilurus boydii: QM unregistered

Hypsilururus modesta: QM unregistered

Hipsilurus spinipes: QM J8330; QM J45306

Hydrosaurus pustulatus: UMMZ 188058

Lophognathus gilberti: NT R 151; WAM R47839; WAM R162926; WAM R162927; WAM R162928

Lophognathus longirostris: NT R1294; WAM R162769; WAM R162818; WAM R162935

Lophognathus temporalis: NT R6184; QM J46374

Moloch horridus: QM J11492; ROM R50; TMM-M721; WAM R2; WAM R27737A; WAM R27737B; WAM R38691; WAM R97222; WAM R146914

Physignathus lesueurii: QM J38108

Pogona barbata: QM J4141; QM J45852; QM J57296

Pogona minor: WAM R111733; WAM R162801

Pogona minor minima: WAM R156920

Pogona mitchelli: NT R1275

Pogona vitticeps: QM 337168

Rankinia diemensis: SAMA R12959; SAMA R35551; WAM R9830

Tympanocryptis cephalus: NT R16768; QM J 21659 (these specimens may represent $T$. intima; see Shoo et al. 2008)

Tympanocryptis houstoni: SAMA R15002; SAMA R17736B

Tympanocryptis lineata: NT R18746; SAMA R02429D

Tympanocryptis pinguicolla: SAMA R43097; SAMA R43345

Tympanocryptis tetraporophora: QM J34580; QM temporary \# JJ00005; SAMA R9931B; SAMA R28998 